\title{
A COMPLETE STREETS ANALYSIS AND RECOMMENDATIONS REPORT FOR THE CITY OF BAKERSFIELD, CALIFORNIA
}

\author{
A Professional Project \\ presented to \\ the Faculty of California Polytechnic State University, \\ San Luis Obispo
}

\author{
In Partial Fulfillment \\ of the Requirements for the Degree \\ Master of City and Regional Planning
}

by

Sherie George

June 2013 
(C) 2013

\section{Sherie George}

\section{ALL RIGHTS RESERVED}

Page ii 


\section{COMMITTEE MEMBERSHIP}

TITLE:

A Complete Streets Analysis and Recommendations

Report for the City of Bakersfield, California

AUTHOR:

Sherie George

DATE SUBMITTED:

June 2013

COMMITTEE CHAIR:

Dr. Michael Boswell, Professor

City and Regional Planning Department

COMMITTEE MEMBER:

Dr. Cornelius Nuworsoo, Assistant Professor

City and Regional Planning Department

COMMITTEE MEMBER: Jim Eggert, City of Bakersfield Planning Director 


\section{ABSTRACT}

A Complete Streets Analysis and Recommendations Report for the City of Bakersfield, California

\section{Sherie George}

Driven by California State legislation, the City of Bakersfield is taking steps to introduce Complete Streets to the community. Working in collaboration with the Bakersfield City Planning Department, this project was prompted by the City's forthcoming update of its Metropolitan Bakersfield General Plan Circulation Element, with purpose to meet the California Complete Streets Act (AB 1358) requirement to plan for a balanced, multimodal transportation network. This professional project intends to provide Bakersfield city officials, staff, and residents tools and information needed to assess and implement Complete Streets within the Community.

The project provides in depth background research on the Complete Street concept, related legislation, design features, and benefits. It reviews three Complete Street projects from similar cities located in the Central Valley with purpose to deliver guiding principles Bakersfield can utilize for successful implementation. The project provides new conceptual street standards with recommended design feature tables based on existing street types. In conclusion, this project evaluates the newly adopted Bakersfield Complete Street Policy through a strategic approach with final recommendations to build a stronger Complete Streets network.

Keywords: Complete Streets, Multimodal, Transportation, Design, Street Standards, Circulation, Policy Recommendations, Central Valley, Bakersfield 


\section{ACKNOWLEDGMENTS}

A sincere thank you to all who have helped me in the professional project process:

First, I would like to thank my committee chair, Professor Mike Boswell, for his continued support, helpful comments, and guidance during the past year. Discussing and reviewing my project has brought greater confidence in my abilities due to his insight. Also, thank you to committee member Cornelius Nuworsoo. His confidence in my research and helpful comments were valuable to the success of the project.

An important thank you to committee member Jim Eggert. As a committee member and client representative, he was essential to making the project possible. Throughout the year, Jim has made himself available to answer questions, provide comments and has become an important connection to the City of Bakersfield.

I would also like to thank Terry Preston, Complete Streets Coordinator for WALKSacramento and Brian Ludicke, City of Lancaster Planning Director, for their time to personally provide comments on the City of Sacramento and the City of Lancaster as case studies for my project.

And finally, a thank you to my family. Thank you Brian George for your encouragement and daily support. 


\section{TABLE OF CONTENTS}

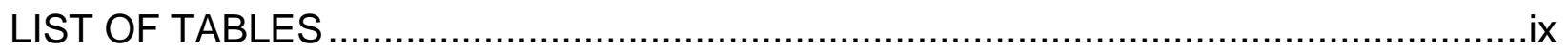

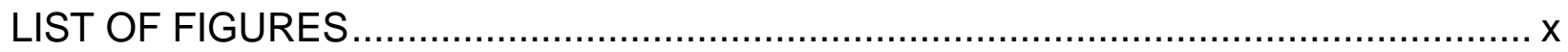

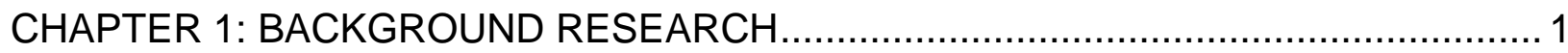

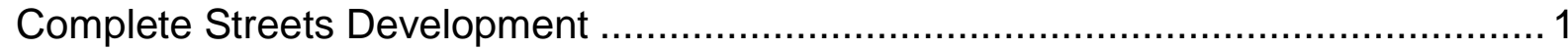

The Shared Street concept............................................................... 1

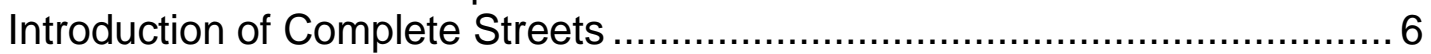

Complete Streets: An Umbrella Concept......................................................... 8

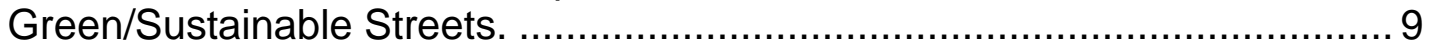

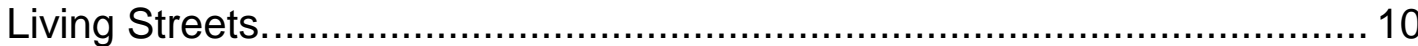

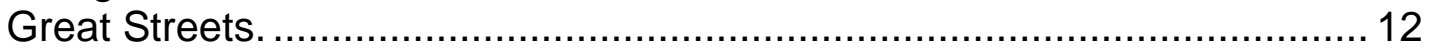

Complete Street Legislation ..................................................................... 14

California Assembly Bill 1358: The California Complete Streets Act.......... 14

U.S. Department of Transportation (DOT) Bicycle and Pedestrian Policy... 16

Safe Routes to School..................................................................... 16

California Assembly Bill 32 and Senate Bill $375 \ldots \ldots \ldots \ldots \ldots \ldots \ldots \ldots \ldots \ldots \ldots \ldots \ldots . . . . . \ldots 18$

Caltrans Complete Streets Policy ..................................................... 18

Kern County Bicycle Master Plan \& Complete Streets Recommendations. 20

Bakersfield Bicycle Transportation Plan. .................................................. 21

Complete Street Design Guidelines .............................................................. 22

Mode Shift through Complete Street Design. .........................................2 23

Reducing Street Width.................................................................... 23

Vehicle Speed Management. ........................................................ 23

Design Elements and Features of Complete Streets...............................2 24

Related Planning Issues with Designing Complete Streets.................................... 33

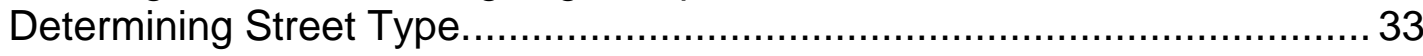

Ensuring Street Connectivity. ............................................................. 34

Level of Service (LOS) Standards and Multimodal Level of Service. .......... 35

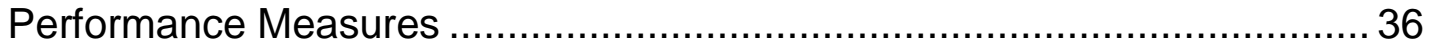

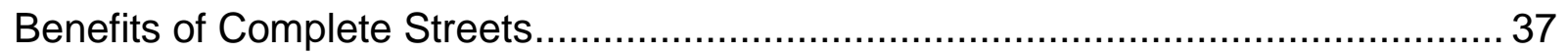

Health and Physical Activity. .............................................................. 37

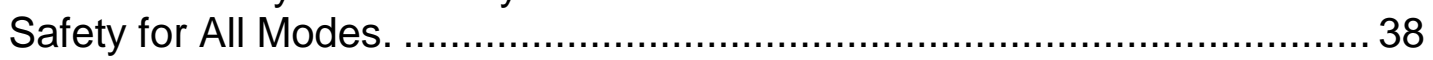

Reduction of Greenhouse Gases. .................................................... 41

Creating Active Public Space. ................................................................ 43

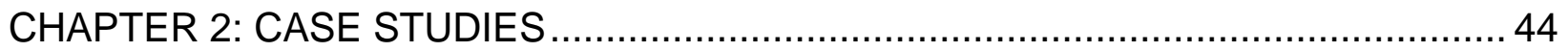




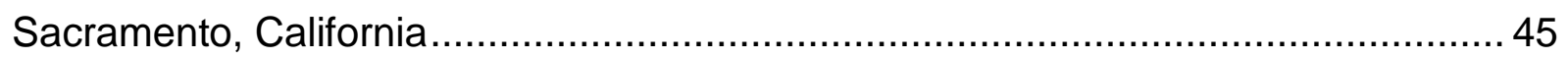

Planning a Complete Street Network ................................................. 45

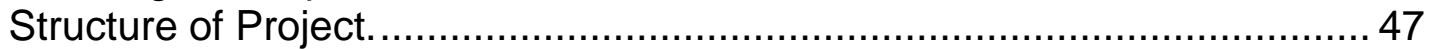

Land Use and Transportation Context................................................ 48

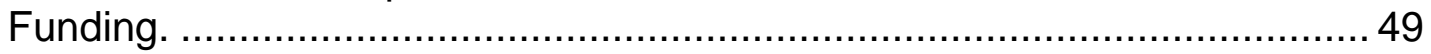

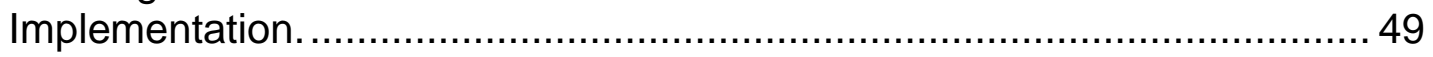

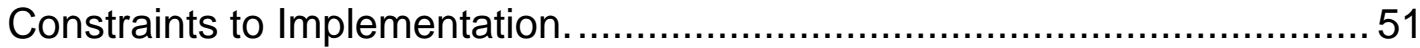

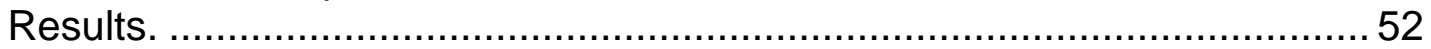

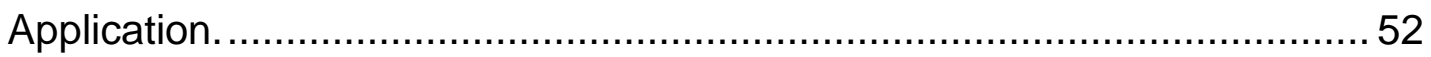

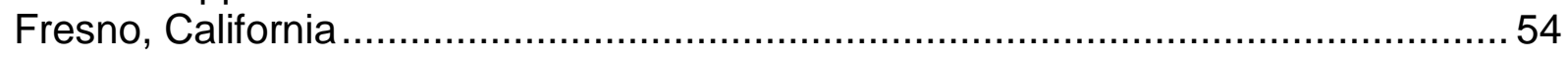

Planning a Complete Streets Network................................................. 54

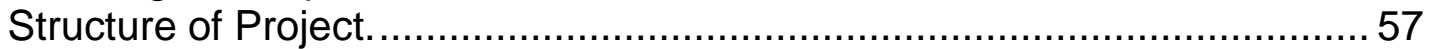

Land Use and Transportation Context................................................. 58

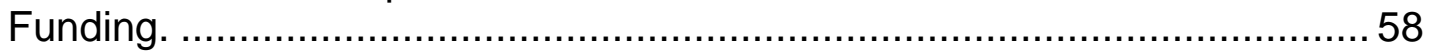

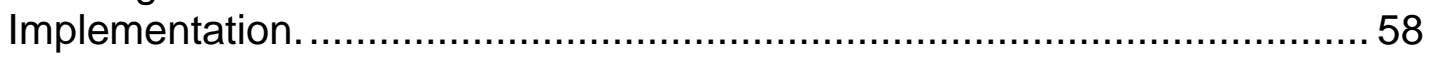

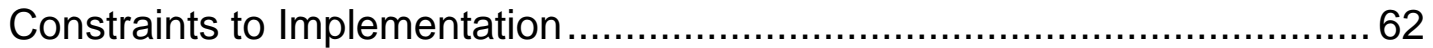

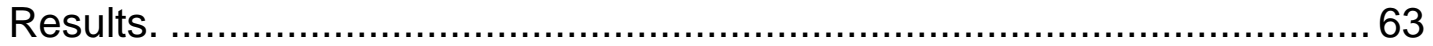

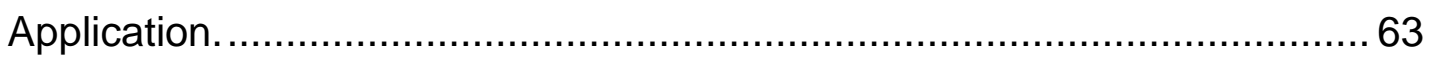

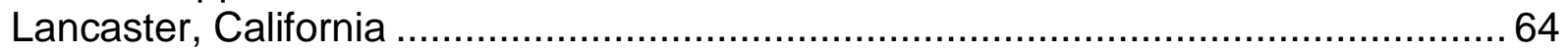

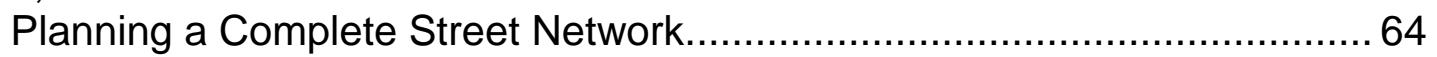

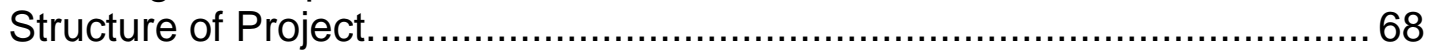

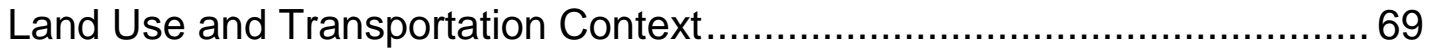

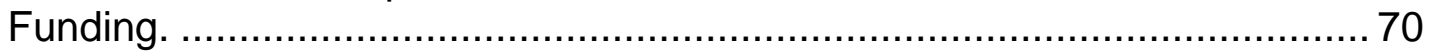

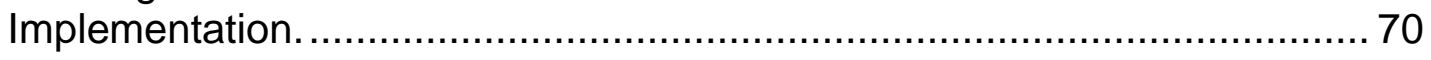

Constraints to Implementation. The ................................................. 75

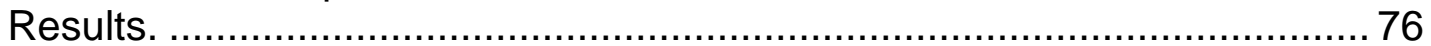

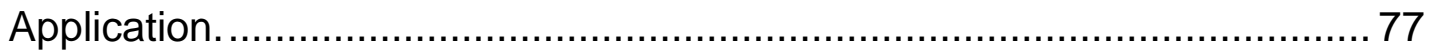

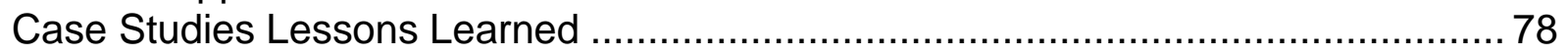

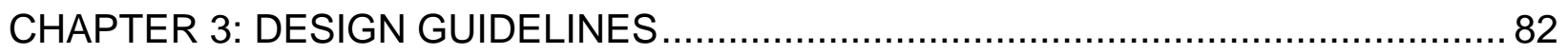

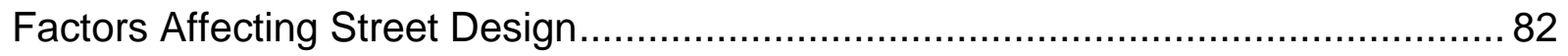

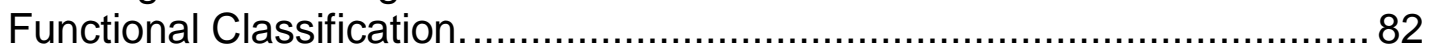

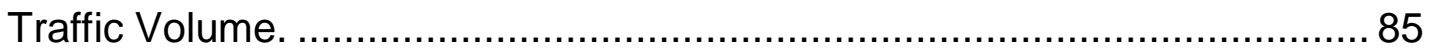

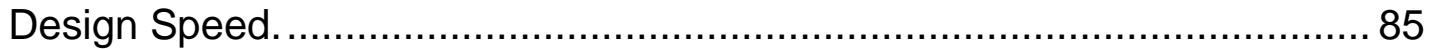

Design Vehicle and Emergency Management........................................ 86

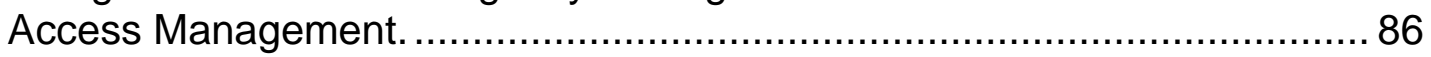

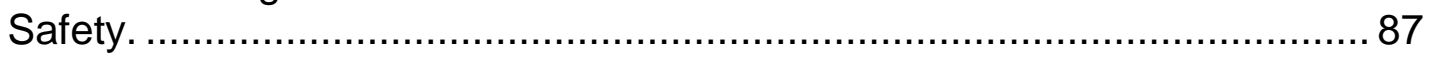

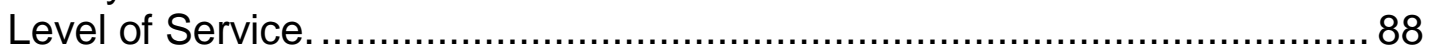

California Environmental Quality Act ................................................ 89

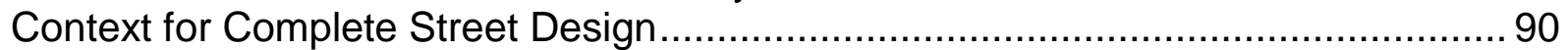

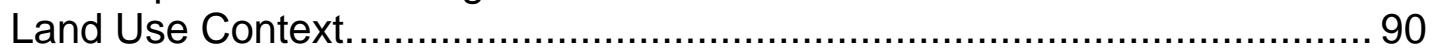

Context Sensitive Street Typologies ....................................................... 93

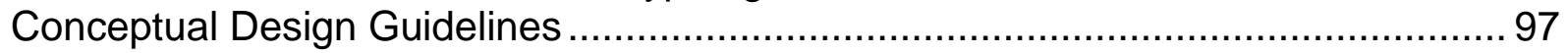

Proposed Roadway Cross section, Arterial ............................................ 98 
Proposed Roadway Cross section, Collector ........................................ 101

Proposed Roadway Cross section, Local ............................................. 104

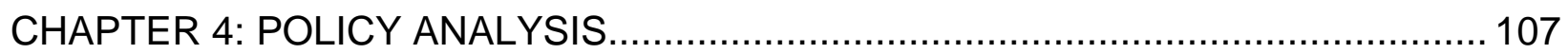

The City of Bakersfield Complete Street Policy ................................................. 107

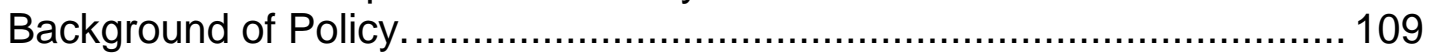

Significance of Policy....................................................................... 110

Analysis of Bakersfield Complete Street Policy .............................................. 110

Measuring Complete Streets Implementation ......................................................111

Policy Element Scoring System...................................................... 112

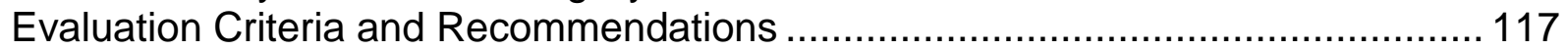

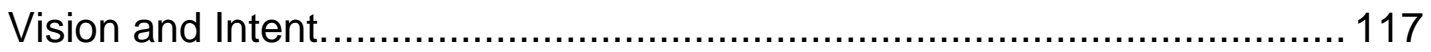

All Users and Modes. .................................................................. 118

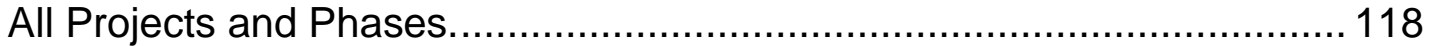

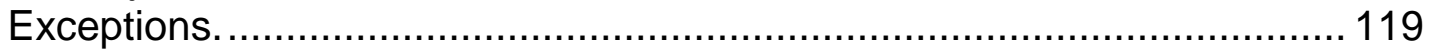

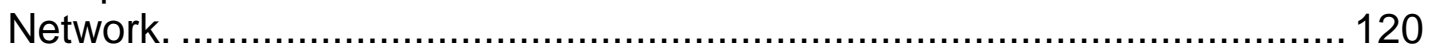

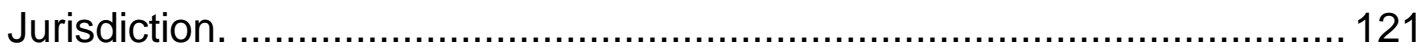

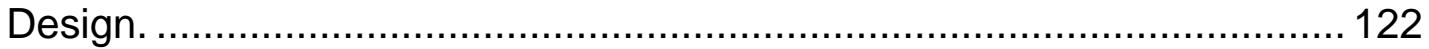

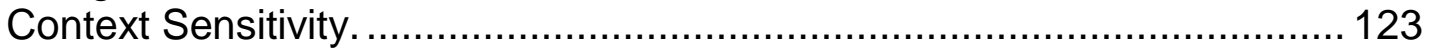

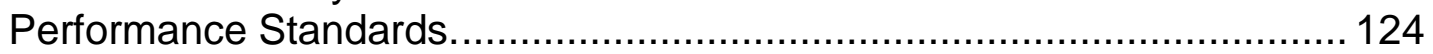

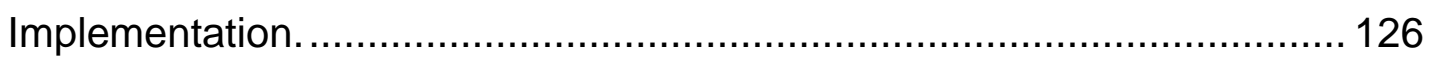

Strategic Approach with Final Recommendations............................................. 127

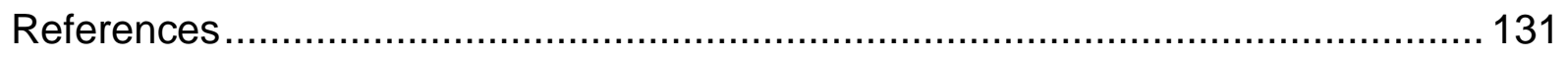

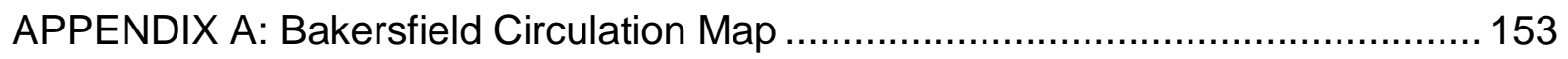

APPENDIX B: Bakersfield Right-of-Way Description ............................................. 154

APPENDIX C: Bakersfield Complete Street Policy ............................................ 155 


\section{LIST OF TABLES}

Table 1. Pedestrian Design Treatment and Facility Examples ......................... 25

Table 2. Bicycle Treatments and Facilities ……............................................ 27

Table 3. Transit Treatments and Facilities...................................................... 30

Table 4. Traffic Calming Treatments and Facilities........................................ 32

Table 5. Additional Arterial Case-by-Case Street Improvements for Complete

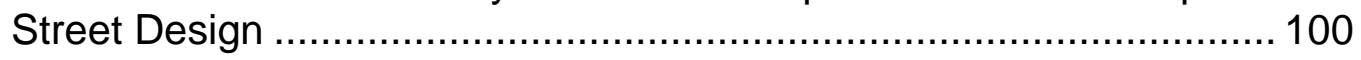

Table 6. Additional Collector Case-by-Case Street Improvements for Complete

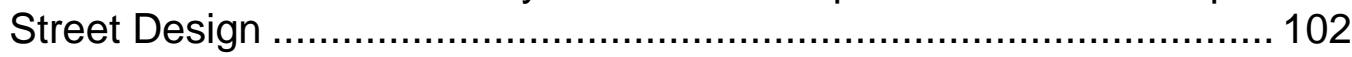

Table 7. Additional Local Street Case-by-Case Street Improvements for

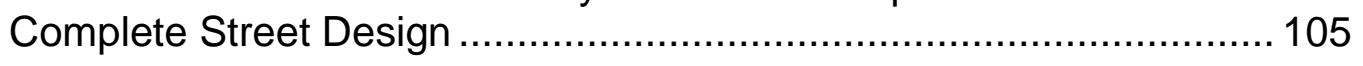

Table 8. Standard Policy Element Scoring System ...................................... 112

Table 9. Policy Element Scoring System reviewed with Bakersfield Complete Streets Policy Resolution 


\section{LIST OF FIGURES}

Figure 1. Green Street SW 12th Montgomery Street, Portland, Oregon............ 10

Figure 2. Living Street Sunset Triangle Plaza, Los Angeles, California .............. 12

Figure 3. Great Street 5th Avenue, San Diego, California ................................ 13

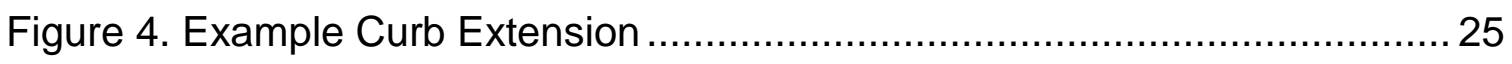

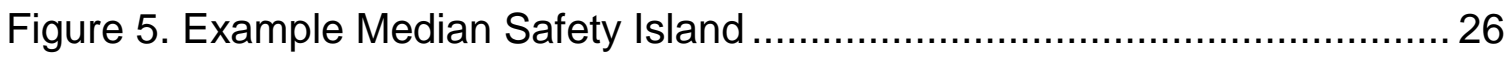

Figure 6. Example Special Paved Intersection ............................................. 26

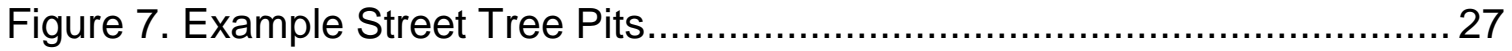

Figure 8. Example Buffered Bike Lane ..................................................... 27

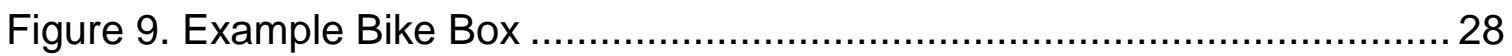

Figure 10. Example Bicycle Signal Detection .............................................. 29

Figure 11. Example Shared Lane Marking ………......................................... 29

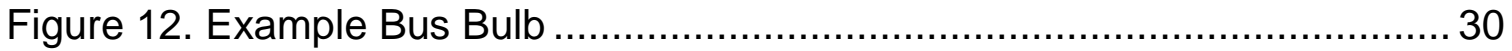

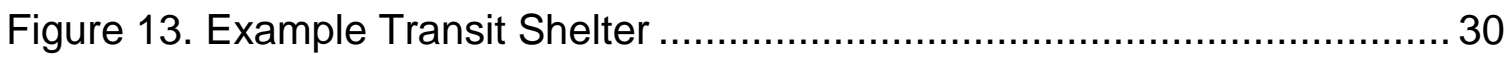

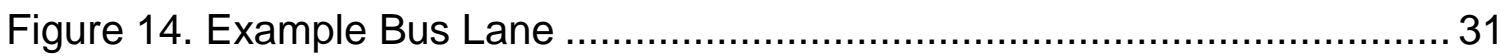

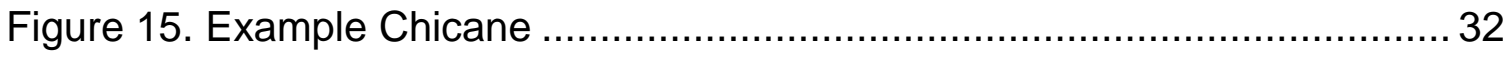

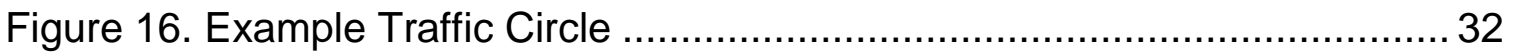

Figure 17. Example Raised Speed Reducer ………................................... 32

Figure 18. 19th Street before the conversion...................................... 49

Figure 19. 19th Street after the conversion...................................49

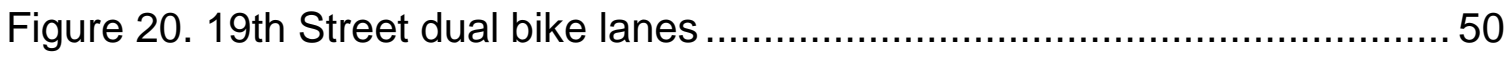

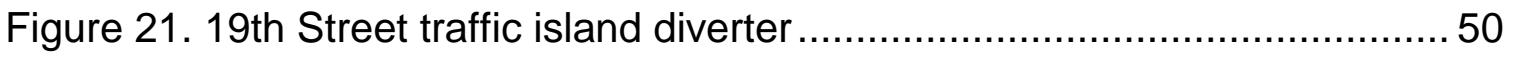

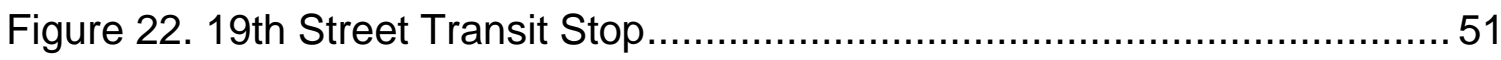

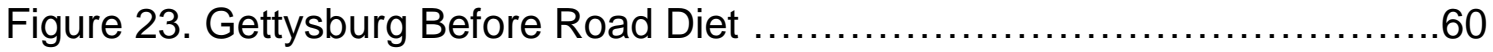

Figure 24. Gettysburg After Road Diet....................................60

Figure 25. Bike lanes on Gettysburg via Google Earth .................................... 60 
Figure 26. Bike lane and Sidewalk on Gettysburg via Google Earth .................61 61

Figure 27. Gettysburg Intersection via Google Earth ....................................... 62

Figure 28. Lancaster Boulevard, 2009..................................................... 72

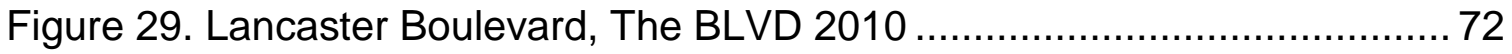

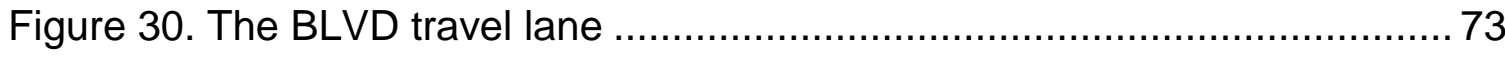

Figure 31. Crosswalk and Bollards directing traffic on The BLVD .................... 73

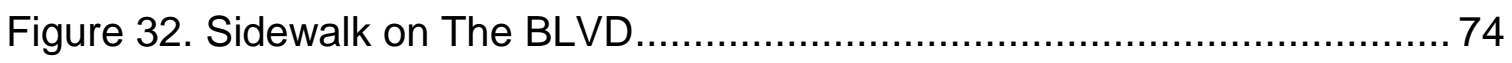

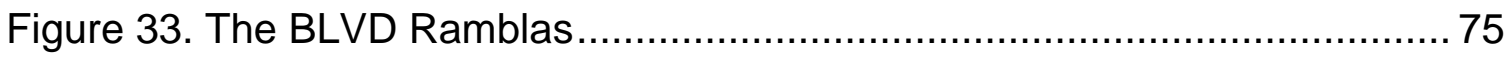

Figure 34. Urban Example, Chester Avenue and 18th Street, Bakersfield, CA .. 91

Figure 35. Suburban Example, Hageman Road, Bakersfield, CA ..................... 92

Figure 36. Rural Example, Seventh Standard Road, Bakersfield, CA ............... 92

Figure 37. New Urbanism transect zones based on context ............................ 93

Figure 38. Boulevard Character, Coffee Road, Bakersfield, CA...................... 94

Figure 39. Avenue Character, Chester Avenue, Bakersfield, CA. ..................... 95

Figure 40. Street Character, $19^{\text {th }}$ Street, Bakersfield, CA ................................ 96

Figure 41. Alley Character, Lawn Street, Bakersfield, CA. ............................. 96 


\section{CHAPTER 1: BACKGROUND RESEARCH}

This chapter provides a theoretical background for the Complete Streets Analysis and Recommendation Report for Bakersfield, California. The case studies, test design, and recommended policies provided in the report considered the topics discussed below. The background research begins with a theoretical emergence of Complete Streets, beginning with the Shared Street concept while ending with the more conceptual designs elements of Complete Streets in the city streetscape. The background research ends with the benefits of Complete Streets

\section{Complete Streets Development}

The Shared Street concept. Within the last 20 years, the Shared Street or integration concept for streets has become a growing design innovation. Shared space is an urban planning and design concept that focuses on an incorporation of spaces by removing traditional road separations between automobiles, pedestrians, and other street users. The Shared Street system prioritizes the community and residential user, who are pedestrians, children at play, and bicyclists. It then allows for parked and moving cars to share the same street space. Although it may seem these users would conflict with one another, the physical design places motorists in a less dominate position, which may create street conditions that are safer for the pedestrian than in common roadway configurations. A Shared Street is not an "anti-car" policy; it is rather the redesign of the street for the social and physical public domain and reclamation of the pedestrian environment (Southworth and Ben-Joseph, 1997). 
The influence of urban design, political culture, and technology varied the use of the urban street space throughout history (Gunnarsson, 2004). Throughout the Twentieth Century, the use of automobiles greatly increased and pedestrians moved off the streets in both residential and commercial communities (Millard, 2011). During this time, authors and advocates including Kevin Lynch, Donald Appleyard, Jane Jacobs, Jan Gehl, Lewis Mumford, and William Whyte explained the street as a physical and social part for the living environment, and its effect on vehicular movement, social contact, and civic activities occurring in Europe and North America (Southworth and Ben-Joseph, 1997). Many of these authors presented space in the right-of-way as an idea for active use. Space plays an important role for public realm vitality, allowing all modes equal priority in the street or limiting traffic speeds through design to create a sense of safety.

The Shared Street concept was first introduced and gained popularity in Europe, where it has been applied in several countries (Southworth and Ben-Joseph, 1997). The philosophical roots can be traced to the Traffic in Towns report published in England by Colin Buchanan, who was commissioned by the Ministry of Transportation in 1959. The report developed early techniques for evaluating urban traffic systems by creating specific zones called environmental areas or urban rooms, which were different in character from typical streets. These zones would be evaluated by the capacity to carry traffic in addition to the environmental quality affected by noise, pollution, social activity, pedestrians, and visual aesthetics. The criteria for evaluating these environmental zones would be used to set standards or limitations of the street design, 
which could include ideas from completely segregating or motorists and pedestrians through redesigning physical features of the street to affect traffic (Southworth and BenJoseph, 1997). Buchanan developed an urban street design that focused on analyzing before regenerating or building.

Although these early concepts of "traffic integration" and "traffic calming" were not well received in England, The Netherlands first developed and executed the concepts (Southworth and Ben-Joseph, 1997). Niek De Boer, a professor of urban planning at Delft University of Technology and the University of Emmen viewed Buchanan's concept of traffic integration and coexistence as a possible solution to overcoming the contradiction between places for people and places for the car. De Boer developed "Woonerf", or "residential yard," which was designed to have motorists sense as if they were in a garden setting, intruding into a pedestrian zone, and force them to consider other users of the road. By designing a Woonerf as a Shared Street, pedestrians and vehicles share the same space, which would slow traffic and support play and other social activities. In 1976, the Dutch Government adopted the first set of Woonerf minimum design standards and traffic regulations. Over the next ten years countries throughout Europe and the world including: Germany, England, Sweden, Denmark, France, Switzerland, Japan, and Israel adopted similar Woonerf and Shared Street regulations and guidelines (Southworth and Ben-Joseph, 1997).

The Shared Street and Woonerf concepts were less developed in North America. In 1981, Donald Appleyard discussed the concepts in the book Livable Streets. In 1989, the Institute of Traffic Engineering (ITE)'s publication of Residential Street Design and 
Traffic Control also discussed Shared Streets. However, no progress or acceptance in legislative or planning agencies further developed the new concept. Instead, more space was accommodated for the increased number of larger automobiles per household (Southworth and Ben-Joseph, 1997).

The Shared Streets concept restores human scale to streets. It creates an attractive public environment and is meant to provide better traffic safety and control. Implementing Shared Streets may lower installation costs and maintenance problems. The early development of Shared Streets was implemented in residential areas. It was less likely applied to other land uses or to be extended further into streets or highways that connected to these residential neighborhoods. As a result, traffic would become burdened on other residential roads and collector streets surrounding the Shared Street corridor (Hand, 2010).

Similar Shared Street urban design movements were introduced within the United States. New Urbanism's development in the late $20^{\text {th }}$ century stood for the restoration of urban centers and towns and the reconfiguration of sprawl into neighborhoods and diverse districts. The movement advocates communities to design for pedestrian and transit as well as the car to create a network of universally acceptable public spaces. It promotes the principle of streets and squares being safe, comfortable, and properly configured to encourage walking and enable physical definition of streets as places of shared use (Congress of New Urbanism[CNU], n.d.). Smart Growth, as an urban planning and design movement, encourages designing neighborhoods to reinvest in the existing infrastructure and place commercial uses and 
other amenities near the home, which occurs through mixing land uses and compact building design options. Smart Growth transportation principles aim to provide residents the option of walking, bicycling, transit, or driving in order to foster economic vitality for the community (United States Environmental Protection Agency[EPA], 2012a). In addition, Smart Growth transportation principles believe investment in road maintenance, rather than new construction, can cut expenses and concentrate on development that will benefit the environment and allow people to choose how to get around (Smart Growth America, n.d.). Together, these two urban design movements' founding principles include the idea of multi-modal transportation, which shares similarities to a Shared Street concept. The value of these transportation principles is not placed on the automobile but on diversifying mode options to change America's traditional community and neighborhood design and reflect on transportation choices and patterns.

Yet for several decades, in the United States and California, there has still been a focus towards the automobile, limiting alternative transportation choices when designing traditional streets (Jackson, 2011). Roadway classifications (arterial, local, and collector) delineate roadway function largely based on the character of automobile traffic, vehicle capacity, access, and safety to the land access allowed. Streets are defined from curb to curb. According to the California Department of Transportation [Caltrans] Complete Streets Implementation Action Plan (2010), multi-modal streets have, for many years, been considered "special projects" which require extra planning, funding, and effort. To reduce automobile dependence, it will be important to manage 
patterns of land use and transportation, while enhancing local livability. This will progress the Shared Street concept to become a successful street design that would work beyond Europe and into the different urban environments seen in the United States.

Introduction of Complete Streets. Complete Streets have created a shared space approach to street design. Despite a strong influence from the Shared Street concept, Complete Streets do not subordinate the automobile space or provide all users complete access of the entire width of the street. The National Complete Streets Coalition (National Complete Streets Coalition[NCSC], 2010a) defines Complete Streets as:

Complete Streets are streets for everyone. They are designed and operated to enable safe access for all users. Pedestrians, bicyclists, motorists, and public transportation users of all ages and abilities are able to safely move along and across a complete street. Complete Streets make it easy to cross the street, walk to shops, and bicycle to work. They allow buses to run on time and make it safe for people to walk to and from train stations.

The term "Complete Streets" grew from the collaborative efforts of people involved from a wide range of organizations that were interested in a more powerful, inclusive name than "route accommodation", which was a term used to express the idea of including bicycles in everyday transportation planning in 2003 (NCSC, 2010b). Specifically, the name "Complete Streets" was created by Barbara McCann, who was working for America Bikes. Smart Growth America's David Goldberg was the first to say 
"Complete Streets" in context when discussing transportation planning to consider pedestrian and bicycle facilities. The concept, which originated among cycling supporters quickly expanded to represent a variety of modes and users (Millard, 2011). After forming a Complete Streets Task Force, which was led by American Bikes and Smart Growth America, participation from AARP, the American Planning Association, the American Public Transportation Association, the American Society of Landscape Architects, and the American Heart Association interacted and participated together. In 2005, the National Complete Streets Coalition was publicly funded to create a diverse representative movement that was meant to support policy adoption at the national, state, and local level (NCSC, 2010b).

The Complete Streets movement redefines the intention of the street and aims to develop integrated, connected networks of streets that are safe and accessible for all people, regardless of the age, ability, income, ethnicity or chosen mode of travel. Complete Streets make active transportation such as walking and bicycling convenient to provide increased access to employment, commerce, and education. The Complete Streets movement aims to break down traditional separation of highways, transit, biking, and walking. Instead, its focus is to create a transportation system that will support the safe use of the roadway for every type of user (NCSC, 2012).

Complete Streets may develop, expand, or retrofit the public right of way. There is no singular design prescription for Complete Streets and is meant to respond to a community's context (NCSC, 2010a). In some sites, inexpensive adjustments using paint, signage, seating, pedestrian islands, wide paved shoulders or bike lanes, special 
bus lanes, accessible transportation stops, traffic and pedestrian signals, traffic signal timing, and narrower travel lanes can re-designate automobile space to provide opportunity for other modes (Millard, 2011). Complete Streets also use Woonerf design techniques like textured pavements, raised crosswalks, curb extensions, bulbouts or bollards, and roundabouts which become traffic calming measures to signal automobile users that the space of the street has been designated to include pedestrian and bicycle users (GreenLA Coalition, 2012).

Complete Streets represent more than physical changes to the street. It stands for a change in transportation planning, design, maintenance, and funding decisions. A Complete Street policy encourages projects to be planned and designed to meet the needs of every type of resident or how they travel, which allows the community to save money, accommodate more people, and create an environment for all to travel safely. These Complete Street policies may be achieved through a variety of methods including: state laws, local policy ordinances and resolutions; design manuals; inclusion in comprehensive plans; internal policies develop by transportation agencies; executive orders; and even policies developed by the community and agency staff adopted by elected officials (McCann and Rynne, 2010).

\section{Complete Streets: An Umbrella Concept}

Although Complete Streets have principal definition, the movement has evolved the concept and its design guidelines into an umbrella term - acting as a single common category that covers multiple ideas. From Complete Streets, there have been a number of sub category phrases that describe diverse street design functions and 
approaches related to Complete Street concepts. Often these subcategories focus to incorporate green infrastructure, multi-modal transport, and encourage pedestrian space.

Green/Sustainable Streets. Complete Streets are a natural complement to sustainability efforts, ensuring benefits for mobility, the environment, and helping the community while realizing the 'green' potential of streets. Many of the street design, construction, and operational elements of a Complete Street can also work for Green/Sustainable Streets with the purpose of environmental sustainability.

Green/Sustainable streets are often concerned with the drainage and storm water runoff issues or challenges occurring from the traditional street development. Negative environmental impacts from storm water management include polluted runoff, sedimentation, and bank erosion. Green/Sustainable Streets using Complete Street efforts focuses on retaining, treating, or eliminating runoff and improving water quality at the source through green infrastructure often connected or defined with low-impact development. It also improves air quality and adds aesthetics to the street while reducing urban heat island effect and reducing pollution. Pavement treatments, landscaping, and providing space for low-emission travel in the right of way are design elements of Complete Streets, in conjunction with green infrastructure, to create opportunity to make the transportation system more sustainable and minimize environmental impact that is highlighted through the terms Green or Sustainable Streets (NCSC, 2010c). 
The City of Portland is a leader in storm water management practices through their highly recognized Green Streets program. The City's Green Street principles to manage storm water runoff at the source and the surface, use plants and soil to slow, filter, cleanse and infiltrate runoff, and design facilities that aesthetically enhance the community have successfully integrated sustainable practices into Complete Streets (CityofPortland, n.d.).

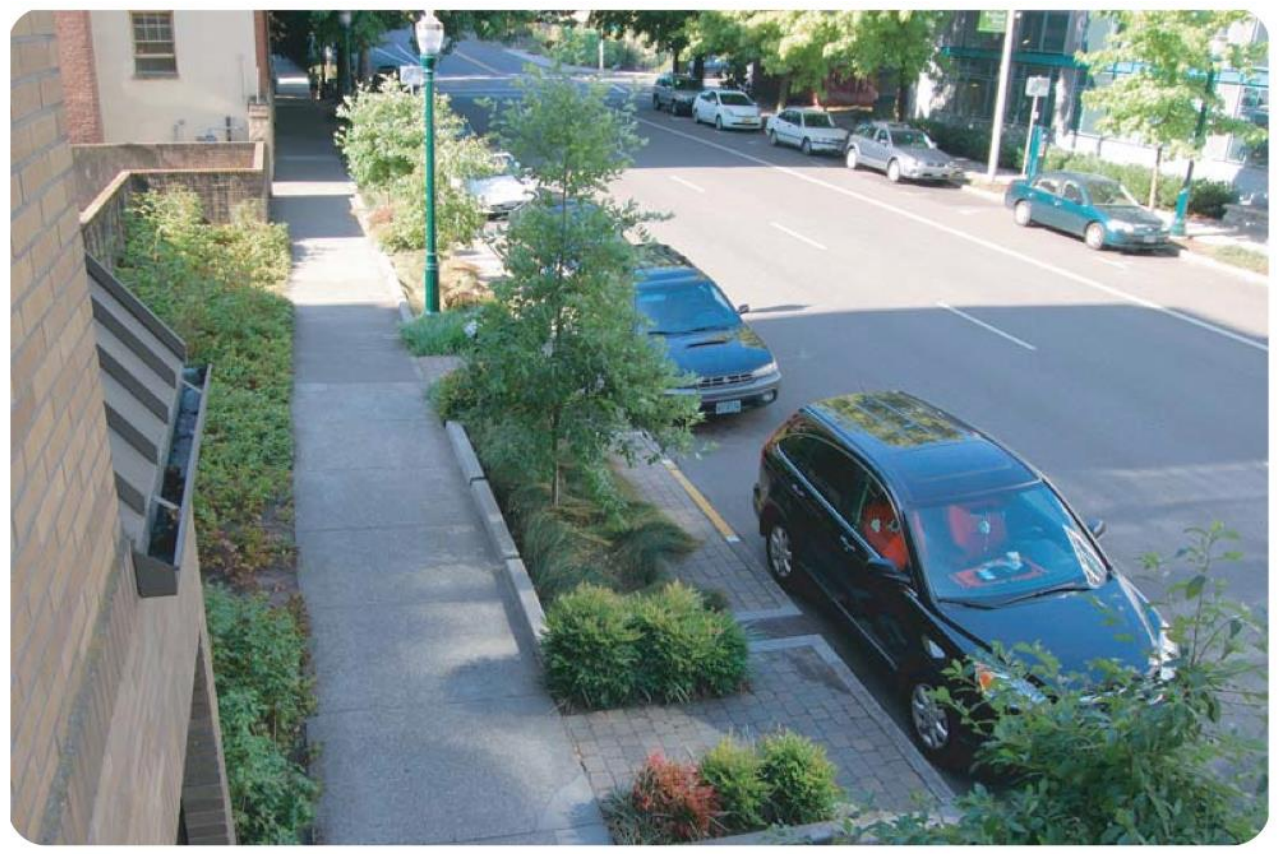

Figure 1. Green Street Example SW 12th and Montgomery Street, Portland, Oregon

Living Streets. Like Complete Streets, a Living Street is also designed with the interest of creating streets safe for all users. Woonerf, the Dutch Shared Street concept from which Complete Streets originate, is loosely translated to "streets for living" (Bain, Gray, \& Rodgers, 2012). Inspired by the Woonerf principles, Living Streets in the United States work to transform streets into a vibrant, inviting, green space with the interests of pedestrian and cyclists to be used as a social space, while reducing the dominance of 
motorized transportation (GreenLA Coalition, 2012). They are designed to integrate income, racial, and social equity into the design and function of the street that works for people of all ages and physical abilities. Living Streets are meant to be inviting, engaging places through street furniture, landscaping, and public art combined with the integration of traffic calming measures that reflect a neighborhood's cultural uniqueness. Other features include: continuous sidewalks, improved crosswalk safety, streetscape improvements, place making and bicycle infrastructure. Similar to a Complete Street, through the integration of land uses adjacent to the street, Living Streets promote economic well-being and aim to foster healthy commerce in the community. To parallel Green or Sustainable Streets, Living Streets also aspire to integrate environmental stewardship and water management by maximizing infiltration and reuse of storm water, while reducing paved areas, energy consumption, greenhouse gases, and air pollution (LA County Dept. Public Health \& UCLA, 2011). The result of a Living Street envisions a healthier built environment with a balanced circulation system (GreenLA Coalition, 2012).

The Silverlake Sunset Triangle Plaza became the first community-designed pedestrian plaza and Living Street in Los Angeles, California. The project, led by the Los Angeles City Planning Commission, is closed to automobile traffic within three traffic intersections. A painted street surface, potted plants and moveable tables and chairs foster a vibrant public space for all ages. An early economic impact study of the area concluded the project has been beneficial to the neighboring business economy (Living Streets LA, n.d.). 


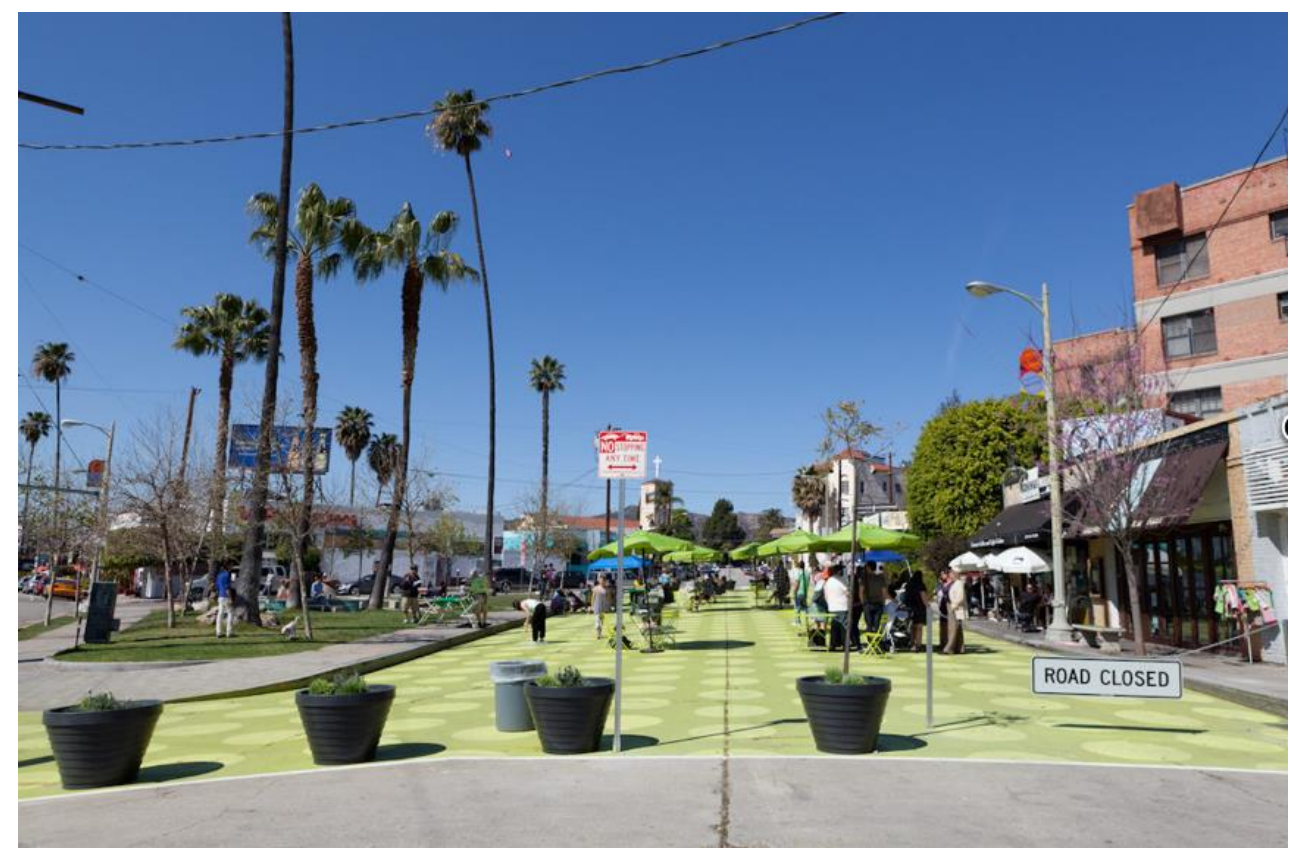

Figure 2. Living Street Example Sunset Triangle Plaza, Los Angeles, California

Great Streets. According to the American Planning Association (APA)'s Greatest Places in America (APA, 2013). Great Streets comprise the entire visual corridor, including the public realm and how it relates to the adjacent land uses. Special emphasis is placed on streets that are "complete," which take into account all users, not only motor vehicles. Great Streets should document a street's character while representing the community, through design or capitalization of natural features. Great Streets work to accommodate social interaction by providing a broader street network and encouraging pedestrian activity through landscaping, street furniture, and capitalization on building design and scale. These streets also utilize green infrastructure to promote sustainability through minimizing runoff, reusing water, ensuring groundwater quality, minimizing heat island, and responding to climate demands (APA, 2013). Allan Jacobs, a member of the Department of City and Regional Planning at the University of California at Berkeley, analyzed and identified important 
design factors necessary to transform streets into better public realms of a Great Street. These factors include: the use of multi-way boulevards to reduce the speed of through traffic with the pedestrian movement, utilizing the power of observation to change Modern Street planning traffic assumptions, and fostering interaction between pedestrians and cars to create livability, mobility, safety, economic opportunity, and open space (Project for Public Spaces, n.d.).

In San Diego, nine blocks of $5^{\text {th }}$ Street form the Gaslamp Quarter. This 2010 APA awarded Great Street adopted guidelines to reuse historic buildings and establish limitation on building height for infill development. It has integrated its historic heritage, promoted pedestrian orientation with large walkable sidewalks, transformed storefronts improving downtown revitalization, and created a vibrant public place, all of which are characteristics of a Great Street (APA, n.d.).

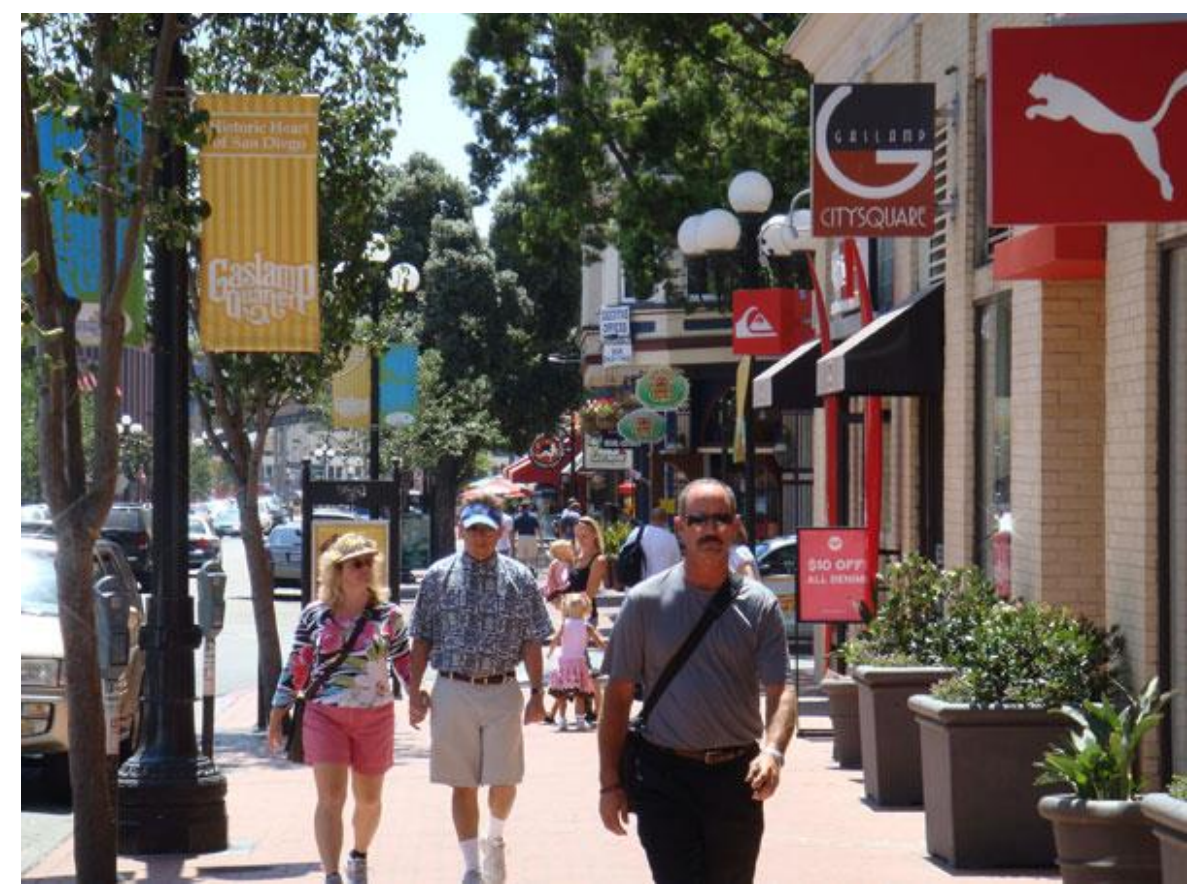

Figure 3. Great Streets Example, 5th Avenue, San Diego, California 


\section{Complete Street Legislation}

The following Complete Street legislative highlights Federal and State policies that influence the direction Bakersfield must adhere to as it pursues improving and updating its own Complete Street policies. The following legislative policies direct the implementation of Complete Streets:

California Assembly Bill 1358: The California Complete Streets Act. The California Complete Streets Act, Assembly Bill 1358 (Chapter 657, Statues 2008) was signed into law on September 30, 2008. The Act states (Sec.2 [g]):

In order to fulfill the commitment to reduce greenhouse gas emissions, make the most efficient use of urban land and transportation infrastructure, and improve public health by encouraging physical activity, transportation planners must find innovative ways to reduce vehicle miles traveled (VMT) and to shift from short trips in the automobile to biking, walking, and use of public transit.

The 2010 update of the California Complete Streets Act requires the Governor's Office of Planning and Research (OPR) to amend the OPR General Plan Guidelines to assist city and counties in integrating multimodal transportation network policies into the circulation elements of their general plans. The following language was added to the Government Code Section 65302(b)(2)(A) and (B):

- Commencing January 1,2011 , upon any substantial revision of the circulation element, the legislative body shall modify the circulation element to plan for a 
balanced, multimodal transportation network that meets the needs of all users of the streets, roads, or urban context of the general plan.

- For the purposes of this paragraph, "users of streets, roads, and highways" means bicyclists, children, persons with disabilities, motorists, movers of commercial goods, pedestrians, users of public transportation, and seniors. According to the Governor's OPR's Update to the General Plan Guidelines: Complete Streets and the Circulation Element (2010), AB 1358 places the planning, designing, and building of Complete Streets into the larger planning framework of a city's general plan by requiring jurisdictions to append their circulation elements and plan for multimodal transportation networks. Upon appending their circulation elements, OPR recommends local jurisdictions view all transportation projects, new or retrofit as possible opportunity to improve safety, access, and mobility for all travels while recognizing all modes of transit as important elements of the community's transportation network, creating contextual design standards based on street types. Additionally, transportation networks should consider the pedestrian, bicycle, and transit routes, which may not always be located on or along streets, road and highways, is a related mandatory circulation element issue. Assembly Bill 1358 introduces a new standard of practice to construct Complete Streets while prioritizing project selection and funding based on the development of a balanced, multimodal, transportation network. To accommodate cities and counties in the process of reaching AB1358 standards, the OPR Update to the General Plan Guidelines provides information on how a local jurisdiction 
may plan for the development of a well-balanced multimodal transportation network, elements and issues to address within the circulation element and its impact or relationship to other general plan elements.

\section{U.S. Department of Transportation (DOT) Bicycle and Pedestrian Policy. The}

DOT's bicyclist and pedestrian accommodation regulations are consistent with Complete Street policies in California AB 1358. The United States Department Policy Statement of Bicycle and Pedestrian Transportation Accommodations Regulations and Recommendations support the "fully integrated active transportation networks" for bicyclists and pedestrians (Governor's Office of Planning and Research [OPR], 2010). The establishment of the well-connected networks and their design should be a part of Federal-aid project developments (Smith, Reed, \& Baker, 2011). The DOT policy encourages local governments and transportation agencies to adopt policies, which ensure all users of the streets, roads, and highways, are taken into consideration when developing new or retrofitting existing transportation networks (OPR, 2010). Transportation agencies are strongly encouraged by the DOT to go beyond minimum standards to provide safe, convenient facilities for all modes because of the numerous individual and community benefits that walking, cycling, and transit provides. The policy recognizes safe and convenient pedestrian and cycling facilities may be different depending on regional, climate, and population density differences, but should be integrated into the transportation systems (Smith, et al., 2011).

Safe Routes to School. The U.S. Congress passed the Safe, Accountable, Flexible, Efficient, Transportation Equity Act: A Legacy for Users Act (known as 
SAFETEA-LU), in 2005. The transportation bill included funding for the Federal Safe Routes to School (SRTS) program. SRTS is a program created to support the use of safe, active transportation modes such as walking and bicycling for children to and from schools. Its benefits include reduced congestion, improved safety, and increased physical activity for children (OPR, 2010). The Federal Highway Administration directs the SRTS program, open for Kindergarten to $8^{\text {th }}$ grades, and distributes federal grant funding to eligible cities and counties for SRTS projects. In California, Caltrans has awarded SRTS funding to include high schools (California Department of Transportation [Caltrans], 2013). SRTS allocates funding for projects that are planned to include pedestrian facilities, traffic calming features, traffic control devices, bicycle facilities, public outreach and education that will improve the abilities for children to bicycle and walk to school (OPR, 2010). Schools have become an important node in the development of local transportation networks. Although it is not a requirement of updating a city or county's general plan, SRTS programs help to implement connected, safe multimodal transportation networks. The City of Bakersfield and Kern County have received SRTS funding from the Caltrans in 2009, which was allocated to curb, gutters, and sidewalk projects for East Bakersfield's Voorhies Elementary and Foothill High School and Oildale's Beardsley Elementary areas (23ABCNews, 2009). Currently, Bike Bakersfield, a non-profit bicycle advocacy group, has established a Safe Routes to School Program, which strives to integrate fitness, health, traffic relief, environmental awareness and safety to the children of the Bakersfield community (BikeBakersfield, n.d.). It is unknown whether this program receives state or private funding. 
California Assembly Bill 32 and Senate Bill 375 . Assembly Bill 32 is the Global Warming Solutions Act of 2006. AB 32 has set California's greenhouse reduction goals: by the year 2020, emissions will be reduced to 1990 levels and by the year 2050, emissions will be reduced to 80 percent below 1990 levels (GreenLA Coalition, 2012). The regional transportation planning process of the Metropolitan Planning Organizations (MPO) have connected greenhouse emission goals set by AB 32 to automobiles and land use with infrastructure planning (OPR, 2010). Senate Bill 375 is the Sustainable Communities and Protection Act of 2008. The bill builds upon the emission reduction goals with transportation and land use strategies (GreenLA Coalition, 2012). One of SB 375 's main objectives is to direct funding of transportation projects that coordinate land use and transportation planning with the support of walking, bicycling, and transit use. SB 375 has required each MPO to prepare a Sustainable Communities Strategy to reduce greenhouse emission as a part of their Regional Transportation Planning updates, which explains feasible land use patterns and transportation system improvements to meet state reduction targets (OPR, 2010). When considering Complete Streets are implemented on the local level, the State has created an important role to provide the guidance and facilitate assistance for project design, planning, and implementation.

California Department of Transportation (Caltrans) Complete Streets Policy. The California Department of Transportation Deputy Directive 64-Revision \#1: ‘Complete Streets: Integrating the Transportation System' (DD-64-R1) was released October 2008. 
The DD-64-RI directs Caltrans to build and maintain roads to support increased mobility and access for all users (OPR, 2010).

According to the California Department of Transportation DD-64-R1, Caltrans is directed to:

- Provide for the needs of travelers of all ages and abilities in all planning, programming, design construction, operations, and maintenance activities and products on the State Highway System

- View transportation improvements (new and retrofit) as opportunities to improve safety, access, and mobility for all travelers and recognizes bicycle, pedestrian, and transit modes as integral elements of the transportation system

- Develop integrated multimodal projects in balance with community goals, plans, values; addressing the safety and mobility needs of bicyclists, pedestrians, and transit users in all projects, regardless of funding

- Facilitate bicycle, pedestrian, and transit travel by creating 'Complete Streets' beginning early in system planning and continuing through project delivery and maintenance and operations

- Collaborate among all Caltrans department functional units and stakeholders to develop a network of Complete Streets. (p.1-2)

The Caltrans Deputy Directive DD-64-R1 codifies the agency's policy supporting Complete Streets. It assigns responsibilities for implementation through the department to support the interdisciplinary responsibility of incorporating Complete Street policies, 
including consulting, collaborating, implementing projects with local jurisdictions. The Directive states that to ensure successful implementation, all department manuals, guidance, and training must be updated and developed to include multimodal planning and design (Caltrans, 2010a). To accomplish the necessary Directive updates, the Caltrans Implementation Action Plan (2010) has developed and prioritized actions establishing a list of responsibilities and deadlines provided to a large cross section of the department staff, which includes: Highest Focus Areas; Guidance, Manuals, and Handbooks; Policy and Plans; Funding and Project Selection; Raise Awareness; Training; and Research. These Caltrans standards reflect opportunities and challenges for multimodal facilities on the State Highway System in which Bakersfield will need to coordinate with its own local transportation planning.

Kern County Bicycle Master Plan and Complete Streets Recommendations. The Kern Council of Governments (Kern COG) has developed the Kern County Bicycle Plan and Complete Streets Recommendations. The document was prepared by Alta Planning + Design and October 2012, KernCOG formally approved the plan (Cox, 2012). The purpose of the Kern Bicycle Plan and Complete Streets Recommendations project is to develop a network of bicycle facilities that will provide better access to the attractive nodes in the County, including transit locations, schools, and shopping destinations. It also provides recommendations for the improvement and expansion of bicycle support facilities such as on-street bike parking, storage areas, and bike rack accommodations of public transit. 
The Complete Street recommendations in the report include policies, best practices, and design guidelines for implementation on Kern County roads. Infrastructure treatments to existing roadways are identified as best practices to create functional Complete Streets that add comfort and safety to alternative modes of transportation while retaining the ability for vehicles to travel without impediment. Complete Street opportunities and constraints are also discussed for additional context to the Kern County environment. Kern County policies including its Circulation Element goals, policies, and objectives are reviewed along with the absence of multimodal LOS and design standards necessary for Complete Street implementation on roadways.

Design guidelines in the report include a summary of the design feature, a discussion on its cost and effectiveness, and guidance from state or federal manuals or guidelines. The Plan recommends communities within Kern County, including Bakersfield, should dedicate resources towards connecting complimentary land uses through pedestrian and bicycle facilities. Through a Complete Street connective network, alternative modes of travel will gain users and acceptance within Kern County (Kern County Council of Governments, 2012). The guidelines in the Kern County Master Bicycle Plan and Complete Street Recommendations Report are not standards which must be followed, but gather innovative practices recognized throughout the United States and promote guidelines that may be used to inform provisions for alternative transportation.

Bakersfield Bicycle Transportation Plan. The City of Bakersfield is currently developing the Bakersfield Transportation Plan. Its purpose is an implementation tool 
for the City's Bikeway Master Plan through the development of strategies and opportunities to maximize competitiveness and funding from the Caltrans' Bicycle Transportation Account. According to the City of Bakersfield Planning Division (City of Bakersfield, n.d.), the plan will include:

- A comprehensive inventory of existing bikeway facilities

- Recommendations for future bikeway facilities, incorporating the existing bikeway network and recommending new routes to address gaps, deficiencies, and needs

- A phasing plan based on a ranking system for the future construction of bikeway facilities. This will also include estimated costs for proposed facilities.

- An implementation plan that will include recommended implementation and funding strategies.

- A set of bikeway design guidelines.

According to Bakersfield Associate Planner, Kate Shea, The Bakersfield Bicycle Transportation Plan is expected to incorporate strategies and policies for Complete Streets Act compliance and analysis. This is expected to be similar to the Kern County Bicycle Master Plan and Complete Streets Recommendations Report (personal communication, September 12, 2012).

\section{Complete Street Design Guidelines}

In the development of Complete Street policy, creating new design standards shifts from traditional vehicle oriented transportation planning to multimodal streets. The listed design features are currently piloted or approved ideas occurring at the state 
or federal levels and appear in private and public jurisdiction manuals. In addition, there are important planning issues that influence the feasibility of Complete Streets and the choices made of design elements when incorporated into a street project

Mode Shift through Complete Street Design. The following principles, often applied to both retrofitting and new construction of streets, recognize an essential change from auto-oriented roadway design towards Complete Streets; working together to improve the roadways for all modes and users.

Reducing Street Width. The width of roads often influences a road's ability to provide for the needs of pedestrians, cyclists, and transit users outside of the vehicle travel lanes. Higher vehicle speeds and limited right-of-way create a more difficult environment for alternative modes as users travel along the road, cross the street and navigate an intersection (McCann and Rynne, 2010). Wider roads also inhibit pedestrians with longer crossing times, which negatively impacts signal timing for vehicular traffic (LaPlante and McCann, 2008). Reducing the width or number of travel lanes, called a "road diet", is an established option used to retrofit a Complete Street when considering the needs of all travelers and to increase the safety and operational benefits of the roadway.

Vehicle Speed Management. Complete Streets consider more than the allocation of space, it also must select a design speed appropriate for all users of the road (LaPlante, McCann, 2008). Lower traffic speeds enable drivers to better avoid crashes and accidents with a greater field of vision; and if a crash occurs, lower traffic speeds result in injuries that are less serious (McCann and Rynne, 2010). Lower traffic speeds 
are more favorable for non-motorized users and Complete Street design must reconsider the traditional practice of speeds based on classifications of roadways with the ability to maintain mobility.

Design Elements and Features of Complete Streets. In order to better assess the numerous design features that can be integrated within a Complete Street, resource tables were created (by transportation mode) listing categorized treatments and facilities. There are several sources of planning and design guidance for Complete Streets from a variety of public and private entities. The following manuals, which were found to be most valuable for general, comprehensive Complete Street design, are recommended for further research into the planning and design guidance for Complete Streets. They are the largest sources for information summarized in the subsequent tables:

- Los Angeles County Model Design Manual for Living Streets ( $1^{\text {st }}$ Ed.) (2011)

- San Francisco Better Streets Plan (2010)

- New York City Street Design Manual (2010)

- Kern County Bicycle Master Plan and Complete Streets Recommendations (Vol. II.) (2012)

- Urban Bikeway Design Guide, National Association of City Transportation Officials

- Complete Intersections: A Guide to Reconstructing Intersections and Interchanges for Bicyclists and Pedestrians, Caltrans (2010)

- Highway Design Manual (Sixth ed.), Caltrans (2012) 
Pedestrian Treatments and Facilities. Pedestrian treatments and facilities are meant to improve universal access of the street for all people, including children and those with disabilities. The walking environment should be safe, inviting, and easy to use and understand with the ability to connect people to places.

Table 1. Pedestrian Design Treatment and Facility Examples

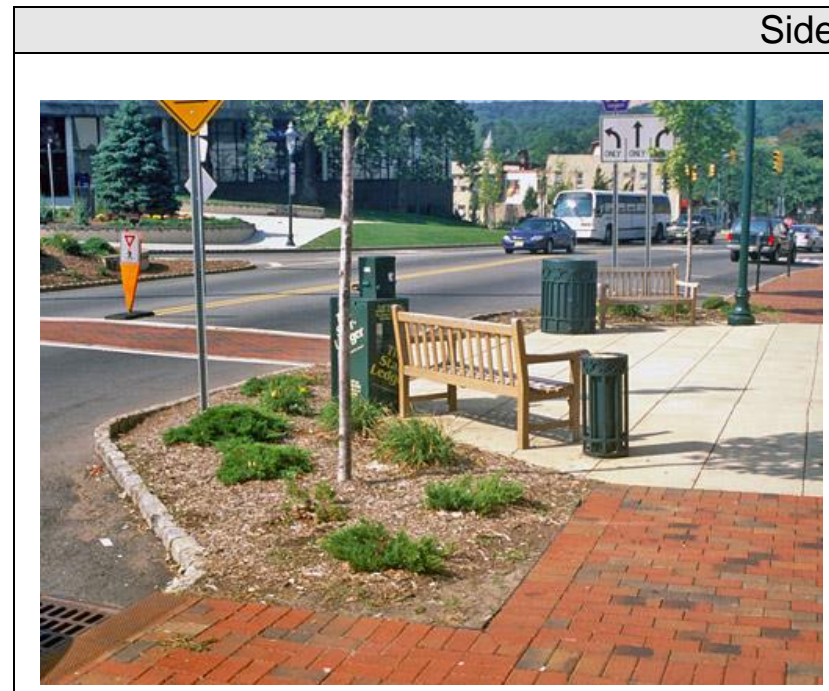

Figure 4. Example Curb Extension

\section{Sidewalks}

Full Sidewalks - Portion of street curbed or lateral lines of roadway and property lines which accommodates pedestrian traffic and a range of street furnishing and fixtures

Ribbon Sidewalks - Separated from street by continuous, unpaved landscaped strip

Limiting Driveways - Driveways can cause conflict between pedestrians, cyclists on sidewalks and drivers when they cross the path of travel.

Curb Extension (Bulb-outs) - Expansion of curb line to lane of roadway adjacent to curb, usually parking lane, placed at corner or mid-block to reduce crossing distances. Can also be extended to provide landscaping or provide community facilities.

Curb Ramps - Allow pedestrian access between sidewalk and roadway for pedestrians of all ages and disabilities. Curb ramps must be installed where pedestrian crossings exist according to ADA guideline standards.

Lighting - Should be consistent along length of corridor in an appropriate pattern to other street furniture and tree elements while providing a sense of safety to the public space. Vary in fixtures and light levels.

Street Furniture - Benches and seating, waste and recycling bins, water fountains, community kiosks, public art and signage are various pedestrian furniture amenities to activate the street. Should be evenly spaced through corridor, not impede on the pedestrian path, and work with other site design elements 


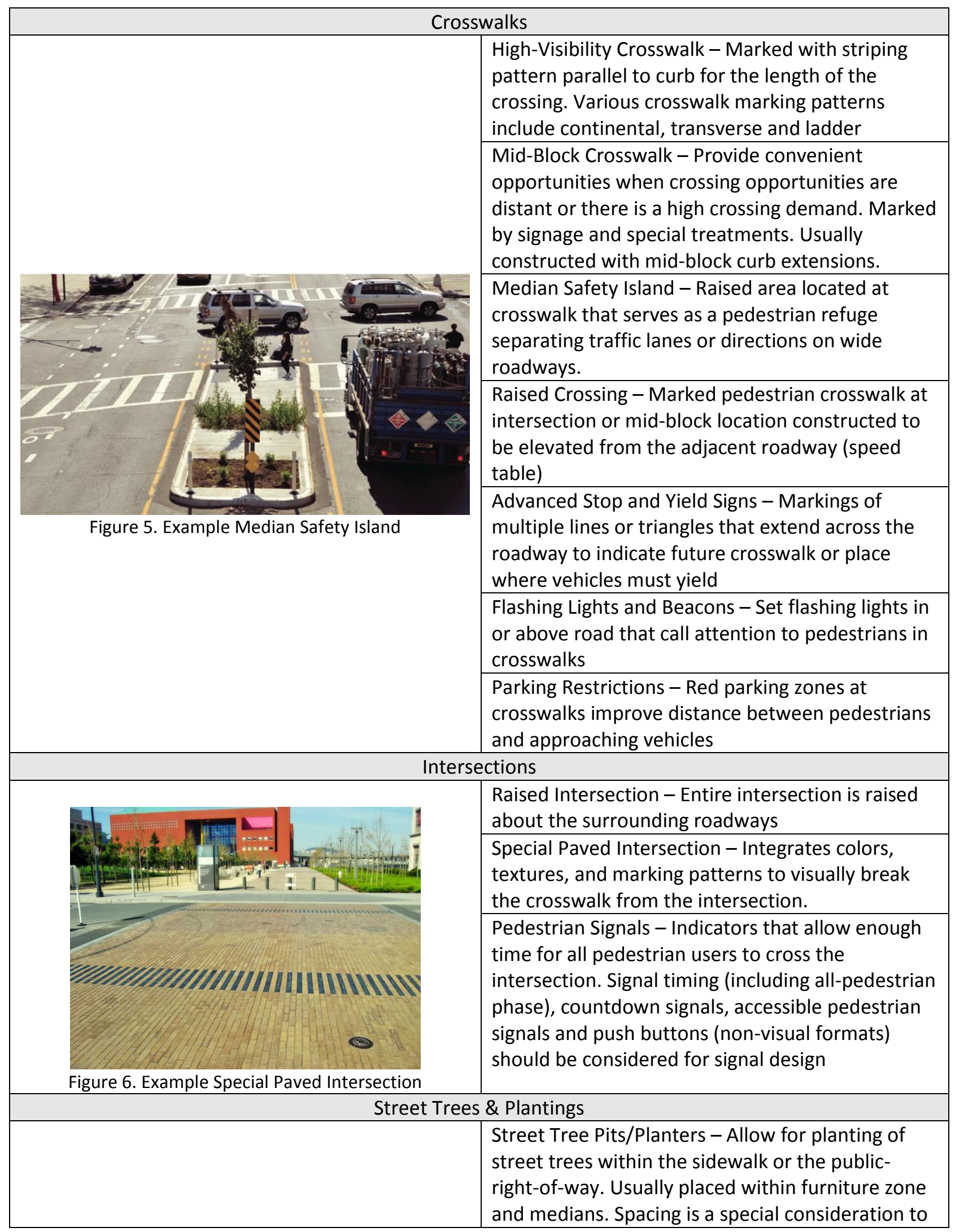

Page 26 


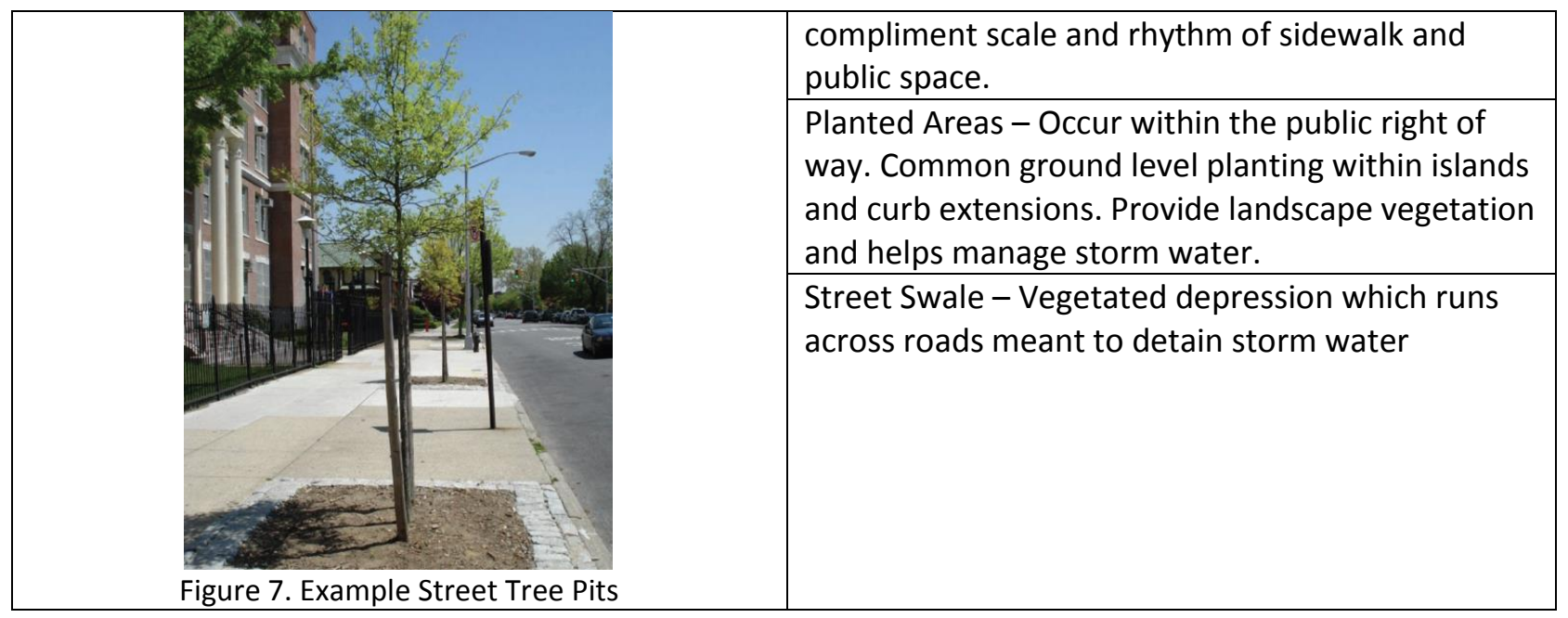

Bicyclists Treatments and Facilities. A bicyclist is a legitimate road user that operates a vehicle and has been provided established vehicular code in California. Complete Streets must provide bicyclists with safe, convenient, and comfortable access on the street. Street design can meet this Complete Street goal by providing appropriate facilities for all types of bicyclists on the roadways.

Table 2. Bicycle Treatments and Facilities

\begin{tabular}{|l|l|}
\hline \multicolumn{3}{|c|}{ Bike Lanes \& Roadways } \\
\hline Figure 8. Example Buffered Bike Lane & $\begin{array}{l}\text { Shared Roadway - Street that bicyclists ride in the } \\
\text { same travel lanes as other traffic. Works well with } \\
\text { low volume, low speed neighborhood residential } \\
\text { streets or rural roads. Known as Class III bikeways or } \\
\text { bike routes. }\end{array}$ \\
\hline $\begin{array}{l}\text { Marked - Portion of roadway designated by striping, } \\
\text { signs, and pavement markings for the use of } \\
\text { bicyclists. Typically on right side of street between } \\
\text { travel lane and curb, road edge, or parking lane. } \\
\text { Usually delineated as Class II bike lane }\end{array}$ \\
$\begin{array}{l}\text { Buffered - Conventional bike lane with designated } \\
\text { buffer space that works to separate bicycle lane } \\
\text { from adjacent vehicle travel lane or parking lane. }\end{array}$ \\
$\begin{array}{l}\text { Shoulder Bikeways - Facility that accommodates } \\
\text { bicycle travel on rural highways and country roads } \\
\text { by providing suitable area for bicycling and reducing }\end{array}$ \\
\hline
\end{tabular}




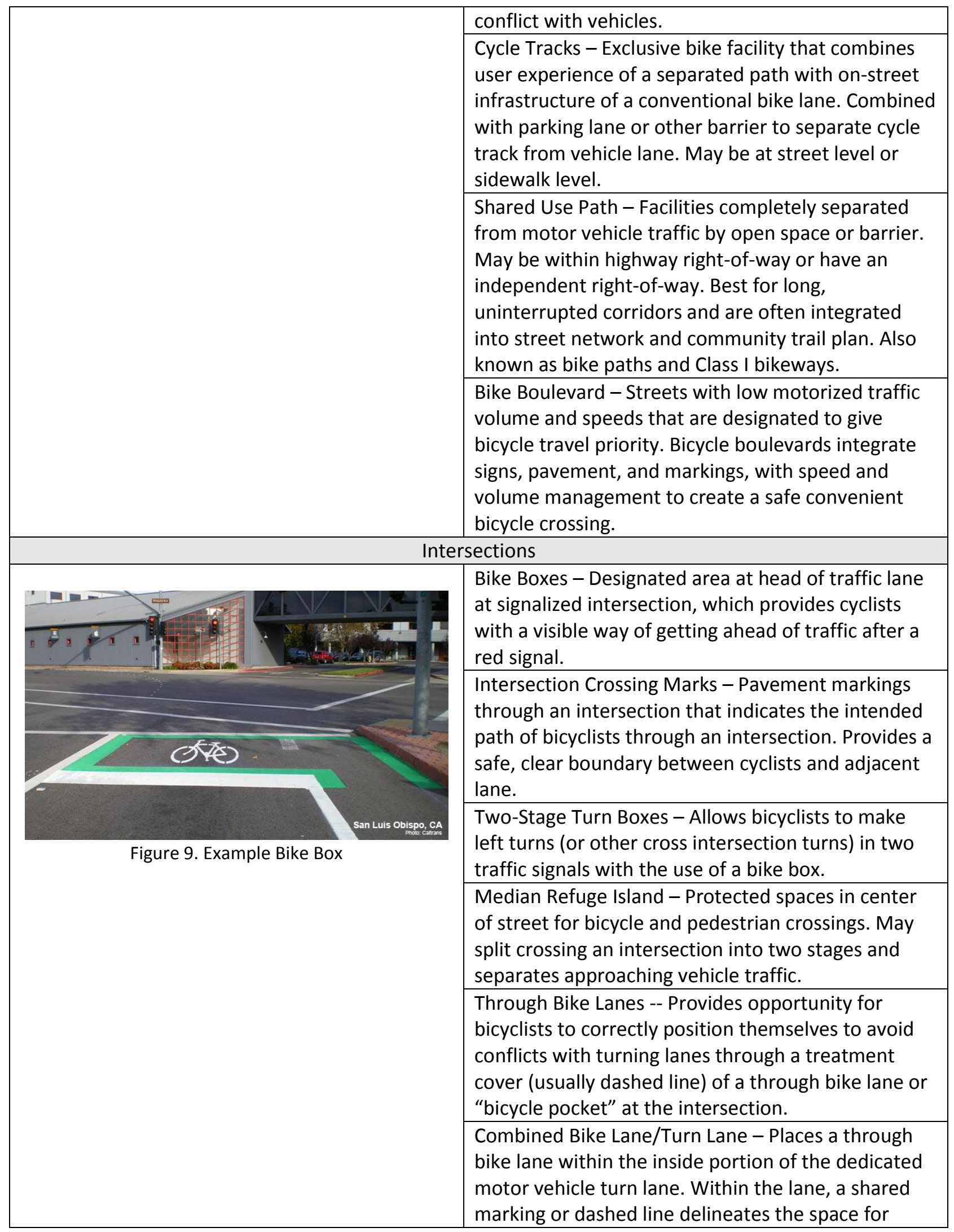




\begin{tabular}{|c|c|}
\hline & bicyclists. \\
\hline & $\begin{array}{l}\text { Bicycle Parking - Secure bicycle parking is integral } \\
\text { for a complete bikeway network. Bicycle parking } \\
\text { should be well lit, secure, and should not interfere } \\
\text { with pedestrian movement. }\end{array}$ \\
\hline \multicolumn{2}{|c|}{ Signals } \\
\hline \multirow{4}{*}{ Figure 10. Example Bicycle Signal Detection } & $\begin{array}{l}\text { Active Warning Beacon for Bike Routes - Use of } \\
\text { flashing lights that supplement warning signs at } \\
\text { unsignalized intersections or mid-block crosswalks. }\end{array}$ \\
\hline & $\begin{array}{l}\text { Hybrid Beacon for Bike Route Crossing - High- } \\
\text { intensity Activated Crosswalk (HAWK), consists of } \\
\text { signal-head with two red lenses over a single yellow } \\
\text { lens, usually placed on major streets to enhance the } \\
\text { bicycle movements and crossings. }\end{array}$ \\
\hline & $\begin{array}{l}\text { Bicycle Signal Heads - Traffic control signal used in } \\
\text { combination with existing conventional traffic signal } \\
\text { or hybrid beacon. Bicycle signal heads may be used } \\
\text { to indicate bicycle signal phases (bicycle only } \\
\text { movements) and other bicycle-specific timing } \\
\text { strategies (leading bicycle intervals). }\end{array}$ \\
\hline & $\begin{array}{l}\text { Signal detection - Actuated signals, adjusted for the } \\
\text { bicycle metallic mass, made to alert the signal } \\
\text { controller of a bicycle crossing demand on a } \\
\text { particular approach. }\end{array}$ \\
\hline \multicolumn{2}{|c|}{ Signing \& Markings } \\
\hline \multirow{3}{*}{ Figure 11. Example Shared Lane Marking } & $\begin{array}{l}\text { Colored Bike Facilities - Colored pavement and } \\
\text { markings increases the visibility of the bicycle } \\
\text { facility. Commonly applied to intersections, } \\
\text { driveways, conflict areas and non-standard facilities, } \\
\text { such as cycle tracks. }\end{array}$ \\
\hline & $\begin{array}{l}\text { Shared Lane Markings (SLMs) - Road markings used } \\
\text { to indicate a shared lane environment for bicycles } \\
\text { and automobiles. Also called 'sharrows' }\end{array}$ \\
\hline & $\begin{array}{l}\text { Bike Route Way finding Signage and Markings - } \\
\text { Comprehensive signing and/or pavement markings } \\
\text { to guide bicyclists to their destinations along } \\
\text { preferred bicycle routes. Way finding signs are } \\
\text { usually placed at intersections or other key locations } \\
\text { leading to bicycle routes. }\end{array}$ \\
\hline
\end{tabular}

Transit Treatments and Facilities. Public transit is also designed within the Complete Street system. The priority and amount of transit features may be dependent 
on the volume of ridership in addition to the classification of the street. However, transit should have an important design influence because of its ability to connect with multiple modes of transportation. Service amenities are also dependent on type of transit route (local, community, bus rapid transit). The city should work with the local bus provider to create an ideal transit design compatible with the community. In commercial areas, the city should work to promote public-private partnerships for the design and location of transit shelters in commercial areas that often appear in suburban communities.

Table 3. Transit Treatments and Facilities

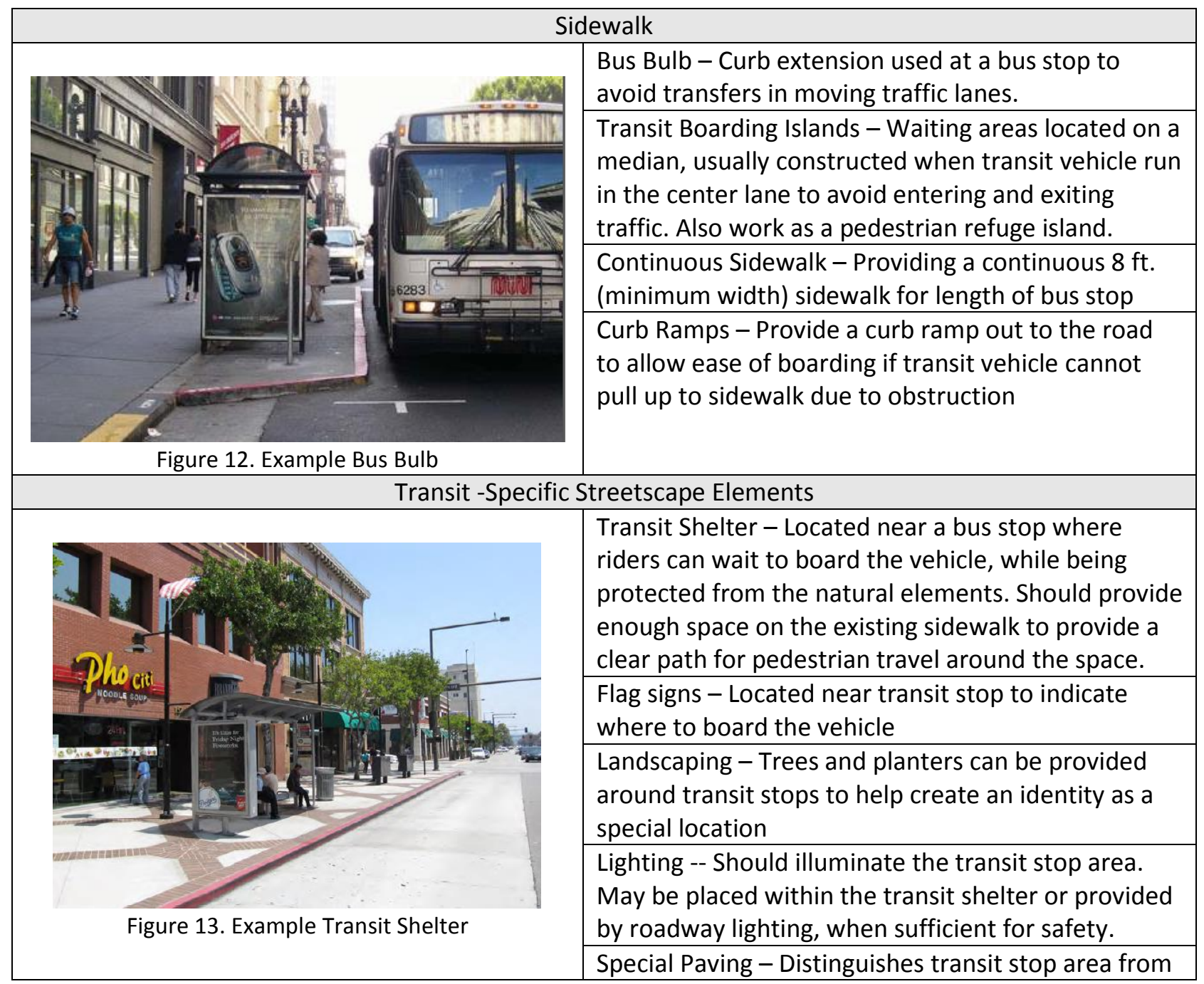




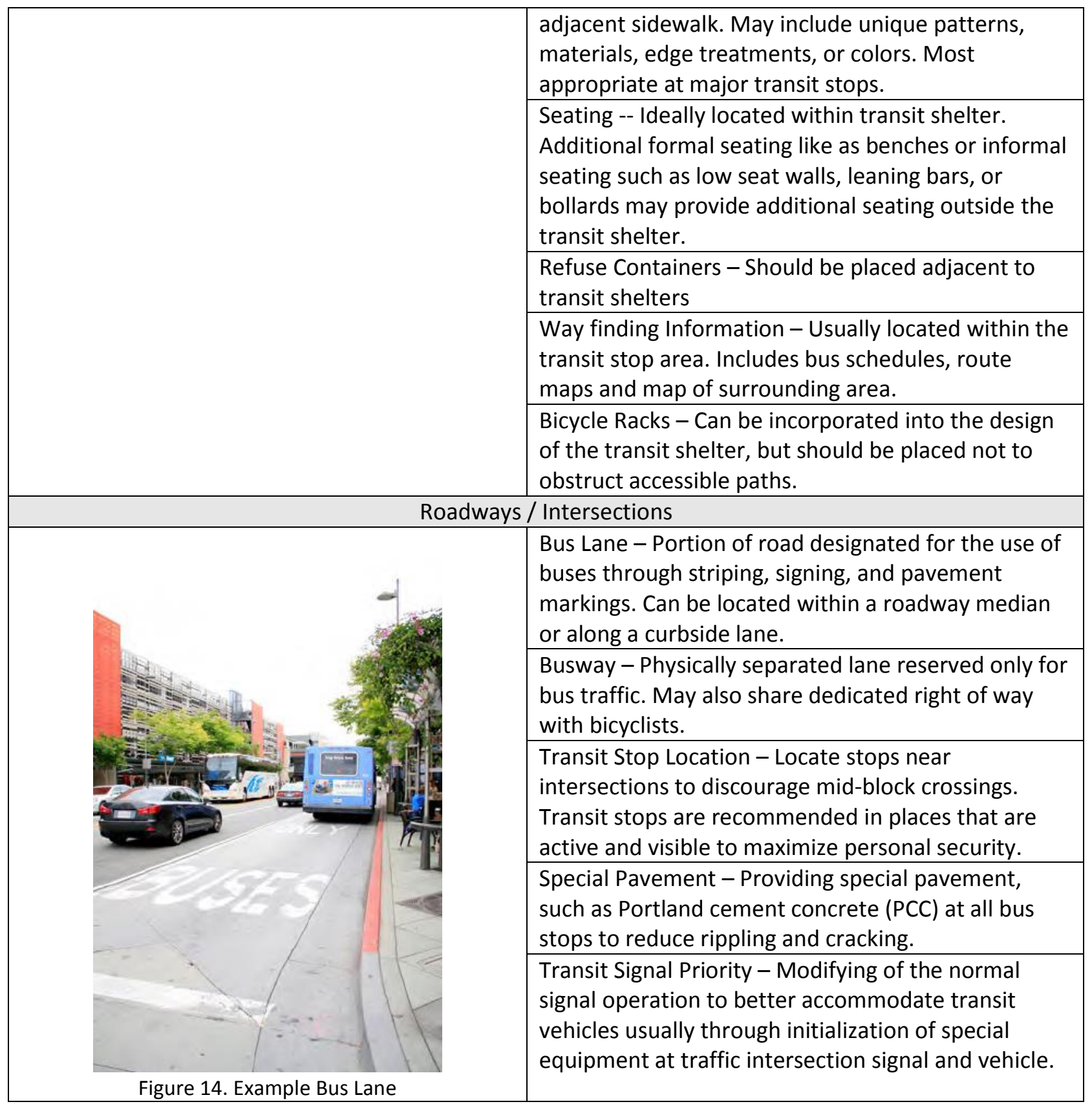

Roadway Traffic Calming Features. Traffic calming design features are physical measures meant to reduce the negative impacts of vehicles, affect driver behavior, and improving conditions for alternative modes of transportation on the street. 
Table 4. Traffic Calming Treatments and Facilities

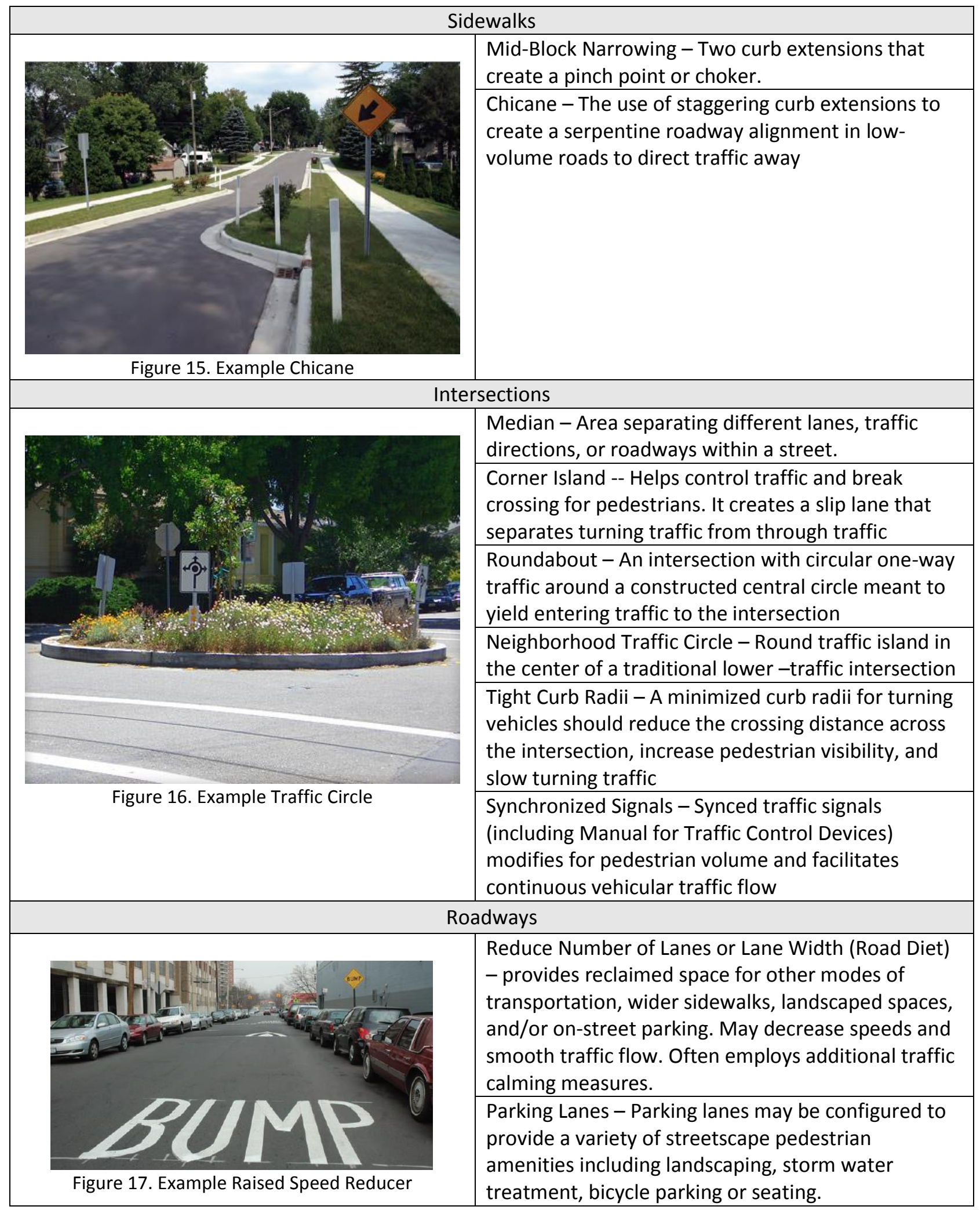




\begin{tabular}{|l|l|}
\hline \multirow{1}{*}{} & $\begin{array}{l}\text { Raised Speed Reducers - A raised area of a roadway } \\
\text { meant to deflect the wheels of a traveling vehicle in } \\
\text { order to reduce its speed. Variations of raised speed } \\
\text { reducers are speed humps (short in length) and } \\
\text { speed tables (longer with flat section in middle) }\end{array}$ \\
\cline { 2 - 3 } & $\begin{array}{l}\text { Forced Turn - An island or sidewalk extension at the } \\
\text { approach to an intersection, which prevents turns } \\
\text { and through movement from intersecting the street. } \\
\text { Forced Turns can also be a barrier or median and } \\
\text { include plantings or other design features. }\end{array}$ \\
\hline $\begin{array}{l}\text { Speed Feedback Signs - Display motor vehicles' } \\
\text { speed on a digital display. }\end{array}$ \\
\hline $\begin{array}{l}\text { Utilities - Within streetscape can include utility } \\
\text { poles, wires, utility boxes and mains, laterals, vaults, } \\
\text { valves, in addition to water, sewer, gas, traffic signal } \\
\text { and light poles and wires. Utility installations may } \\
\text { occur in both the street and sidewalks. Locating } \\
\text { utilities should be placed underground when } \\
\text { feasible and minimize conflicts with access or other } \\
\text { streetscape elements }\end{array}$ \\
\hline
\end{tabular}

\section{Related Planning Issues with Designing Complete Streets}

There are a few, important planning issues that influence the feasibility of Complete Streets and the design element choices made when incorporated into a street project. Each issue is interrelated to affecting street design.

Determining Street Type. The context of a street type is directly related to the traffic volume of the street. When designing a Complete Street, the city should observe the existing land uses, for example residential, commercial, industrial, or mixed use. What are the transportation characteristics of the street: major arterials with higher traffic volumes and speeds or local functional secondary streets with lower traffic and speeds (City of San Francisco, 2010)? These existing street types influence design features. A local, neighborhood street may incorporate more traffic-calming features while a denser throughway may integrate pedestrian and bicycle treatments that buffer 
or protect the alternative mode users. A contributor to the success of a Complete Street is the appropriate amount of attractors, defined as the reason why people travel to a destination. When a diverse amount of land uses are provided along the Complete Street, more travel will be generated in all forms of its different mode capacities (McCann and Rynne, 2010). An alternative mode for travel becomes more feasible with the closer proximity of uses (LaPlante and McCann, 2008).

Ensuring Street Connectivity. There is an important relationship between street connectivity and Complete Streets. Direct street connectivity provides shorter routes for bicyclists and pedestrians and includes multiple access opportunities for public transportation through more roads or paths connecting one geographic block area to another (Litman, 2003). Parallel streets from a grid pattern create alternative travel routes to a destination, reduces congestion, and increase safety (NCSC, 2010d). A street grid pattern also creates an opportunity to uniquely comprise the encompassing Complete Street design by featuring a transportation mode for a specific street network.

The 1950's suburban style street pattern is characteristically a roadway design of widely spaced arteries fed by smaller roadways that rarely connect with each other (NCSC, 2010d). The result of concentrated motorized traffic, including affecting public transit, causes longer trips and limited alternative travel routes. The suburban style street pattern's indirect connectivity presents a challenge for alternative transportation modes. Indirect routes may lengthen trips; making it difficult for those who may wish to walk or bike without compromising safety or comfort by facing a high-speed arterial.

Access Management. It is important to have a well-connected street network. 
Public transportation serves more neighborhoods that provide multiple entry points (NCSC, 2010d). However, multiple access points may increase the number of conflicts between users that occur at intersections and driveways (LA County Dept. Public Health \& UCLA, 2011). Access management is important to provide the balance between traffic flow and safety.

Level of Service (LOS) Standards and Multimodal Level of Service. Traditional LOS is focused on intersection performance for the motor vehicle. The LOS is a categorical scale of letters. In summary, LOS F is the greatest delay and LOS A is no delay with the greatest quality of service for traveling motorists. A high LOS will often create a large intersection with large turning movements, multiple lanes, exclusive turning lanes, and higher speeds around crosswalks. This may be intimidating for pedestrians, cyclists, and those wishing to access public transit (LaPlante and McCann, 2008). Instead, multimodal level of service (MMLOS) was developed under the National Highway Research Program (NCHRP) project 3-70 (LA County Dept. Public Health \& UCLA, 2011). MMLOS measures the degree in which an urban street design meets the needs for all modes of travel with the facility design and operation of all users. The four levels of service results for the street in MMLOS are auto, transit, bicycle, and pedestrian and each LOS is calculated separately. The MMLOS calculation for each mode is based on the perceived LOS by the user in addition to the streetscape factors that influence the individual's perception (Dock, Greenberg, and Yamarone, 2012). MMLOS is an important metric that is more effectively assessing the performance of 
Complete Streets than traditional LOS. It also may be used as an analysis of existing roadways to determine deficiencies in the system for all modes of transportation.

Performance Measures. Performance measure framework is structured around a set of calculated goals set by an agency. It provides quantifiable evidence for the consequences of a decision or action. Transportation performance measures specifically evaluate and monitor the degree to which a transportation system has accomplished the adopted public goals and mobility objectives (Caltrans, 2010b). Caltrans has created Smart Mobility Performance Measures (SMPMs) that are meant to identify the relationship between land use decisions and transportation with the effects on economic, social, and environmental conditions. With principles including: location efficiency, reliable mobility, health and safety, environmental stewardship, social equity, and robust economy, a community can adopt performance measures for their Complete Streets, which demonstrate the progress to meet greater goals, like the SMPMs. Complete Streets related performance measures may include the following examples (City of Huntington Park Complete Streets Policy, Resolution No. 2012-18, 2012):

- The total miles of on-street bikeways defined by streets with clearly marked or signed bicycle accommodations

- Total miles of streets with pedestrian accommodation

- Number of missing or non-compliant curb ramps along City streets

- Number of new street trees planted along city streets

- Percentage of new street projects that are multi-modal

- Number and severity of pedestrian-vehicle and bicycle-vehicle collisions 
- Number of pedestrian-vehicle and bicycle-vehicle fatalities

\section{Benefits of Complete Streets}

Successful Complete Streets include additional co-benefits to their implementation. They may become an indirect solution to widespread problems communities face today. Potential benefits extend to public health, safety, sustainability and community revitalization.

Health and Physical Activity. Public health and safety are connected to the formation of Complete Streets legislation. By promoting different modes of transportation, such as biking and walking, Complete Streets foster more physical activity while improving the health of the individual and the greater community (Jackson, 2011). Obesity is an epidemic the Centers for Disease Control and Prevention (CDC) has recognized and specifically recommends adoption of Complete Street policies to increase the amount of physical activity in daily lives, in addition to providing the transportation infrastructure to accommodate access to healthy food resources (LaPlante and McCann, 2008). A community study of six cities found residents with "walkable" neighborhoods walked twice as much as residents with less walkable neighborhoods (Saelens, Sallis, and Frank, 2003). Similarly, in a study published in the American Journal of Preventative Medicine, the effect of using light rail transit on BMI, obesity and recommended physical activity concluded that improving neighborhood environments to increase the use of a light rail transit system could provide improvements in health outcomes for millions of individuals (MacDonald, Stokes, Cohen, Kofner, and Ridgeway, 2010). The research link between Complete Street 
policies and health outcomes is rather difficult to evaluate. Introduced Complete Street policies are still relatively new to calculate with a limited, subjective scope addressing adjacent land uses, which influences an individual's trip generation (Sadler, 2010). However, by looking at the overall trends over time, a comparison of obesity levels and the rates of bicycling and walking trends can be determined. The 2009 American Community Survey and the CDC's 2009 Behavioral Risk Factor Surveillance System are two data sources the Alliance for Biking \& Walking have used in their 2012 Bicycling and Walking in the United States Benchmark Report to ascertain the established relationship between bicycling, walking, and obesity. It was determined that states with higher levels of bicycling and walking averages have lower obesity, diabetes, and prevalence of high blood pressure rates. States with higher levels of bicycling and walking also have higher levels of physical activity.

Safety for All Modes. One of the fundamental purposes of creating Complete Streets is the need to provide safe travel for our users. On the roadways today, those who chose alternative modes of transportation are still at risk. Special populations including children, older adults, and those with disabilities may be at greater risk when attempting to cross a street without appropriate accommodations and refuge from vehicles. Nationwide, approximately 5,000 pedestrians and bicyclists die each year and more than 70,000 are injured on U.S. roadways (LaPlante and McCann, 2008). According to the National Highway Traffic Safety Administration's (NHTSA) Traffic Safety Facts and Data, the 4,280 pedestrian fatalities in 2010 were an increase of four percent of total fatalities from the previous year. These deaths accounted for thirteen 
percent of all traffic fatalities in the United States. About three-fourths (73\%) of pedestrian fatalities occur in urban settings versus a rural setting. Nearly four-fifths (79\%) of pedestrian fatalities occur at non-intersections. The majority of these deaths (68\%) occur during the nighttime. The NHTSA has also released Traffic Safety Facts and Data for Bicyclists and Other Cyclists. In 2011, 677 pedalcyclists (all non-motorized vehicle powered solely by pedals) fatalities occurred and an additional 48,000 were injured in motor vehicle crashes. This is a nine percent increase from the previous year. Similar to NHTSA's reported pedestrian data, the majority of pedalcyclist fatalities (69\%) occurred in urban areas and at non-intersections (59\%). Additionally, the majority of pedalcyclist fatalities (30\%) occurred between 4 p.m. to 8 p.m. The pedalcyclist fatality rate per capita was almost six times higher for males than females and four times higher for pedalcyclist injuries in 2011.

Although there may be external factors, such as alcohol involvement, which influence the pedestrian and cyclist fatalities and injuries that have occurred, the design of city streets can reduce accidents through comprehensive safety improvements seen within Complete Streets. A FHWA review found sidewalks, raised medians, better busstop placement, traffic calming measures and treatments for users with disabilities can improve pedestrian safety (Campbell, Zegeer, Huang, and Cynecki, 2004). One study found designing for pedestrian travel by installing raised medians and redesigning intersections and sidewalks can reduce pedestrian risk by 28 percent (King, Carnegie, \& Ewing, 2003). 
Complete Streets have been proven to reduce vehicle traffic collisions and injuries through safety improvements and treatments. In a safety evaluation of lane width for arterial roadway segments, there was no indication, with exception for limited cases, that the use of narrower lanes increases crash frequencies (Potts, Harwood, \& Richard, 2007). The evaluation continues to determine lane width effects in analysis were either not statistically significant or rather lowered the number of crash frequencies. Road diets, which narrow the lane width of both urban and suburb arterials and often occur with the retrofit of Complete Streets, can be a benefit for pedestrians and cyclists by reducing crossing distances and providing extra space for additional bicycle lanes and buffer areas. The Federal Highway Administration published a 2010 Evaluation of Lane Reduction "Road Diet" Measures on Crashes report. This Highway Safety Information System produced report is an evaluation of "road diet" treatments in Washington and California cities that reexamines data using more advanced study techniques and adds an analysis of road diet sites in smaller urban communities in lowa. Results conclude the evaluation of total crash frequency indicated a statistically significant effect of the road diet treatment in both data sets with a substantial reduction of total crashes in both urban and suburban contexts.

Transportation for America's 2011 Dangerous by Design Report ranked Bakersfield as the worst place in California for pedestrian injury and death from automobiles. Based on Metro Data collected from the years 2000 through 2009, Bakersfield had 183 total pedestrian fatalities, making 11.5 percent of all traffic deaths. 
The Report calculated a 2.5 fatality rate per 100,000 persons based on 2009 population (Transportation for America, 2011).

Reduction of Greenhouse Gases. Complete Streets enable alternative modes of transportation. Public transit, walking, and biking may greatly reduce or eliminate the production of carbon emissions from travel. Alternative modes of transportation also improve the public health of the community through the reduction of harmful gas emissions from traffic congestion with high emission rates (McCann and Rynne, 2010). In 2011, 28 percent of the country's greenhouse gas emissions originated from the transportation sector, the second largest contributor of U.S. greenhouse gas emissions (EPA, 2013). Even with improvements to vehicles and the fuel economy, carbon emissions from transportation are estimated at 41 percent above today's levels by 2030 if driving in cars is not reduced (NCSC, 2010e). For America to reach its overall reduction targets and reduce impact of global warming, it will be necessary to change how cities frame their streets. The 2009 National Household Transportation Survey reveals the three fourths of all walk trips and half of bike trips are made for utilitarian purposes such as getting to work, school, shopping, visiting friends, and accessing public transport (Pucher, Dill, and Handy, 2010). Yet, of all trips three miles or less, 1.8 percent are biked, 21 percent are walked and 72 percent are driven (League of American Bicyclists \& American Bikes, 2010). Complete Streets work to link Land Use and alternative transportation modes together. The 2009 study Moving Cooler: An Analysis of Transportation Strategies for Reducing Greenhouse Gas Emissions evaluated the effectiveness of multiple transportation strategies to reduce transportation 
sector emissions. The report determined a comprehensive set of policy tools could reduce transportation levels from projected baseline levels by 24 percent by 2050 . For example, by using transit instead of driving to work, an individual commuter can reduce carbon dioxide emissions by 20 pounds per day (NCSC, 2010e). Portland, Oregon was the first city to adopt a plan to reduce GHG emissions to $10 \%$ below 1990 levels by 2010. Because of heavy investment in infrastructure improvements for transit, bicycling, and walking, the city has reduced its per capita carbon dioxide emission reductions to 12.5 percent. In Boulder, Colorado the increase of bicycling and transit trips from an extensive Complete Streets network between 1990 and 2003, resulted in a reduction of car trips and annual CO2 emissions by half a million pounds (NCSC, 2010e).

In 2013, Bakersfield was ranked worst in the nation for short-term (24-hour) particle pollution, annual particle pollution, and third worse for high ozone pollution days by the American Lung Association's State of the Air. This significant air pollution problem is largely due to geography, meteorology, and human-created emission sources. The Central Valley has three surrounding mountain ranges. The mountains act like a pool for pollutants, which are trapped by an inversion layer of warm air (Berg, 2011). The Central Valley's stagnant weather patterns for long, extended periods of time build and concentrate particle pollutants in the ozone levels (San Joaquin Valley Air Pollution Control District, 2012). Burning fossil fuels through mobile vehicle transportation sources is a primary contributor for particle pollution (American Lung Association, 2013b). Continued population growth brings more cars to the road, creating a 1 to 2 ratio of people to vehicle miles traveled according to the San Joaquin 
Valley Air Pollution Control District (Berg, 2011). Complete Streets may provide solutions to the reduction of greenhouse gasses and vehicle miles traveled.

Creating Active Public Space. Complete Streets can also contribute to the concepts of creating public space, livability, and quality of life in planning. According to the Los Angeles County Model Design Manual for Living Streets, the revitalization of neighborhoods, which emphasizes creating space through sidewalks, street trees, and other place-making techniques for the pedestrian are created as a result of Complete Street policies and design standards (LA County Dept. Public Health \& UCLA, 2011). This also can instill community growth and economic revitalization in areas within a Complete Street network. Making it easier to use transit, walk, or bike can create a "green dividend" that creates a savings from alternative modes of transportation and allowing residents to spend their money in other ways. This also keeps money within the local economy. San Francisco's Valencia Street in the Mission District narrowed its travel lanes to slow traffic and accommodate other users of the street. Merchants in the area have reported an increase in sales with 60 percent of more residents shopping locally (NCSC, 2010f). Complete Streets can also stimulate private investment for retail and downtown districts. The City of Lancaster, California revitalized a section of their downtown to include a Complete Street with pedestrian safety features, a pedestrian only plaza, wider sidewalks, landscaping and traffic calming. The project was renamed The BLVD and lead to $\$ 130$ million in private investment, a $26 \%$ increase in sales tax revenue and 1,900 new jobs. The public investment was $\$ 10.6$ million (EPA, 2012b). 


\section{CHAPTER 2: CASE STUDIES}

In order to better understand the context and practical application of creating Complete Streets for Bakersfield, case studies of Complete Streets in other cities were evaluated. A Complete Street in an urban environment may have a different planning approach to successful implementation than a Complete Street in a suburban or rural environment. These case studies were selected based on location and demographic similarities to Bakersfield in the Central Valley. The case study cities and their Complete Street projects were researched using document review and interview. The core of the research focused on public planning document review, web resources and available published presentations related to a case study's Complete Street design and planning, in addition to related scholarly sources. The research was conducted prior to a short personal interview to help inform and narrow the focus of the interview questions. Individuals who were more familiar with a specific Complete Street project or policy of a case study city were contacted via email or telephone. The significance of these evaluative case studies for the City of Bakersfield is to achieve an understanding of the planning approaches, constraints, and lessons learned by each city. The following discussion of each case study represents the analysis of practices done by a similar agency and what key principles can be determined to make a Complete Street in Bakersfield most successful. 


\section{Sacramento, California}

Planning a Complete Street Network. The City of Sacramento has a long history of external advocacy for transportation reform. The diverse coalition groups in the Sacramento area are composed of bicycle, pedestrian, and disabled advocacy groups created to advocate better air quality and active transportation in the City (Hill and Disher, 2009). The commitment to addressing multiple users and population groups in an effort to make streets more "complete" began with the landmark 2002 court case which upheld the precedent that all sidewalks installed and maintained by the city must be ADA compliant. It was through the settlement of this case the City of Sacramento began to spend $20 \%$ of its annual transportation funds on pedestrian facilities and amenities including sidewalks, ramps, and crosswalk improvements (McCann and Rynne, 2010).

The Partnership for Active Communities, which grew from the Sacramento Safe Routes Partnership and WALKSacramento, brought together multidisciplinary organizations to create projects and partnerships to support and increase walking and cycling in Sacramento (Geraghty et al., 2009). The partnership conducted reviews and submitted comments on development projects that would influence the City's land use and made strong efforts to advocate for Complete Street policies with improved transportation infrastructure for all users.

In a response to citizens' complaints about high residential traffic speeds, the City of Sacramento's Traffic Engineering Department drafted Pedestrian Friendly Street Standards. These standards required sidewalks to be separated by landscaped strips 
for all street types and dedicated bike lanes for collector and arterial roads. The standards for street improvements were updated and amended into the General Plan (McCann and Rynne, 2010).

The City's 2030 General Plan Mobility Update included six specific implementation policies for Complete Streets, including:

M 4.2.5 Multi-Modal Corridors. The City shall designate multimodal corridors in the Central City, within and between urban centers, along major transit lines, and/or along commercial corridors to receive increased investment for transit, bikeway, and pedestrian way improvements

M 4.2.6 Identify Gaps in Complete Streets. The City shall identify streets that can be "more complete" either through a reduction in the number or width of travel lanes or conversions, with consideration for emergency vehicle operation. The City shall consider new bikeways, enhanced sidewalks, on-street parking, and exclusive transit lanes on these streets.

These policies are connected with other transportation goals to support a comprehensive transportation network.

Regional planning also influenced Sacramento's movement towards Complete Streets. The Sacramento Area Council of Government's Blueprint Transportation and Land Use Study indicated low density and auto dependent development patterns and transportation systems would not accommodate predicted growth (McCann and Rynne, 2010). In 2005, with an external stakeholder collaborative group, Sacramento Area 
Council of Governments created the Best Practices for Complete Streets advisory report (Hill and Disher, 2009). The Sacramento Area Council of Governments also began a Complete Streets screening tool when selecting projects submitted by local governments for funding, including those of the City of Sacramento (NCSC Local Gov't Commission, 2012).

Sacramento works with private developers to create Complete Street projects during the development review process using the bicycle and pedestrian master plans. The City also brings Complete Street ideas into the CEQA review by having projects provide pedestrian, bicyclists, or transit improvements to meet CEQA requirements (McCann and Rynne, 2010).

The City's General Plan dropped the citywide Level of Service (LOS) standard from $A-C$ to $D$, and accepted a minimum LOS of $E-F(M .1 .2 .2 b)$. A flexible LOS standard will support planned development and also require enhanced infrastructure to support transit, walking, and multi-modal districts beyond performance measures for vehicle traffic flow and auto congestion related to traditional LOS standards.

Structure of Project. The City of Sacramento began to implement experimental pilot projects, like $19^{\text {th }}$ Street, as they introduced Complete Streets into the Community. The large population growth, which led to low-density, automobile-oriented residential and commercial development with wide, long boulevards in suburban areas of the City, created the problem of managing traffic in the Sacramento Region. Even the older areas of the City, although well connected, tree-lined and attractive for pedestrians and bicyclists, were not accommodating for these users against high traffic speeds (NCSC 
Local Gov't Commission, 2012). Implementation of Complete Street pilot projects was focused to create safety for multiple transportation choices. The City of Sacramento began to retrofit streets to improve bicycle and pedestrian facilities.

The City of Sacramento's $19^{\text {th }}$ Street is one case where the City converted a downtown street into a Complete Street with safer opportunities for healthier transportation options. The reconfiguration for the pilot project, which occurred in September 2007, included a road diet, from three automobile lanes to two (known as a three-two conversion). The additional space provided for Class II bike lanes on both sides of the one-way street.

Land Use and Transportation Context. Nineteenth Street, located directly in Downtown Sacramento, was identified as an ideal pilot project location for multiple reasons. The connection to mixed residential and commercial land uses ensured tripgenerating destinations are close to points of origin and are feasible for pedestrian, bicycle, or transit transportation. Nineteenth Street is a part of a larger grid patterned network of the Downtown, serving as an alternative travel route from other major streets, while still providing direct connection to multiple land uses. The Regional Transit Bus System utilizes $19^{\text {th }}$ Street as a route in its public transportation network emphasizing the need for appropriate street improvements and design features for alternative transportation users. According to Complete Streets Coordinator Terry Preston, appropriately determined traffic, bicycle, and pedestrian traffic volume levels demonstrated the street carried enough traffic to support funding of the project, but not 
so much traffic to exceed the roadway's capacity with the reconfiguration (personal communication, 2013).

Funding. The $19^{\text {th }}$ Street Complete Street project was funded as a Public Works street improvements repaving and restriping project. It was expected to improve street conditions and manage multimodal traffic flow at minimal cost, which would also work over a long period of time.

Implementation. The $19^{\text {th }}$ Street Complete Street project was initially proposed by the City of Sacramento. WALKSacramento, provided design review, political support and publicly encouraged implementation of this project.

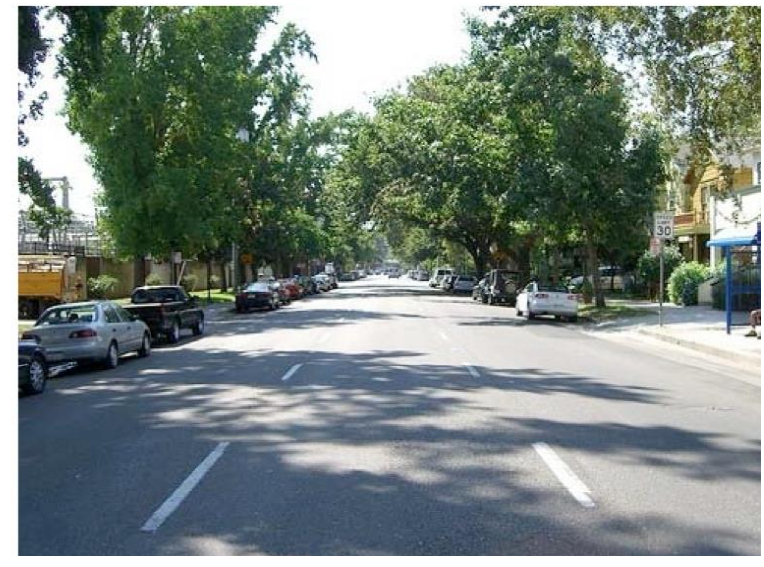

Figure 18. 19th Street before the conversion

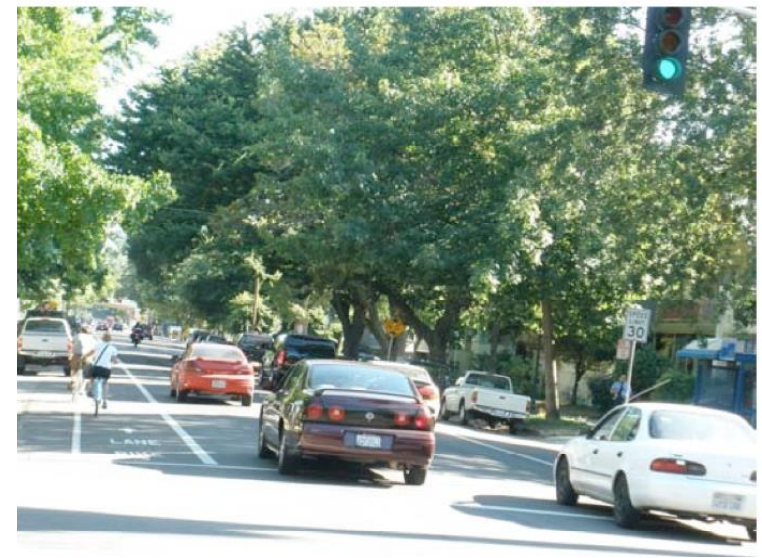

Figure 19. $19^{\text {th }}$ Street after the conversion

The dual bike lanes of the $19^{\text {th }}$ Street Complete Street Project make a more comfortable environment and the left-sided bike lanes make it easier to enter or exit the one-way street. A wide bike lane on the right side creates a deceleration right turn lane for cyclists. The narrowing of the travel lanes also makes it safer for pedestrians to 
cross the right-of-way and reduces a driver's field of vision as a traffic calming measure to reduce traffic speeds (NCSC Local Gov't Commission, 2012).

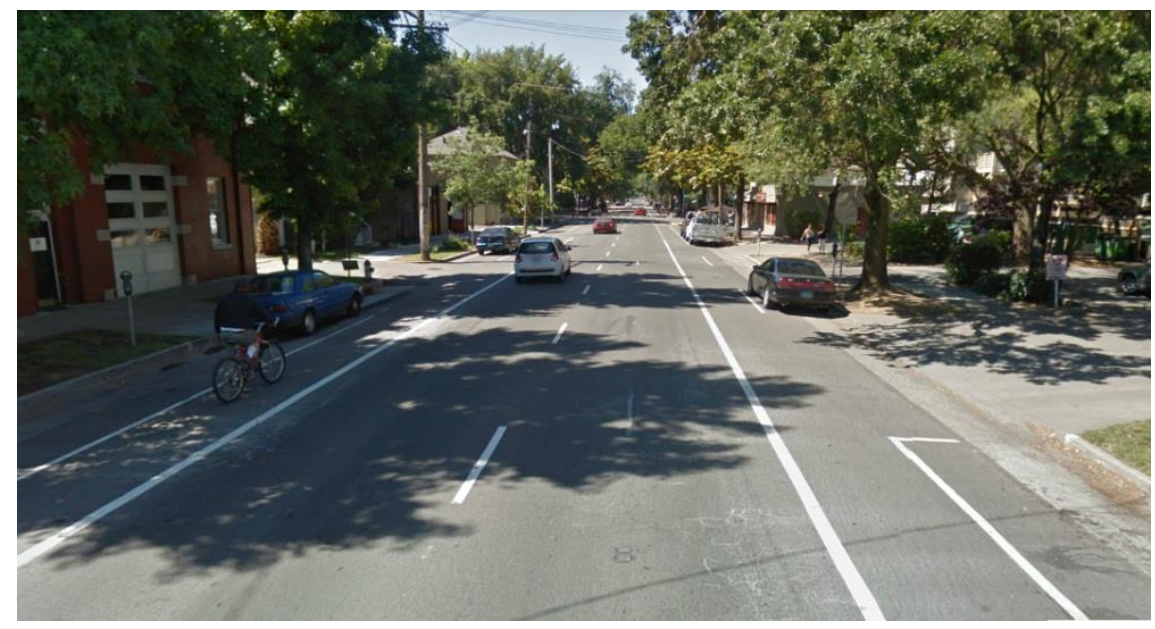

Figure 20. 19th Street dual bike lanes

The $19^{\text {th }}$ Street Complete Street Project also includes solid traffic island diverters around the mid-block crossings and intersections. Being placed in the extra space of the street, the island diverters prevent vehicles from intersecting a crosswalk corner or bicycle lane. Continental striping creates patterned crosswalks used to increase visibility for those crossing the street. They are placed in mid-blocks and intersection crossings.

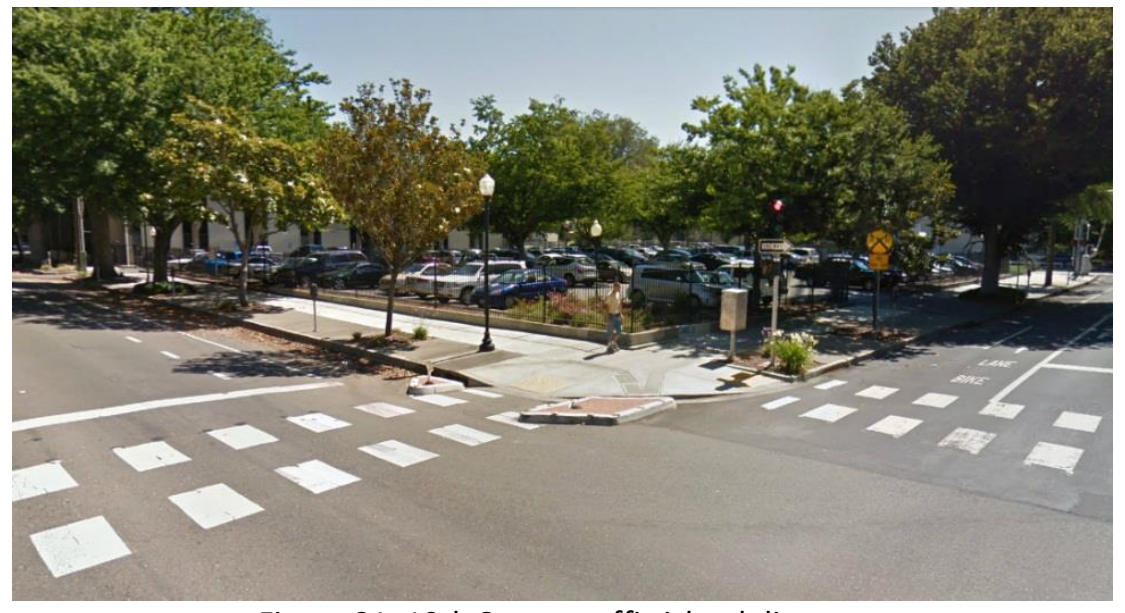

Figure 21. 19th Street traffic island diverter 
Transit stops along the $19^{\text {th }}$ Street Complete Street Project have been marked and signed to prevent vehicles from parking in front of the transit stop. Some transit stops have a sidewalk ramp adjacent to provide access for those with physical disabilities.

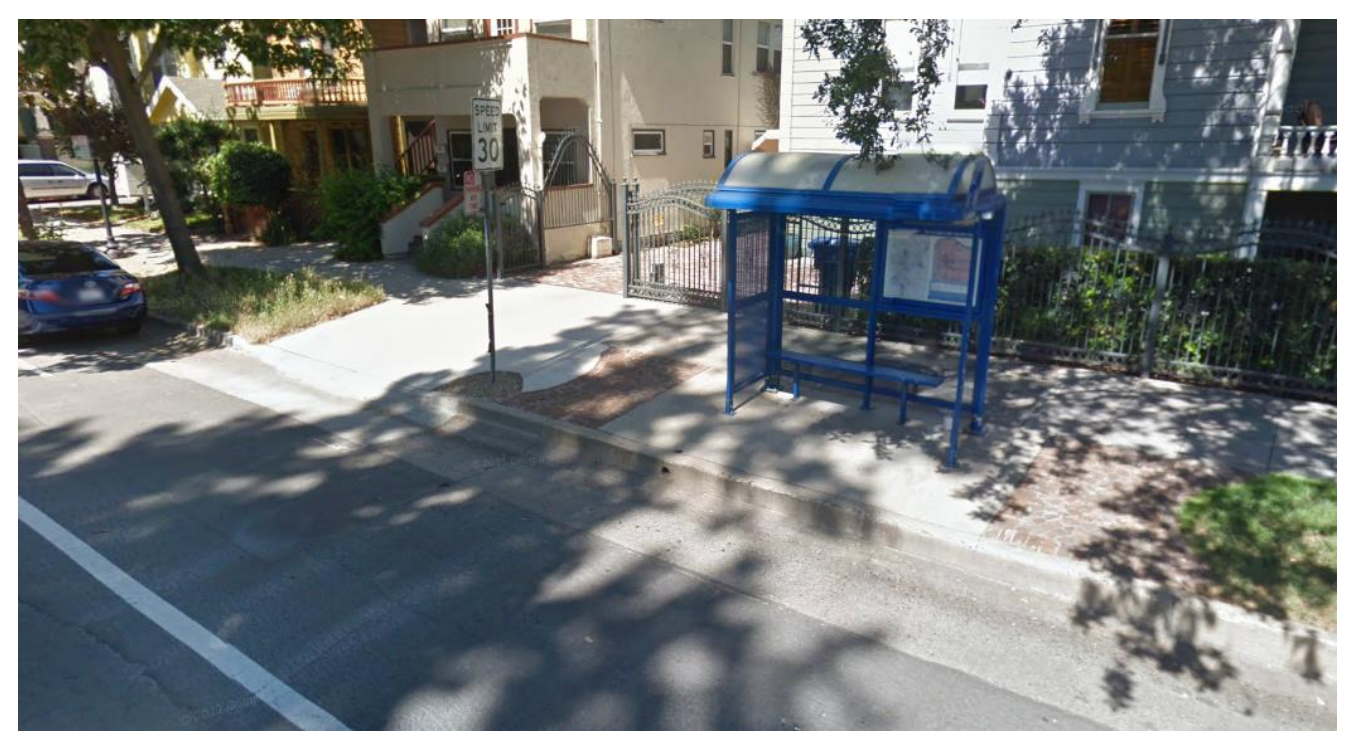

Figure 22. 19th Street Transit Stop

Constraints to Implementation. The dual bike lanes are on the inside of the parking lane and still close to parked vehicles. Only painted stripes separate bicyclists from parked doors on one side and moving cars on the other side, which may present a sense of feeling unsafe or uncomfortable for less experienced cyclists. In a bicycle count study performed by the Sacramento Area Bicycle Advocates, even after the implementation of the $19^{\text {th }}$ Complete Street, approximately 25 percent of cyclists still rode on the sidewalk (SABA, 2008).

There was mixed response to support of the $19^{\text {th }}$ Street Complete Street project by the community. Preston, Complete Streets Coordinator for WALKSacramento, 
recalls homeowners were resistant to the lane conversion, feeling a loss of lane was punishment on drivers (personal communication, 2013). Education about Complete Streets and further information about the project, provided by WALKSacramento and the City, was necessary with implementing the street improvements.

Results. According to the Sacramento Area Bicycle Advocates, bicycle counts completed before and after the $19^{\text {th }}$ Street Complete Street conversion showed an increase in bicycle riding. From September 2007, before the project's completion to September 2008, there was a 260 percent increase in ridership during a weekday twohour period. Annual counts displayed similar increasing trend. Overall safety on $19^{\text {th }}$ Street increased with the reduced number of collisions reported, including automobile versus automobile collisions (NCSC Local Gov't Commission, 2012).

Application. The City of Sacramento has the unique circumstance of being the location of the California State Capital, Caltrans Headquarters, and the Sacramento County Regional Governments. Many stakeholder organization groups are represented through the Sacramento region and work closely with City government projects creating an active civic area. According to the American Journal of Preventative Medicine article "Partnership Moves Community toward Complete Streets," there are key lessons learned about the multidisciplinary Partnership for Active Communities, which contributed to an interconnected system of Complete Streets in the City. The Partnership's preparation and dialogue of different courses of action for new transportation infrastructure brought together changes beyond independent action from a single organization or agency alone. Early land-use development review from the 
Partnership maximized opportunities to make positive changes from land use development before considerable design investment (Geraghty et. al, 2009). It created a focused objective of Complete Streets, a message that local government staff and elected officials would reciprocate with important policy changes.

Preston, the Complete Streets Coordinator for WALKSacramento, recognizes there are significant actions an agency can take for successful implementation of Complete Street projects.

- A city should seek input and create inclusive environment as early as possible on the start of a project.

- Empowering local groups and advocacy organizations to make recommendations and support the project will provide much needed community support as the project reaches approval. It is important to relay Complete Streets are meant to improve the street, not to punish drivers.

- Providing evidence about road diets and Complete Streets such as a reduction of traffic speed, better drivers, and better road conditions are important facts to share with community members or political leaders who may be against a project.

- Implementing demonstration Complete Street projects will create early "buy in" from the community. As recognized and successful pilot projects, Complete Streets can become recognizable and connect with people as a city begins to develop a greater Complete Street network (Preston, 2013). 
Ed Cox, the City of Sacramento's Bicycle and Pedestrian Coordinator, shared important design lessons for implementation of Complete Streets (Completing Streets: Lessons Learned, n.d.).

- The best opportunity to add bike lanes is when the street is being re-surfaced. When adding bike lanes, the lessons learned are to adjust lanes before adding bike lanes (to prevent overcrowding), place valued parking on one side, and use available traffic calming or safety methods such as striped buffers to treat excess pavement.

- A bikeway plan, which the City of Bakersfield is currently producing, helps identify streets that should be considered for bike lanes.

- The result of three to two road diet conversions, such as $19^{\text {th }}$ street, is slower speed, lower collisions, and little congestion impacts. It is important to study the congestion of possible Complete Street project locations to analyze and verify there will be no significant issues with removing a traffic lane.

For future projects, Ed Cox recommended more road diet "lane drops" in Complete Street projects to create bike and pedestrian facilities. To create a bicycle and pedestrian friendly community, there needs to be a push for wider sidewalks while minimizing the number of travel lanes for shorter crossings. New development will follow the design standards and decrease auto dependence.

\section{Fresno, California}

Planning a Complete Streets Network. The City of Fresno has made significant changes and improvements to become a more bicycle friendly community and build a 
greater Complete Street network. The most significant transition occurred with the adoption of Measure C, a half-cent sales tax extension approved by Fresno County voters. The tax allocated approximately $\$ 25$ million dollars for bicycle infrastructure to the City of Fresno. It required the City to adopt a Bicycle Master Plan by 2012 to receive the funding (City of Fresno, 2010).

The City of Fresno completed an updated and revised Bicycle, Pedestrian, and Trails Master Plan, as required under Measure C in 2010. The goal of the Bicycle, Pedestrian, and Trails Master Plan is to create changes and improvements within Fresno and become a bicycling friendly community through planning policies, programs, and development standards. The Bicycle, Pedestrian, and Trails Master Plan was developed in agreement with the Public Facilities Element of the 2025 Fresno General Plan, with included goals and policies to accommodate all modes of transportation which speak to Complete Street defined objectives including:

\section{E-13-a. Goal: Bicycle System Expansion}

To develop a complete bicycling system that is suitable for different types of bicyclists and that offers access to major destination areas.

\section{E-13-c. Goal: Multimodal Integration}

Promote the integration of bicycling with other forms of transportation, including public transit.

Adoption of the plan, allowed Fresno to qualify for grand funds issued by the California Department of Transportation through the Bicycle Transportation Account. 
Road diets, often apart of a Complete Street implementation design, is a street design tool used to implement new bike lanes on City streets (City of Fresno, 2010). The road diet projects are also consistent with the 2025 City of Fresno General Plan, the City of Fresno Bicycle, Pedestrian, and Trails Master Plan, and the California Assembly Bill 1358 ‘Complete Streets Act.” (City of Fresno, Traffic Engineering, n.d. $[b])$.

The City of Fresno has developed a Bus Rapid Transit Master Plan (2008) and Fresno Area Express Short-Range Transit Plan (2007) to provide integrated multimodal transportation throughout the City. These plans identify the need for Complete Street infrastructure that could accommodate multiple modes of transportation.

Transitioning from preliminary road diets, the city has begun to create specific "Complete Street" projects. Currently in development, the High-Speed Train Station Area and Complete Street Connectivity Project, which creates a "Complete Streets" network, is a part of a larger specific plan to revitalize the Downtown. This project replaces the Fulton Mall's pedestrian only landscape and introduces bicycles, transit, and automobiles into the right-of-way. The multiple residential and commercial land uses in the area, with the addition of a new Bus Rapid Transit hub and High Speed Rail Station, will aim to connect and contribute to the vibrancy of the new Complete Streets (City of Fresno, 2012c).

To create a more efficient street network, The City of Fresno has implemented an Intelligent Transportation Systems (ITS) Plan, with a purpose of synchronizing traffic signals in corridors to allow for more efficient movement of motorists. The Intelligent 
Transportation System Network, which is created by using advanced technology with the help of sensors implemented in roadways and connected to traffic signals with fiber optic cables or wireless transmitters, is based on the volume and congestion of highest traveled corridors. The City has established a Traffic Operations Center, which uses ITS and other advanced technologies, to monitor traffic, detect problems, and take necessary actions to return flow to normal. Synchronized traffic flow improves air quality, fuel consumption, and reduces travel time for automobiles, including public transit (City of Fresno, Traffic Engineering, n.d. [a]).

The City of Fresno is also in the preliminary stage of developing a Draft General Plan Update for its Mobility and Transportation Element. The purpose of the element will be to provide efficient multi-modal transportation system to meet the needs of all residents of the Fresno Community. Complete Street policies and street section designs will be presented in the draft element. In addition, the updated element will provide performance standards for multi-modal systems, context sensitive level of service (LOS) and multi-modal LOS that help implement the feasibility of Complete Street projects (City of Fresno, 2012b).

Structure of Project. Gettysburg Avenue, located in northeast Fresno, is one of the City's recently constructed projects in the City's pilot road diet program to build a more Complete Street roadway network. Gettysburg Avenue was first identified in the 2010 City of Fresno, Bicycle, Pedestrian and Trails Master Plan as a critical east-west link in the bicycle lane network (City of Fresno, 2012a). The original infrastructure as a four lane, two-way travel collector street was built to a level of service for maximum 
traffic volume of automobiles, leaving the street overbuilt for 22-23 hours of the day (City of Fresno, Traffic Engineering, n.d. [b]). The configuration to a two-way travel lane with center left turn lane and Class II bike lanes could be implemented to serve the same traffic volume while improving the safety and convenience for cyclists. Gettysburg Avenue road diet's additional benefits include reducing costs to maintain the asphalt of the right-of-way, reduces the urban heat index, and improves air quality.

Land Use and Transportation Context. Gettysburg Avenue, moves traffic from adjacent Shaw Avenue and Ashlan Avenue, the heavier traveled arterial roadways. Because Gettysburg Avenue has a lower set speed and volume, it is ideal for cyclists. The identified portion of Gettysburg Avenue included in the project has mixed residential and commercial land uses. Schools and parks are also within the vicinity of Gettysburg Avenue (Watkins, 2012). This ensures trip-generating destinations are close to points of origin and are feasible for pedestrian and bicycle travel.

Funding. The Gettysburg Avenue road diet and bike lane project was completely funded with Congestion Mitigation and Air Quality funding from the Fresno Council of Governments with the intention of reducing air pollution. The Fresno Council of Governments also allocated funding from the voter-approved Measure $C$ program. The construction contract was awarded to Intermountain Slurry Seal, Inc. for the $\$ 328,000$ project (City of Fresno, 2012a).

Implementation. The beginning of a road diet project in the City of Fresno occurs with the monitoring of the half-mile roadway segments; identified in the City's created half-mile grid system of expressways, super arterials and arterials, and collectors 
throughout the City are evaluated on their $85^{\text {th }}$ percentile speed, traffic volume, and accident information. Based on this information, Fresno Public Works, Traffic Engineering Services Division can make a determination to modify a lane configuration. The project can be proposed with restriping and paving project. In addition to the traffic engineering analysis and roadway evaluation, the road diet project must be consistent with the 2025 City of Fresno General Plan Policies, goals, and objects, the City of Fresno Bicycle, Pedestrian, and Trails Master Plan, and AB 1358, the California Complete Streets Act (City of Fresno, Traffic Engineering, n.d. [b]).

The Gettysburg Avenue road diet and bike lane project began with Council adoption in the Department of Public Works Fiscal Year 2010 Budget. The City prepared the original plans for this project in accordance to the 2009 'Call for Projects' CMAQ grant application to secure funding by the Fresno Council of Governments (City of Fresno, 2012a).

After council district neighborhood meetings about the proposed project, the Public Works Department modified the planned roadway striping to maintain four lanes of traffic in a location where traffic volumes are the highest in the corridor (between First Street and Cedar Avenue). Gettysburg Avenue would be restriped and configured surrounding this location to reduce travel lanes as a two-way travel lane with center left turn lane and Class II bike lanes on a 2.7 mile portion of the roadway (City of Fresno, 2012a). 
Creating a two-way travel lane with a pocket left turn lane street section allows motorists to pull out of the travel lane into the pocket lane to make a left turn, rather than stopping or reducing the traffic flow.

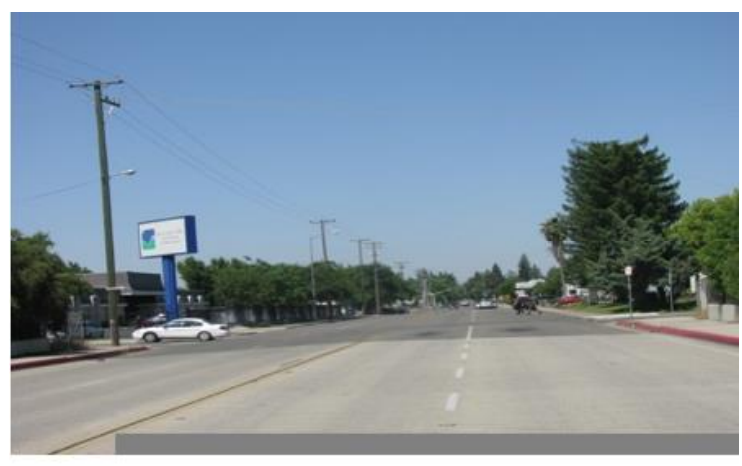

Figure 23. Gettysburg Before Road Diet

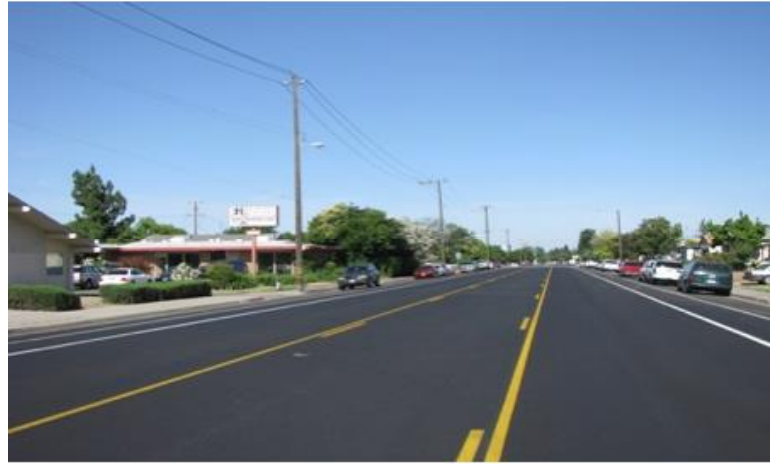

Figure 24. Gettysburg After Road Diet

The bike lanes on Gettysburg Avenue create a safer, more comfortable environment for cyclists. Because traffic flows in both east-west directions, two lanes are provided on either side of the right-of-way. Narrowing the street width provides additional vehicle speed management that increases visibility and safety for cyclists.

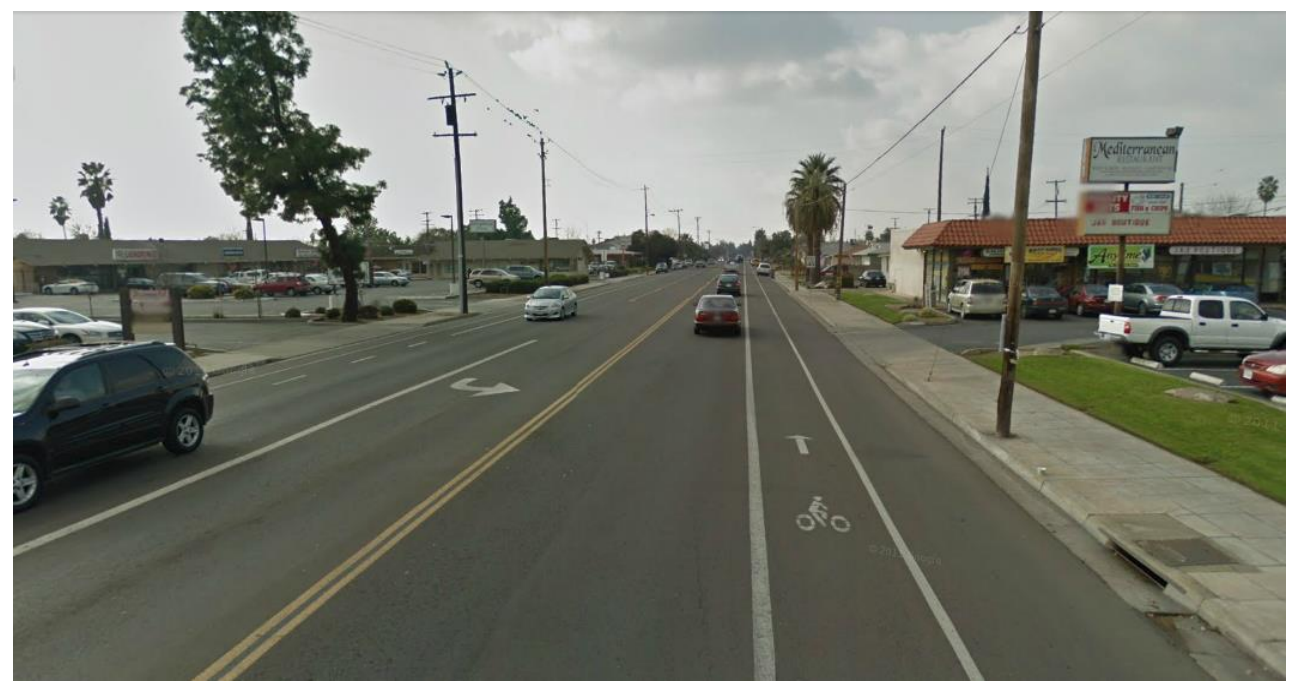

Figure 25. Bike lanes on Gettysburg via Google Earth 
To create a more pedestrian friendly environment, sidewalks are wide enough for all users, accommodating to special populations including those with physical disabilities. Much of the right-of-way includes shade from lined street trees.

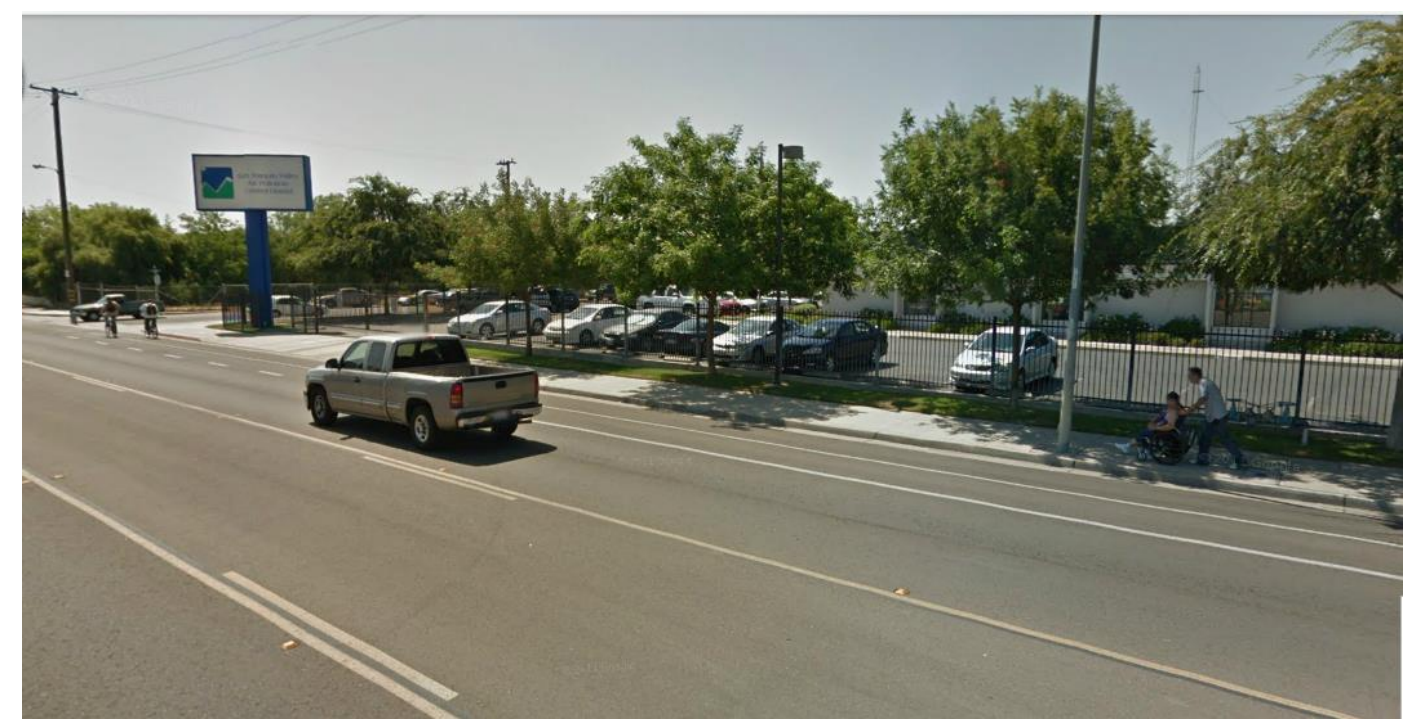

Figure 26. Bike lane and Sidewalk on Gettysburg via Google Earth

A reduced lane width creates a shorter distance for pedestrians crossing an intersection. To ensure visibility and safety in large, wide-lane intersections that bisect the project, median refuge islands are provided as protection for pedestrians wishing to cross. Pedestrian crossing signals are provided on the refuge island to make certain of a complete two-phase crossing. The median has landscaped areas to create an inviting, more visual streetscape. Trees in the median, as vertical elements, visually narrow the roadway and act as a traffic calming measure for automobiles (McCann and Rynne, 2010). 


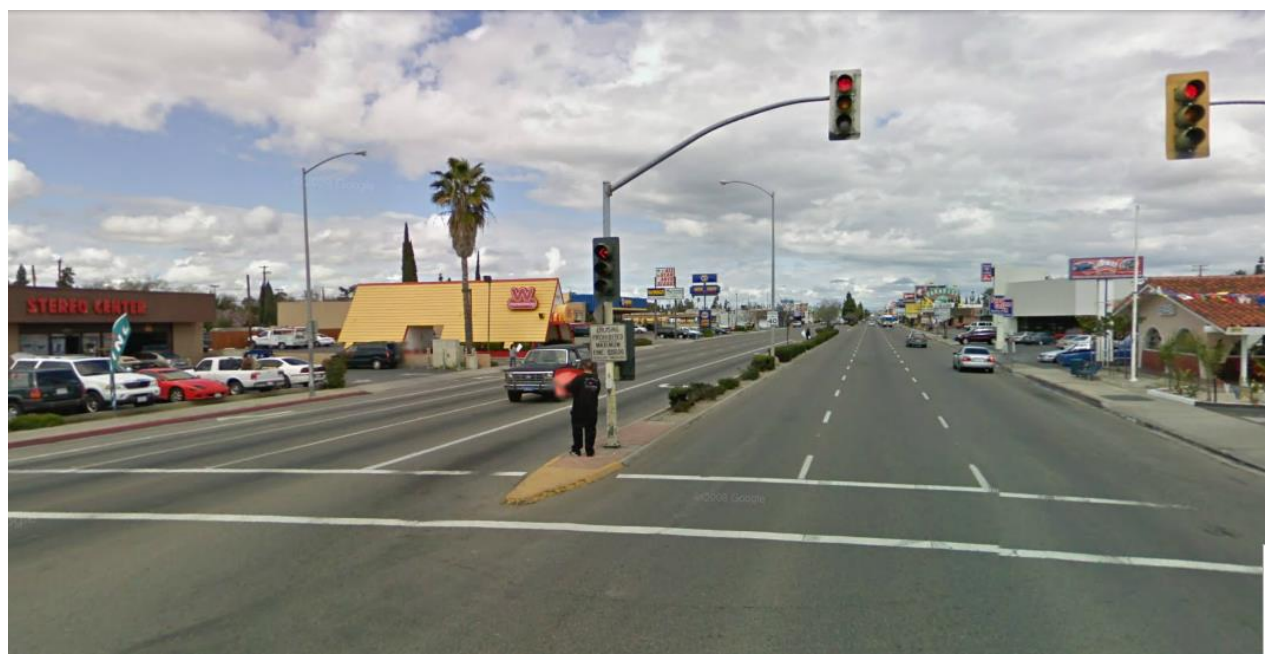

Figure 27. Gettysburg Intersection via Google Earth

Constraints to Implementation. The Gettysburg Avenue road diet and bike lanes project was delayed six months prior to seeking formal City Council approval after a controversial neighborhood district meeting in November 2011 was held to share information and obtain community feedback about the project. Homeowners in the area had voiced their concerns over what the reduction of lanes would do to the area. Some community members believed reducing the lanes would cause traffic congestion and make it more difficult for automobiles to exit driveways. Others were concerned over the expenses of the project (KFSN-TV, 2012). Cyclists who also attended the meeting showed support for the project for its health and safety. Gettysburg was viewed as a safer street to travel on rather than the heavier traffic levels of adjacent Shaw and Ashlan Avenue. The bike lanes would provide dedicated space for visibility and safety rather than taking the lane on the majority of the existing Gettysburg Avenue (Watkins, 2012). In response to the meeting, the revision of the Gettysburg Avenue road diet and bike lane project resulted in removing bike lanes from the heaviest traffic volume area between First Street and Cedar Avenue. 
Results. Within a year of the Bicycle, Pedestrian and Trails Master Plan's adoption in 2010, the City of Fresno installed more than 30 miles of Class II bike lanes, three miles of Class I bike paths, and grade separated path crossings increasing to the over 164 miles of existing bikeway network. In the spring of 2011, Fresno was awarded a Bronze Level Bicycle Friendly Community status by The League of American Bicyclists (Bicycle Friendly America, 2011). It was the first City in the Central Valley from the Tehachapi Mountain Range to Sacramento and from the Sierra Mountain Rage to the Central Coast Mountain Range to receive the honor (City of Fresno, Traffic Engineering, n.d. [b]).

Application. Dick Poeschel, AICP and principle planner of the Fresno land planning firm, Dirk Poeschel Land Development Services, wrote of the general strategies for gaining acceptance of narrower streets by the City of Fresno. The same lessons can be applied to seeking reception from the community through (Poeschel, 2009):

- Providing pictures and diagrams that illustrate how other cities have addressed similar projects (with greater standards and accommodations) forms the rational of accepting the narrowing of lanes on demonstrated peer city acceptance.

- Narrowing of traffic lanes is a more cost-effective alternative to traffic calming that pavement undulations, or "speed bumps", that were once the prominent device for slowing traffic in neighborhood streets. 
- Creating narrow, but better traffic managed, travel lanes improves emergency response by removing additional traffic calming devices that may slow response time and also provides the ability for emergency vehicles to control the entire traffic lane if necessary

Poeschel identified how the benefits of narrow lanes meet new community-building objectives in Fresno, which provide additional incentive for acceptance by the community:

- Revising street standards to reduce the number of travel lanes helps facilitate the mobility of pedestrians with shorter crossing distance and traffic speeds.

- On street parking for homeowners and businesses can still be provided on narrow streets without the interruption of City services or inhibiting access of others.

- The trend of vehicle standards (based on the safety and economy) is becoming smaller and more efficient. Wide turning radius required of infrastructure for commercial and city vehicles alike is becoming more obsolete (Poeschel, 2009).

\section{Lancaster, California}

Planning a Complete Street Network. The City of Lancaster has made significant actions and improvements within the City through local plans and policies to build a successful Complete Street network. As an auto-centric city, Lancaster first began introducing multimodal transportation surrounding appropriate development in local specific plans. 
In 2003, the City adopted the Downtown Transit Village Plan, which built around the construction of the Metro link Commenter Rail Station that was in walking distance of the downtown (Konar, 2012). The North Downtown Transit Village Project connected the provision of affordable housing, education, commercial, religious and public uses to the feasibility of using alternative transportation, primarily walking. The goal of the plan was to provide potential mixed-use transit development opportunities to strengthen the environment, economic, and social dimensions of the community (City of Lancaster, 2009a).

The Downtown Lancaster Specific Plan, adopted in 2008, was created to further improve revitalization of the area. The plan follows a form-based regulating code for the Lancaster Boulevard corridor (Konar, 2012). Its emphasis is to improve the Downtown as a place of historic, cultural, social, economic and civic vitality by creating a mix of commercial, residential and transit uses. The goal is to create a pedestrian-friendly environment that would implement these community-oriented uses. The circulation section of the Downtown Lancaster Specific Plan is designed to incorporate traffic calming measures, reduce speeds, enhance pedestrian safety, and promote walkability of the area; transforming Lancaster Boulevard into a "Main Street" (City of Lancaster, 2008a). Traffic Impact analysis, parking analysis, and alternative scenarios of reconfiguring street improvements with Complete Street designs are discussed within the plan (NCSC Local Gov't Commission, 2012).

The City of Lancaster's Traffic Engineering Division also developed a Citywide Traffic Calming Policy in 2008. The objective of this policy is to improve the livability of 
neighborhood streets while maintaining safe and efficient arterial street system that complements the local neighborhood street system (City of Lancaster, 2008b).

Complete Street strategies including reducing vehicle speeds, traffic volumes, cutthrough traffic, and incorporating traffic calming infrastructure elements in the design of different street classifications are included in this policy.

Within the same year, The City Council of Lancaster also adopted a City of Lancaster Bicycle Transportation Plan. This initial plan, which estimated bicycle users and accounted for existing and proposed bikeways made the City eligible to receive BTA (Caltrans Bicycle Transportation Account) funding. Its purpose is to improve safety and convenience for bicycle commuters through the implementation of Complete Street infrastructure (Resolution No. 08-97).

The 2030 General Plan Update for the City of Lancaster, adopted in 2009, established multimodal priorities through goals, policies, and actions in the City's physical mobility element. The minimum Level of Service to define roadway segments during peak hour traffic is LOS D. The plan emphasizes the available alternative modes of transportation available to residents including vanpooling, local and regional bus services, the Metro link, cycling and walking. Policies to encourage more alternative modes through the design of new development and roadway improvements are further specified:

Policy 14.4.1: Under the guidance of the Transportation Master Plan, support and encourage the various public transit companies, ridesharing programs and other incentive programs that allow residents to utilize modes of transportation other 
than the private automobile, and accommodate those households within the Urbanizing Area of the City that rely on public transit.

Policy 14.4.3: Encourage bicycling as an alternative to automobile travel for the purpose of reducing vehicle miles traveled (VMT), fuel consumption, traffic congestion, and air pollution by providing appropriate facilities for the bicycle riders

Policy 14.4.5: Design transportation facilities to encourage walking, provide connectivity, ADA accessibility, and safety by reducing potential auto/pedestrian conflicts. (City of Lancaster, 2009b).

The City of Lancaster Master Plan of Trails and Bikeways is a comprehensive plan to design and develop pedestrian, bicycle and trail facilities that will encourage the community to use healthy transportation modes throughout Lancaster. The Master Plan of Trails and Bikeways is a direct response to citizen input in the General Planning process and was identified as an important implementation tool for the Physical Mobility Element of the 2030 General Plan (City of Lancaster, 2012). The Master Plan of Trails and Bikeways incorporates a number of different recommended plans and projects including a bicycle plan, trails plan, pedestrian plan, and ADA transition plan. Implementation recommended in The Master Plan of Trails and Bikeways Plan includes bicycle, pedestrian, trails, landscape, maintenance and operation, and plans and development guidelines to ensure best practice. As a resource for the City, each of the Plan's elements design principles work in coordination to compose a Complete Street. 
The City's 2011-2012 fiscal year committed 24\% of its Capital Improvement program to implementing this plan (Baerg, 2013).

Lancaster has received six Caltrans State Safe Routes to School grants for Complete Street infrastructure improvements. The completed projects have designed and installed improvements for the safety and visibility or pedestrians including flashing beacons and crosswalks. Other expected projects will include bulb outs, curb cuts, pedestrian paths, and bike lanes that may require restriping of the right-of-way (Baerg, 2013).

Structure of Project. A public-private partnership for a major pilot project laid the foundation for revitalization of Lancaster Boulevard, known as The BLVD Transformation Project (LRA, 2012). The City worked in partnership with The BLVD Association (comprised of downtown merchants), InSite Development, and with the help of Architecture and Urban Design Firm Moule and Polyzoides, to develop The BLVD Transformation project as the first major pilot project to implement The Lancaster Downtown Specific Plan (EPA, 2012a).

Before efforts were made for any downtown revitalization, Lancaster's downtown, like many other cities, was economically declining. Lancaster Boulevard was home to growing crime and unemployment rates. Deemed unwalkable, high speed automobiles controlled the street and intersections were controlled by traffic signals (Gordon-Koven, 2012). Residents believed the street was dangerous to cross with an unpleasant experience when walking or shopping (NCSC Local Gov't Commission, 2012). 
The Lancaster Boulevard was originally a four-lane divided roadway, with a continuous left-turn lane, trending in an east-west direction. The proposed Complete Street design included in the Circulation Plan discussed narrowing Lancaster Boulevard to two lanes of 9 city blocks between $10^{\text {th }}$ Street West and Sierra Hwy. It was designed to include a center plaza for walking and community events with angled parking, enhanced crosswalks, abundant landscaping, lighting, and seating (Gordon-Koven, 2012). These same improvements were extended along Elm/Ehrlich and Fig Avenues, with two key side streets along Lancaster Boulevard (LRA, 2012). The Downtown Specific Plan also includes form-based development codes with street standard guidelines that enable the street to slow traffic, reduce traffic noise, improve pedestrian safety and contribute to a safe walkable street (City of Lancaster, 2008).

\section{Land Use and Transportation Context. The Lancaster Downtown Specific Plan} provided the necessary blueprint to build Lancaster Boulevard as a Complete Street project. The plan recommends Lancaster Boulevard, the heart of historic Lancaster, as a revitalization alternative by creating a "Main Street" environment as a feature for the entire downtown area. As the hub of the district, the Boulevard is a major center of community activity. The commercial use area includes wide variety of businesses include shopping, dining, and entertainment that attract the residents and visitors. The Boulevard also connects to major transit hubs including the Los Angeles County Metro link Station and local transit bus routes providing direct public transportation access. Additionally, Lancaster Boulevard is within a reasonable walking distance to new 
housing projects identified in the Lancaster Downtown Specific Plan, allowing people the freedom to walk to their trip destinations.

Funding. Funding for The BLVD Transformation Project was a combination of both public and private investment. The Lancaster Redevelopment Agency invested $\$ 41$ million from housing set-aside money for housing in the Downtown area adjacent to The BLVD (Ludicke, 2013). Apart of the $\$ 41$ million investment, $\$ 10.4$ million in economic development money raised from bonds issued by the redevelopment agency was spent on the street, landscaping, and pedestrian improvements on The BLVD directly (Ludicke, 2013). Private development, from business and construction investment, in the downtown area has reached approximately $\$ 130$ million (Gordon-Koven, 2012). The Lancaster Redevelopment Agency allotted approximately $\$ 430,000$ as incentive for new business to the Downtown area and provides existing businesses opportunity for upgrading storefront façades (LRA, 2012).

Implementation. The first steps to implementation of The BLVD Transformation Project began with The Downtown Specific Plan. With RBF Consultants, the City conducted extensive community outreach to develop the Lancaster Boulevard through The Downtown Specific Plan in order to receive early community and stakeholder buy-in (LRA, 2012). According to Lancaster City Planning Director Brian Ludicke, a three-day "community immersion event, which included walking tours, presentations, interviews with community leaders and business owners and community service providers like police and fire, cumulated with a design charette, which developed the basic concepts for the Downtown area (personal communication, 2013). Residents and business 
owners were able to share their needs and wishes for the street (EPA, 2012c). The Lancaster City Council adopted The Downtown Specific Plan, with the Lancaster Boulevard alternative, in September 2008 (City of Lancaster, 2008). The Lancaster Redevelopment Agency launched implementation of the Plan with The BLVD Transformation Project. Moule and Polyzoides Architects and Urban designers were chosen to create the design for the street.

After the Complete Street design was finalized, construction of the project began March 2010. Lancaster-based Hanes and Associates were contracted for construction of the project (City of Lancaster, 2010a). All businesses located in the area of construction remained open. To reduce impact to business, permitting and construction was accelerated (EPA, 2012c). The construction was divided into three phases to ensure a group of businesses was only affected for three months or less. After eight months of construction the project was completed in November 2010.

Beyond implementation of the new streetscape, the BLVD Transformation Project rehabilitated commercial space and simultaneous developed a new park, museum, affordable housing apartments and condos, inclusive for special populations including seniors and disabled adults. These amenities and land uses within walkable distance of The BLVD helped to engage with the Complete Street streetscape (EPA, 2012c). Further improvements for The BLVD Transformation project included establishing a façade improvement program in March 2011. 
The BLVD has implemented a number of Complete Street design elements to create a "Living Street", connecting multiple modes of transportation, and transforming the streetscape to a place-making environment with a welcoming identity.

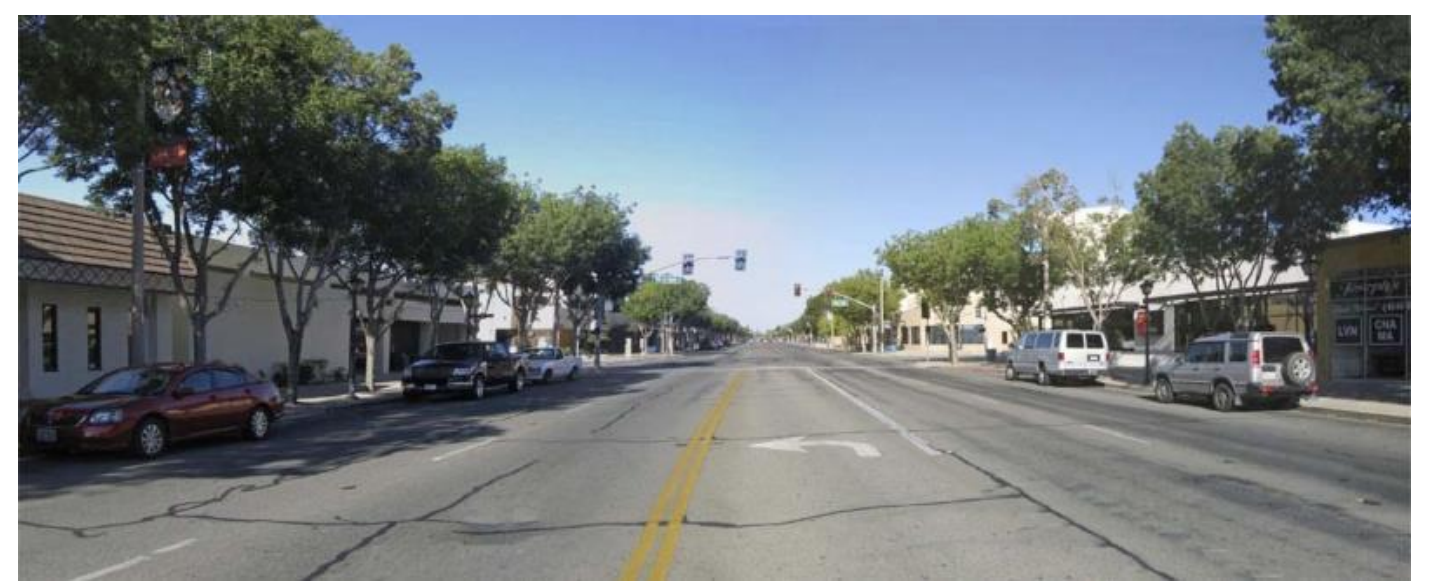

Figure 28. Lancaster Boulevard, 2009

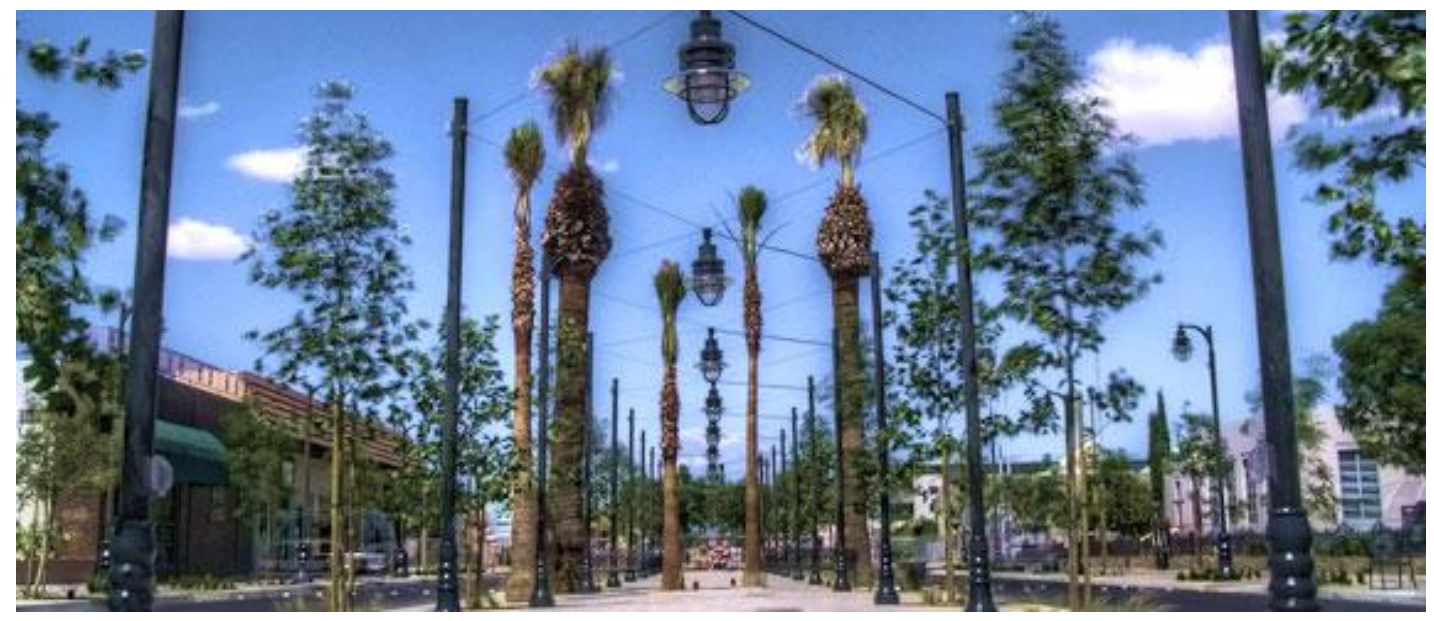

Figure 29. Lancaster Boulevard, The BLVD 2010

Traffic calming measures have been placed to increase safety and visibility of pedestrian and cyclists. The reconfiguration of the street has created two, approximately 10-feet, narrow travel lanes, designated as sharrows for cyclists and cars. This allows bikes and cars to travel in the same lane (LRA, 2012). 


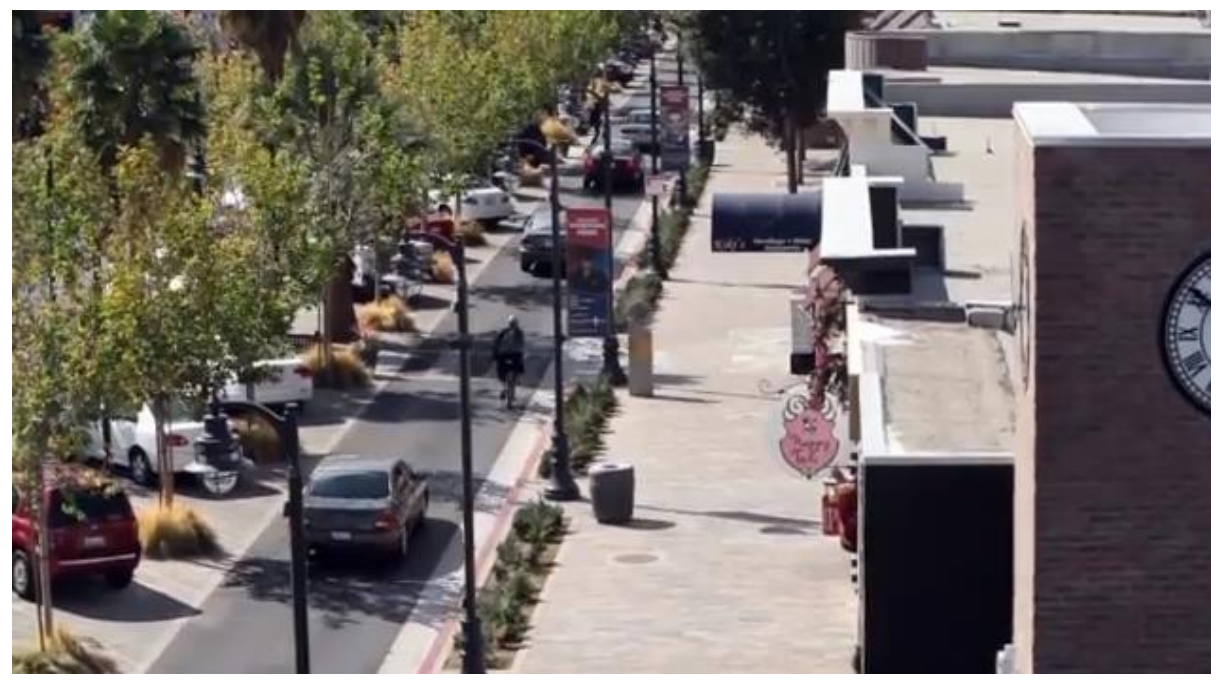

Figure 30. The BLVD travel lane

There are no traffic signals, but the incorporation of approximately 21 high visibility mid-block crosswalks keeps drivers aware of people wishing to cross the street. In addition, strategically placed plant containers and bollards prevent cars from venturing into a pedestrian plaza or sidewalk. Diagonal parking forces vehicles to back out into the travel lanes and parallel parking that lines the sidewalk creates a "parking lot" feeling for drivers, which also instinctively reduces speeds (Konar, 2012).

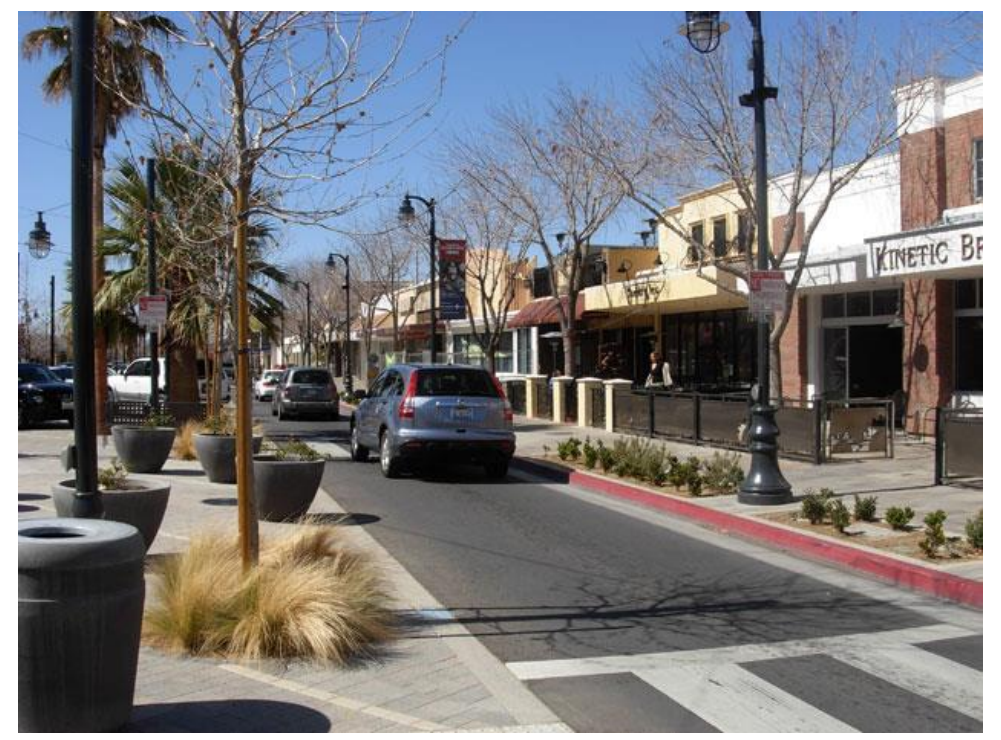

Figure 31. Crosswalk and Bollards directing traffic on The BLVD

Page 73 
Building to property line with form-based code to unite pedestrians with surrounding buildings creates a pedestrian friendly environment. Land uses are diverse between commercial, residential, mixed-use and public facilities. The streetscape has included important Complete Street pedestrian amenities such as wider sidewalks, droughttolerant landscaping for shade, lighting, street furniture and public art.

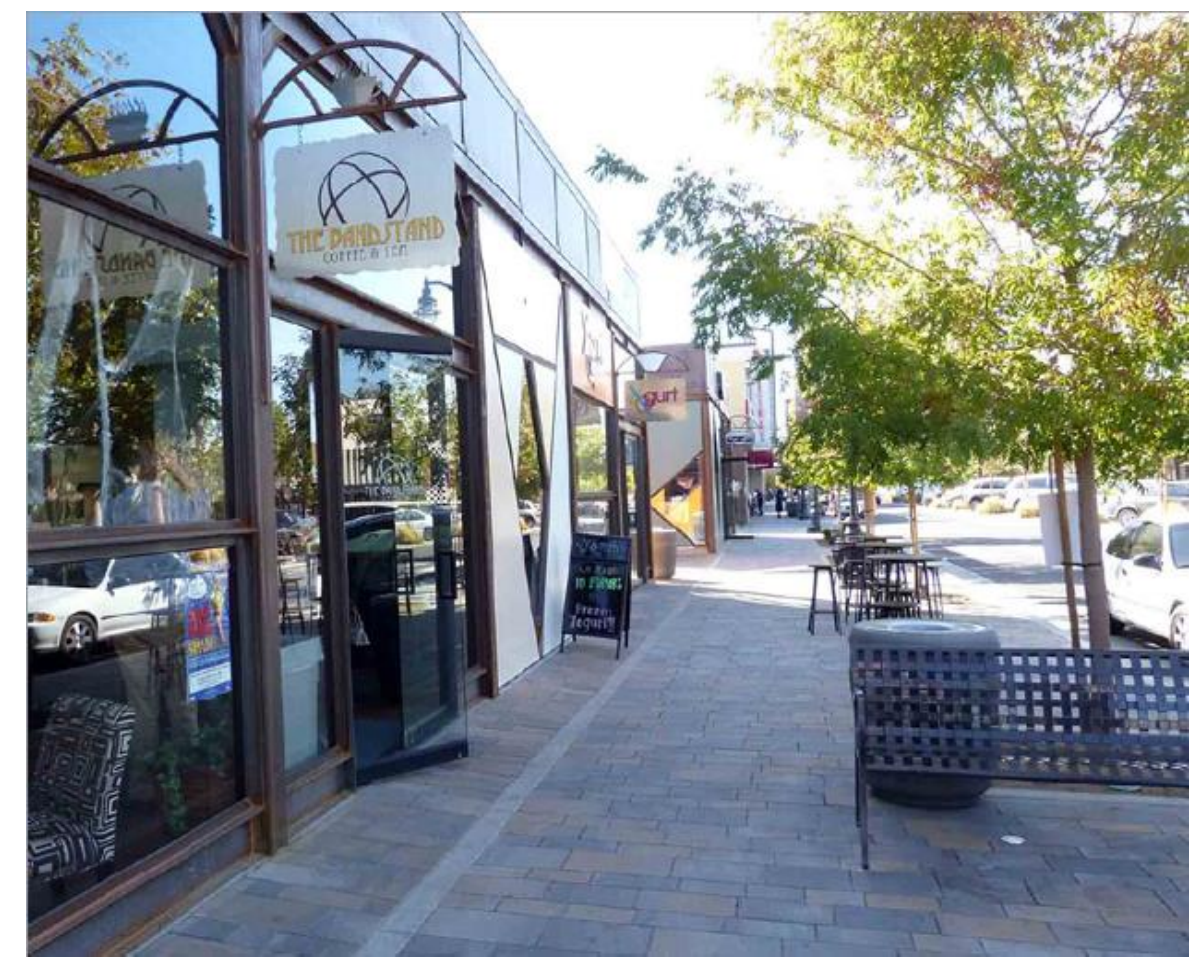

Figure 32. Sidewalk on The BLVD

The most prominent pedestrian feature of the right-of-way is the center ramblas, an open, central plaza with special pavement that is specifically created for walking and civic gatherings. When not in use, it transforms into additional diagonal parking (Gordon-Koven, 2012). 


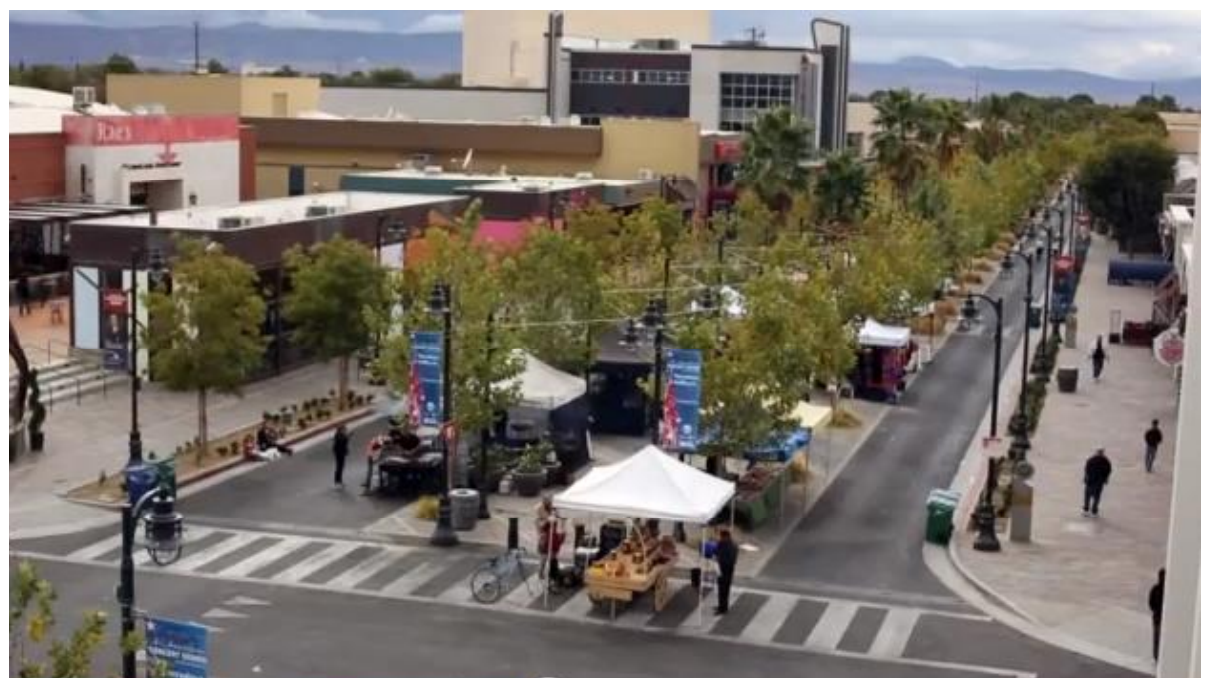

Figure 33. The BLVD Ramblas

Constraints to Implementation. The proposal of The BLVD Transformation Project occurred at the height of a U.S. Recession. The BLVD was a high-cost project. Despite the funding provided by the City agencies alone, the City of Lancaster's Redevelopment Agency needed to attract private investment to meet the cost of the project. In addition, the agency needed to aggressively attract businesses that would enhance the mix of uses and tenants in the Downtown area. With a significant Complete Street transformative design, the Agency needed to develop trust with business owners and developers (LRA, 2012).

To help attract and retain private developers and business, the City transformed its regulatory system. Flexible development codes, clear rules, and an accelerated permitting process were some of the actions taken to increase investment in The BLVD Transformation Project (EPA, 2012c). Staff from the Lancaster Redevelopment Agency remained on site during construction of the project to maintain communication with existing businesses (LRA, 2012). The City also prepared periodic videos that gave the 
general public the ability to know the status of the project and when to expect closures in certain areas.

City Planning Director Brian Ludicke shares residents and some local public service providers were apprehensive about the changes that would occur on Lancaster Boulevard. Some residents shared their misunderstanding at City Council meetings about the design of the street and removing two travel lanes. After The BLVD was completed, residents shifted complaints to the lack of parking from the redesign. The Los Angeles County Fire Department also complained about potential hardship when discussing alternative approaches to street widths and compromising fire codes (personal communication, April 19 2013).

Results. Investment in The BLVD Transformation Project with a Complete Street streetscape, housing and business development has transformed Lancaster Boulevard into a lively place-making district bringing jobs, economic growth and community revitalization (EPA, 2012c). Safety has increased from the dramatic reduction of traffic speeds. Collisions in the area dropped from an average of approximately three per month to less than one per month. From December to August 2009, before the Complete Street conversion, eleven collisions with injury were reordered. After the transformation, no single person was injured in a collision during the same nine-month time frame (NCSC Local Gov't Commission, 2012).

The BLVD has also created a remarkable economic investment in the Downtown Lancaster area. According to the City's tracked economic indicators, sales tax revenue in the downtown area has increased by 26 percent, with over forty new businesses 
opening within the past two years and an estimated vacancy rate of four percent (NCSC Local Gov't Commission, 2012). Nineteen hundred new jobs are attributed to the project. In return of both public and private investment, the City estimates a resulted \$273 million in economic output (EPA, 2012c).

Application. According to the Lancaster Redevelopment Agency, in order to achieve long-term viability, The BLVD needed to increase the number of residents to support commercial activity (LRA, 2012). In the City of Lancaster, The BLVD was accompanied by residential development in the area supporting the North Downtown Transit Village Project.

Through revitalization projects, a City can make services more accessible for special populations and take opportunity to form meaningful partnerships. The Lancaster Redevelopment Agency purchased "blighted" commercial properties and created a partnership with both the Mental Health Association and a private developer to construct affordable housing and provide services for mental health care (LRA, 2012). A children's facility, The Children's Center of the Antelope Valley, is also an example of a successful non-profit partnership.

Lancaster Planning Director Brian Ludicke shared the successful elements of the Complete Street design of The BLVD:

- Narrowing travel lanes allows a reduction in collisions, slower vehicle speeds, an environment more visible and safer for children, and better opportunity for exercise like biking and walking. 
- Parking flexibility is important. The BLVD provides curb parking availability close to business. The ramblas provides convertible parking space for community events (personal communication, April 19 2013).

- At the BLVD, some of the successful entrepreneurial businesses have become flagship stores for the area, providing new reasons for people to come to the Living Street (EPA, 2012b).

On March 12, 2013, Lancaster Planning Director Brian Ludicke was interviewed for the City's news show, Outlook. Ludicke explained what actions the City has taken after the success of The BLVD Transformation Project. The project provided an opportunity to look at how people are using space; providing insight on the steps and design features needed to make an area comfortable for walkers, but still maintaining accommodations for vehicle travel. The BLVD Transformation Project also raised a discussion on what is good for business and residents when defining and identifying a community. The ultimate question from the success of the project asks, what can be taken from the Downtown's success and transfer to other areas of the City? Ludicke discusses the identification of important mobility elements to draw business and development while revitalizing what is already there. In addition, the importance of a strong partnership with an investor provides strength for economic growth (City of Lancaster, 2013a)

\section{Case Studies Lessons Learned}

The purpose of the following lessons is to capture the important principles learned from the case study review in order to provide insight the City of Bakersfield can utilize on similar future projects. 
- DISCOVER new opportunities for Complete Streets

Funding is often a critical challenged often faced by cities to pay for improving or converting streets. The Complete Street projects implemented in the Cities of Sacramento and Lancaster were funded through standard Public Works Operations and Maintenance budgets. With the largest street improvement attributed to paving and restriping the roadway, overall project cost is relatively low. This may be a more feasible approach to building a Complete Street network with a constrained budget. Alternatively, using a Complete Street as an investment opportunity can produce greater financial return as the City of Lancaster's The BLVD has demonstrated with millions in economic output, private investment, and a transformation to a thriving residential and commercial Downtown district.

- DECIDE what you want to accomplish using Complete Streets As the case studies prove, each community is different. The Cities of Sacramento and Fresno emphasized their Complete Street project on achieving bicyclists, pedestrian, and motorist access and safety. The BLVD in the City of Lancaster placed focused on place making with economic revitalization. Other goals may include better community health or air quality. It is important to find what resonates with the Bakersfield community and connect Complete Streets to meeting these goals.

- EDUCATE the community to gain strong public support \& EMPOWER local advocacy groups. 
Ensuring both the City Government and the Public are in agreement can move a Complete Street project more efficiently. Key staff, including members the Planning Department, the Public Works Department, and the City Manager should share similar Complete Streets philosophy goals and approach to move forward. Once staff is in agreement, political support through the public is absolutely essential. Complete Streets are naturally controversial as they affect businesses, property owners, and residents. It is important to clearly convey what is expected of the goals and outcomes for a Complete Street project. Empowering local advocacy groups can be indispensable to providing these goals through political leadership and supporting stakeholder voices in the community. All three case studies had strong local advocacy groups or communication with local stakeholders during the entire Complete Street project process.

- MEASURE the Complete Street project Determining measurements beforehand is important to creating a benchmark for comparing the progress of a Complete Street project. In the case of The BLVD, tracking metrics included: number of new businesses, change in property value, chance in tax revenue, number of vehicle collisions, number of new employees, and amount of private investment, as determinants for performance. The City of Sacramento used percent change in bicycle ridership and number of reported collisions as performance measurements indicating the effectiveness Complete Streets had with utilizing new bike lanes and improving safety. Sharing the 
performance measurement results with the community is important. People generally respond best to data they can relate and comprehend. Performance measurement results, as facts, can provide a level of confidence and support for future Complete Street projects.

Page 81 


\section{CHAPTER 3: DESIGN GUIDELINES}

The conceptual design section of this report evaluates the existing Bakersfield street network, comparing traditional roadway classification to street typologies that have become more relevant to understanding the successful implementation of Complete Streets. Additional factors affecting street design are discussed in relationship with Complete Streets. Reviewing previous Complete Street standards and other relative policy guides, conceptual design guidelines have been created for each street traditional type. Illustrations provide a general understanding of the intended spatial relationship of the street and serve as a diagram for one, or more, possible street configurations. The created design guidelines are meant to provide flexibility to respond to context and conditions, while supporting a multimodal Complete Street network.

\section{Factors Affecting Street Design}

Traffic characteristic, state standards and environmental guidelines affect street design. These established factors can help further design input for appropriate Complete Street guidelines or geometric features of a roadway. They provide existing transportation context. The following discussion intends to provide guidance to design and not to replace a development process.

Functional Classification. The City of Bakersfield's streets, like most jurisdictions in the United States, are categorized in an order to better understand and connect to how they serve motor vehicle traffic. Complete Street projects are recommended to take into consideration roadway classification to help determine how to handle traffic volumes and other conflicts, which may arise as a result of proposed design changes. 
The Federal Highway Administration's American Association of State Highway and Transportation Officials (ASHTO) define functional roadway classification as (FHWA, 2012):

The process by which streets and highways are grouped into classes, or systems, according to the character of traffic service that they are intended to provide. There are three highway functional classifications: arterial, collector, and local roads. All streets and highways are grouped into one of these classes, depending on the character of the traffic (i.e. local or long distance) and the degree of land access that they allow.

The road classifications listed the 2010 Comprehensive Circulation Plan for the City of Bakersfield and defined by the FHWA Functional Classification Guidelines (2013), are as follows:

Freeway - highest classification of arterials designed for long, uninterrupted travel. Made for high speeds and high traffic volumes of only motorized vehicles. Provides partial or limited access linking major urban areas. Examples include Golden State 99 Highway and The Barstow-Bakersfield 58 Highway.

Expressway - the principle arterial systems that derive from service for major movements within the urbanized areas carrying traffic entering or leaving the urban area or bypassing the central city. The principle arterials should serve the major centers of activity within the metropolitan area with the highest traffic volume corridors and the longest trip desires; carrying the highest proportional urban area travel on the minimum 
mileage. Examples include Taft Highway, Alfred Harrell Highway, and Seventh Standard Road.

Arterial - the street system that interconnects with and augments the expressway arterial system and other roads. It provides service to trips of moderate length with a slightly lower level of travel mobility than a principle arterial like an expressway. More emphasis is placed on land access and may carry local bus routes. Aims to provide intra-community continuity without cutting neighborhoods. Examples include Stockdale Highway, California Avenue, Chester Avenue, and Oswell Street.

Collector - the street system that serves to provide land access service and traffic circulation within residential neighborhoods, commercial and industrial areas. Collectors travel through residential neighborhoods and connect trips from arterials to their ultimate destinations. Collectors also link trips from local streets in residential neighborhoods and channel to the arterial system. In areas like the Downtown or other neighborhoods with traffic density and development, the collector system creates a street grid. Examples include College Avenue, H Street, and Camino Media.

Local - serves as the street system to primarily provide direct access to the adjacent residential or commercial land uses and connects with larger street systems. Through traffic is usually discouraged.

[See Appendix A for City of Bakersfield Existing Circulation Map] 
Traffic Volume. Traffic volume represents the count or estimate of the number of vehicles passing a given point on a road in a given period of time (Caltrans, 2012). Traffic volumes may be expressed in terms of average daily traffic (ADT) or design hourly volumes, which are used to calculate service flow rates. Ranges of these traffic volumes are categorized in low (under 5,000 ADT), moderate (over 5,000 ADT), moderately high (over 10,000 ADT), and high (over 20,000), all dependent on the number of vehicles per day (Active Transportation Alliance, 2012). Often, traffic volume range relates with the number of lanes required based on area type, land use, and street type (NCDOT, 2012). For example, a two-lane street will carry low to moderate traffic volumes. When determining applicable Complete Street projects, low to moderate traffic volume in a minor arterial or collector is often better suited for bike lanes that safely help bicyclists travel through a created bicycle network, often adjacent to higher volume arterials.

Design Speed. Design Speed is a selected speed used to establish the various geometric design features of the roadway (Caltrans, 2012). Like traffic volume, speeds are characterized in a moderately low $(20-25 \mathrm{mph})$, moderate $(25-35 \mathrm{mph})$, moderately high (30 - $45 \mathrm{mph}$ ), and high (35 to $50 \mathrm{mph}$ ) range (Active Transportation Alliance, 2012). Selecting a practical, high speed is the traditional approach for setting a design speed (LA County Dept. of Public Health \& UCLA Luskin School of Public Affairs, 2011). The traditional selection for design speed is influenced by primarily the character of the terrain, economic considerations, extent of adjacent development, and highway type (Caltrans, 2012). Design Speed is important to the creation of Complete 
Streets. Speed should be set to create an environment that provides safety and comfortability for all users of the roadway. Designing with lower speeds that traditional highway design is desirable, as it determines the appropriate design features allowed to improving conditions.

Design Vehicle and Emergency Management. A design vehicle is the vehicle type accommodated on a specific roadway, which guides the purpose of designing the road (New Haven, 2010). The design vehicle influences roadway design features including lane width, corner radii, and median nose design, amongst other intersection details. A larger design vehicle than necessary may create wider travel roadways and intersections, increasing speeds, and creating safety challenges for pedestrians and cyclists when crossing or traveling adjacent to vehicles (ATA, 2012). However, designing a roadway for a smaller vehicle may result in operational problems for larger vehicles and conflict with emergency vehicles standards. Design vehicles in a Complete Street should reflect the predominant intended users of the street and avoid a "one size fits all” intersection radii (ATA, 2012). Emergency Service Field Tests, as demonstrated by the City of Sacramento when creating new street standards, can resolve the dilemma of Uniform Fire Codes' determined width and a expectations for narrow streets through test emergency operations and maneuvers that identify acceptable an street width application (Owens, 1999).

Access Management. Access management is the design, implementation, and management of the entry and exit points, including driveways, between roadways and adjacent properties (FHWA, 2010). General access considerations include the 
functional classification, the area of the intersection, the location and number of access points, the number of resulting conflict points, the use of medians, and driveway design. The presence of many driveways creates conflict between vehicles and bicyclists or pedestrians riding or walking along a street and should therefore be reduced or consolidated (LA County Dept. of Public Health \& UCLA Luskin School of Public Affairs, 2011). Access density provides a measurement of the amount of development and interaction on a street (NCDOT, 2012). Lower speeds are generally needed more for areas of density and can provide more flexibility for pedestrians, bicyclists, transit users, and vehicles.

Safety. Traditional urban standards that create wide straight roads and lanes, with infrequent intersections, may encourage speeding resulting in a higher number of crashes (San Diego Section of The American Planning Association \& WALK San Diego, 2012). Municipalities should be encouraged to review current collision data when rethinking road standards in favor of Complete Streets. In addition to local police accident reports, the California Highway Patrol Statewide Integrated Traffic Records System has recorded vehicle/pedestrian collisions and vehicle/bicyclists collision history and data reports, which may provide insight for a specific user of an area within the City. Collision data statistics including rear end crashes, rear end left turn crashes, head on crashes, head on left turn crashes, total 4-types of crashes, and crash per mile per year can influence the need for improved safety design or traffic calming features addressed in Complete Streets for motorists on specified roadways. 
Level of Service. Traditionally, performance measures for transportation planning have occurred through Level of Service (LOS). Level of Service is a grading system for the amount of automobile congestion, categorized using the letters $A$ through $F$ to represent the least amount (free-flow) to most (stop-and-go) amount of congestion (FHWA, 2012b). This measurement from a driver's perspective ignores the perspective of users such as pedestrians and bicyclists (Hillard and Milam, 2009). Most general plans establish an LOS threshold to determine the size and design of the roadway system. A specified LOS as a primary transportation performance raises traffic flow accommodation above other community goals described in the general plan, including alternative transportation or traffic safety (San Diego Section of The American Planning Association \& WALK San Diego, 2012).

As an alternative to the barriers that may arise from traditional LOS, some cities have designated a lowered LOS standard in corridors or intersections where walking, bicycling, and transit is prioritized. The BLVD in Lancaster, CA, examined closely in Chapter 2, is a successful example. Other cities, such as San Francisco, have replaced their LOS metric with "Auto Trip Generated" to minimize new vehicle trips and fund improvements to biking, walking, and transit (San Diego Section of The American Planning Association \& WALK San Diego, 2012).

Multimodal Level of Service (MMLOS) thresholds can also accompany Level of Service. Multimodal Level of Service applies to streets with all modes of travel included on the roadway. It assesses the impacts of facility design and operation for all users and serves a tool to predict travel perceptions for quality of service of each mode (LA 
County Dept. of Public Health \& UCLA Luskin School of Public Affairs, 2011). The 2010 Highway Design Manual, which serves as a main reference document form many transportation planners and engineers, includes a MMLOS methodology for evaluating walking, cycling, and public transportation, as well as vehicle travel conditions.

California Environmental Quality Act. The California Environmental Quality Act (CEQA) requires all state and local agencies to give consideration to environmental protection in regulating public and private activities and should not approve projects for which there exists a feasible and environmentally superior mitigation measure or alternative (California Resources Agency, 2005). Future traffic congestion, as an environmental impact, has often trapped transportation planners and traffic engineers to accommodate vehicle trips that meet the required LOS for the roadway to comply with CEQA transportation impact analysis (Hillard and Milam, 2009). In 2010, the revisions to the State CEQA Guidelines changed emphasis to consideration of project impacts on all transportation modes and allow the use of transportation measures other than Level of Service (San Diego Section of The American Planning Association \& WALK San Diego, 2012). In addition, each city may evaluate their threshold criteria for determining a mitigated negative declaration in relationship to street improvements, creating categorical exemptions for projects that remain in the same total right-of-way, such as a restriping or road diet project. 


\section{Context for Complete Street Design}

A different design approach than functional classification and traditional street design criteria alone are required for the planning and design of Complete Streets. Implementation works successfully with the use of a context-based approach, which recognizes Complete Streets are not "one size fits all." Traditionally, the goal of a street is to connect one place to another as efficiently as possible, rather than consider the greater impact a street has on economics, the environment, or use of public space. Context requires an understanding of the existing and future land uses that connect with the street. It requires an understanding of the existing and future transportation contexts. Different design treatments affect a person's ability to safely and comfortably use the street, regardless if they walk, ride, bike, or drive. Using context, these Complete Street design treatments should be considered from the conception of a project, regardless if it is new development, retrofitting, or restriping of the street

Land Use Context. The overall land use area patterns also should be considered in the planning and designing of Complete Streets. The Federal Highway Administration (FHWA) has expanded its own definitions of "macro" urban, suburban and rural area context, which recognizes the boundaries and distinctions between types of land use patterns is often blurred (FHWA, 2005a). A street design appropriate for a low-density neighborhood may have similarities to narrow streets of downtown and commercial land uses, which have a high pedestrian volume. Conversely, streets with wide travel lanes may consider design treatments that balance pedestrian and large vehicles. Existing or 
future trip generators, determined by land use within the area of a proposed project, might affect travel patterns and connections within and around the suggested corridor.

Urban areas can be broadly defined as the entirely of a city. It usually represents the heavy commercial, residential, industrial, and civic activity of the urban core, or central business district. The street network of an urban area is traditionally a grid or modified grid pattern. Urban areas are the most likely to have access to multiple modes of transportation.

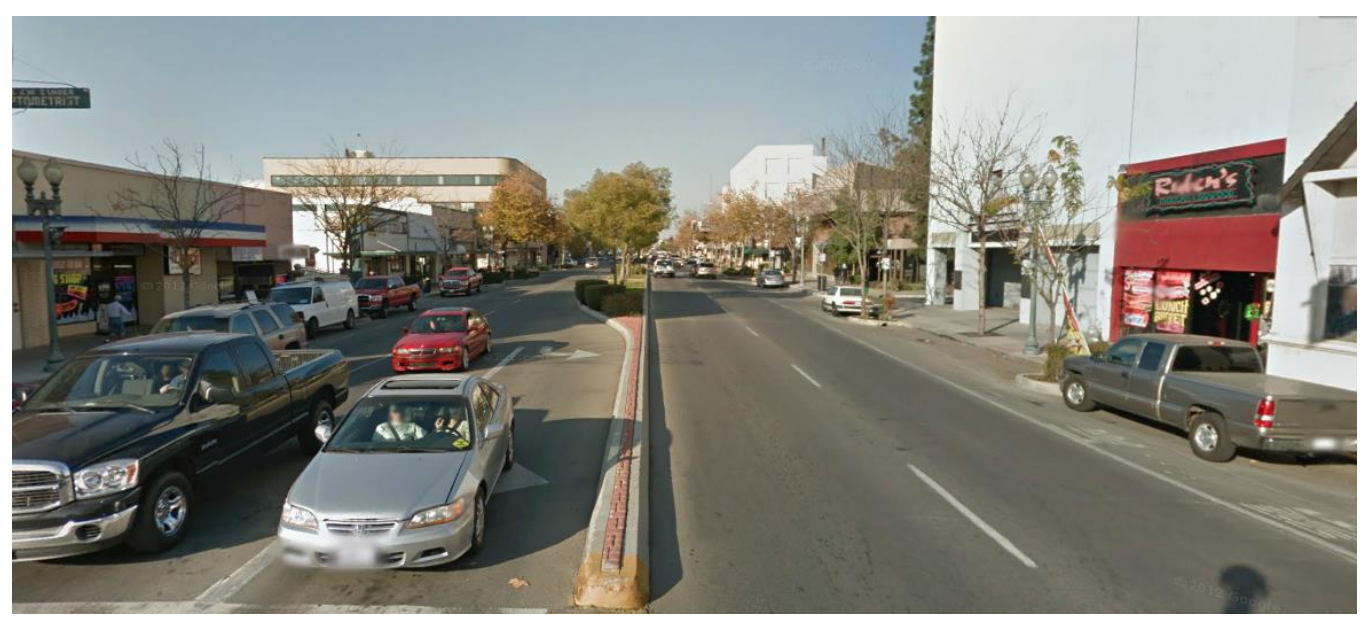

Figure 34. Urban Example, Chester Avenue and 18th Street, Bakersfield, CA. Source: Google Earth

Suburban areas are defined as metropolitan areas with lower densities. The land uses are often auto-oriented and separate from residential with pockets of development. Suburban areas can change widely in character and level of density. Roadways are usually widely spaced and fed by smaller streets that may not guarantee access with each other, providing connection challenges for pedestrian, bicyclists and transit users. 


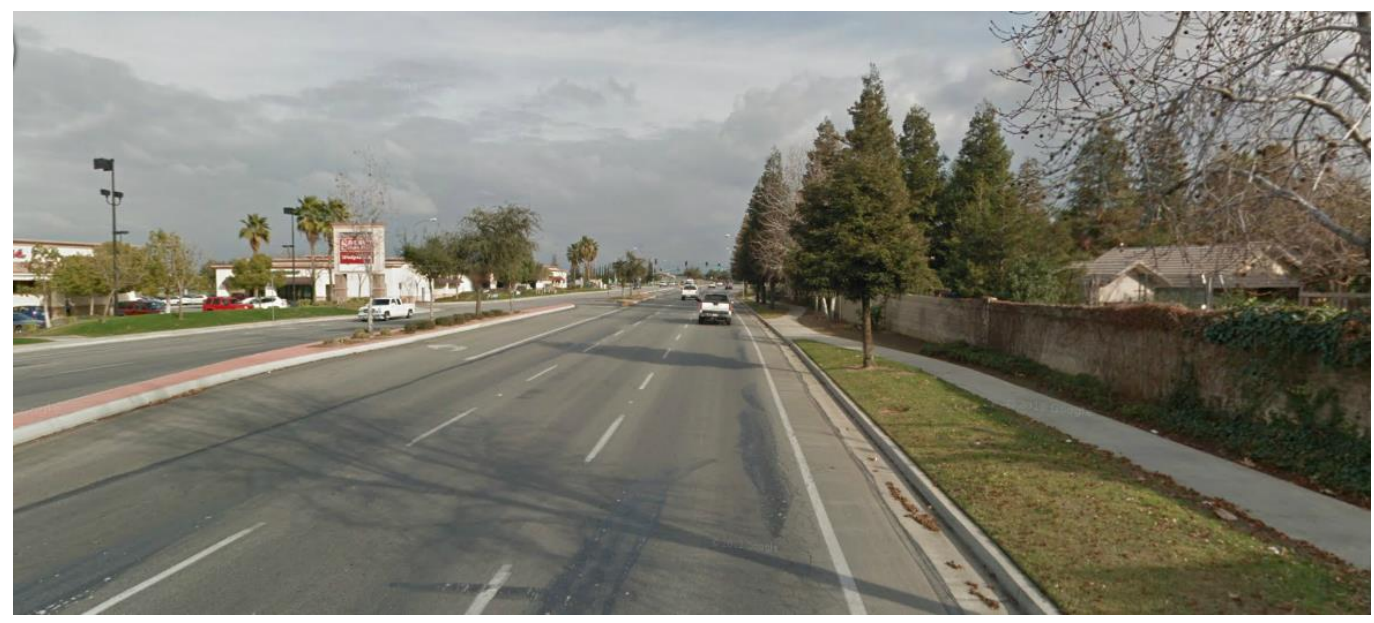

Figure 35. Suburban Example, Hageman Road, Bakersfield, CA. Source: Google Earth

Rural areas are commonly defined as areas with large expanses of undeveloped or agriculture land, dotted by small towns, villages, or any other small activity clusters. Land uses are primarily residential or isolated commercial/industrial uses. Rural roads are the most likely to be "incomplete" without paving, sidewalks, or wide shoulders for walking or biking.

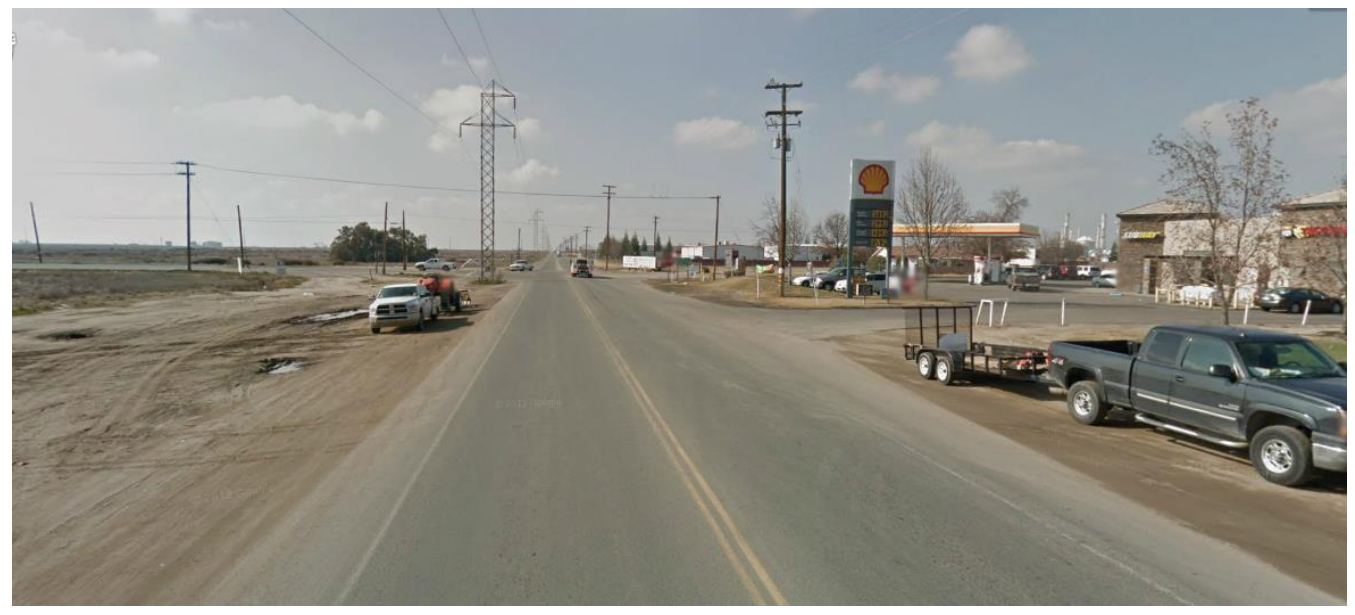

Figure 36. Rural Example, Seventh Standard Road, Metropolitan Bakersfield, CA. Source: Google Earth 
Streets defined by land use context can describe what the New Urbanism movement identifies as the 'Transect Zone,' which transitions the built environment from rural to urban settings. Context zones can work similar to the Transect Zone and become a tool to consider the street network, density, land use, and place making of the Metropolitan area rather than solely zoning (ATA, 2012). The City of Bakersfield experiences many context zones (urban, suburban, rural), which can be further evaluated for creating unique Complete Street design principles and context sensitive street typologies.

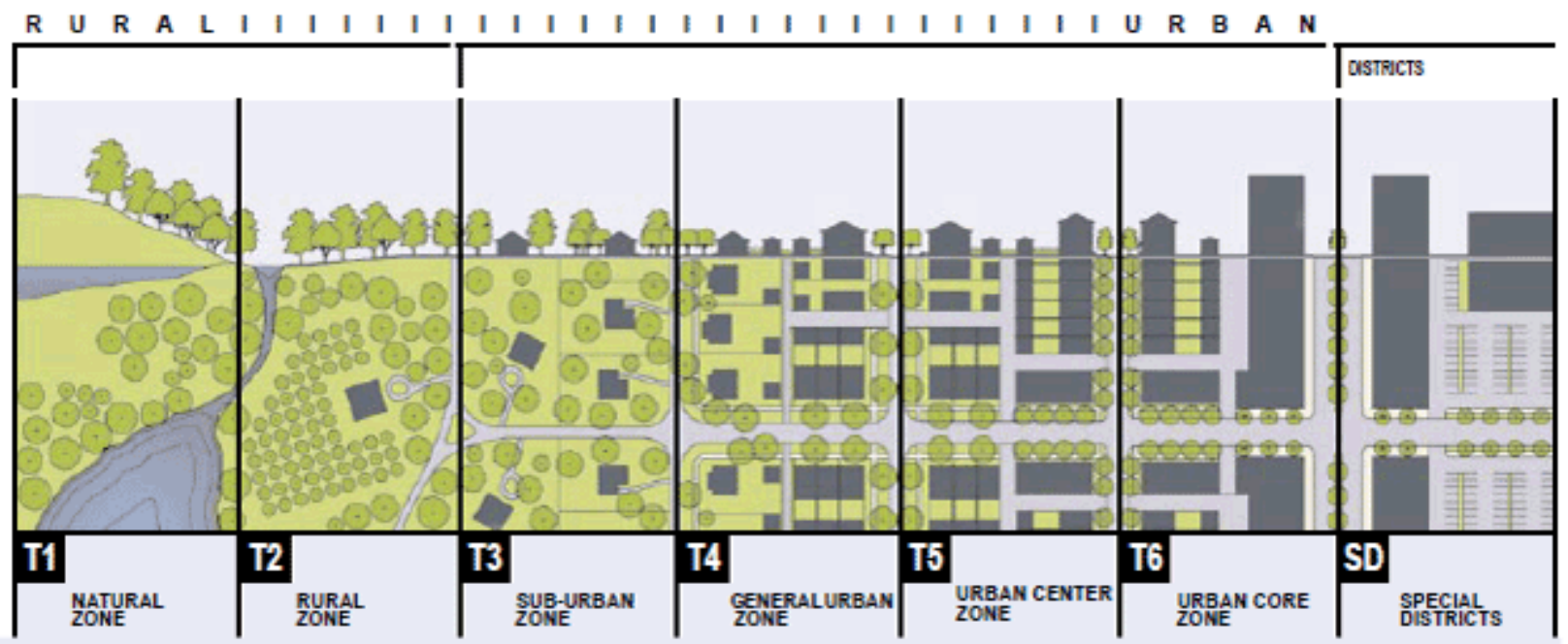

Figure 37. New urbanism transect zones based on context

Context Sensitive Street Typologies. Context sensitive Complete Street programs have taken a variety of approaches to roadway classification. A selection of published Complete Street design manuals and some influential local jurisdictions have gone beyond the traditional functional classification to categorize streets into "typologies," customized and context sensitive, which account for alternative transportation road users in addition to land use context and environmental factors. 
Developing new street types can combine an existing functional classification to adopt more design and access standards and account for different needs.

The Street typologies below are adapted from The Model Design Manual for Living Streets (LA County Dept. of Public Health \& UCLA Luskin School of Public Affairs, 2011) and The Designing Walkable Urban Thoroughfares: A Context Sensitive Approach Report (ITE, 2010).

Boulevard (conventionally arterial) - designed for higher vehicular capacity and moderate speed, traversing an urbanized area. Boulevards serve as primary travel routes for longer distances. Typically, these streets are long corridors with multiple lanes. Boulevards are designed to carry local motorized traffic, pedestrians and bicyclists. They should be equipped with bike lanes and may have bus lanes or side access lanes that buffer wider sidewalks. Many Boulevards include a landscaped median.

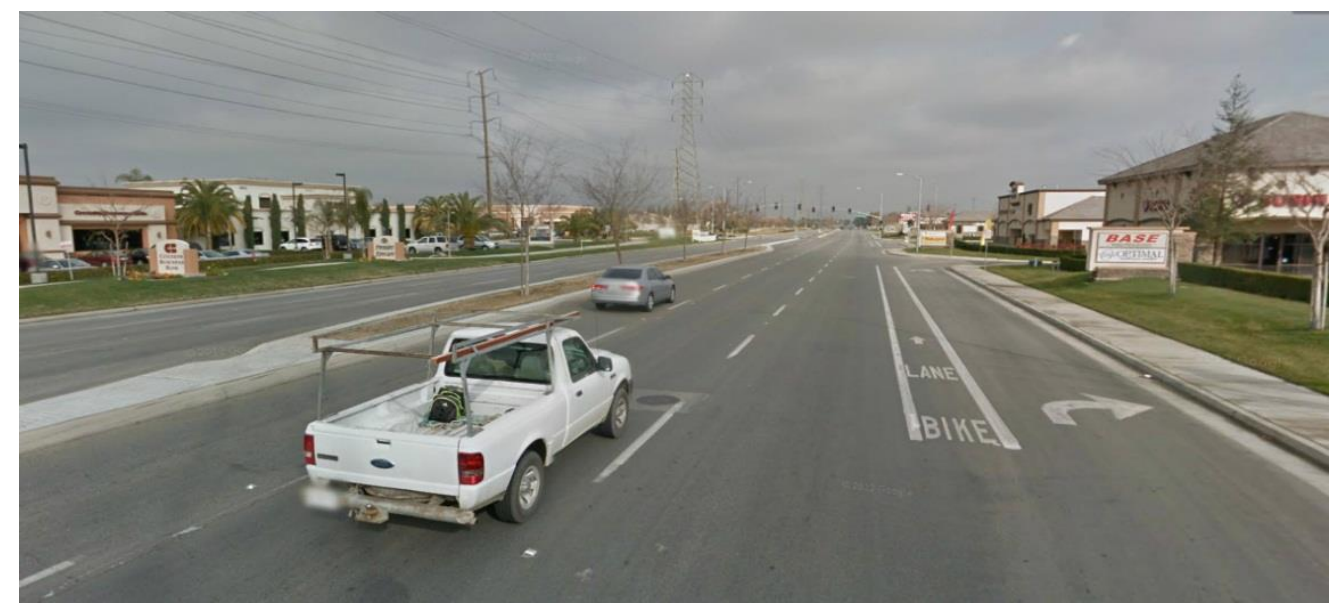

Figure 38. Boulevard Character, Coffee Road, Bakersfield, CA. Source Google Earth 
Avenue (conventionally collector) - designed for moderate to high vehicular capacity and designated with low to moderate speeds. An avenue, which does not exceed four lanes, acts as a short distance connector between urban centers and development that links with boulevards. These streets are designed for all vehicles, including transit. Also serves as primary pedestrian and bicycle routes, with amenities located along the street. May include a landscaped median and provide curb parking.

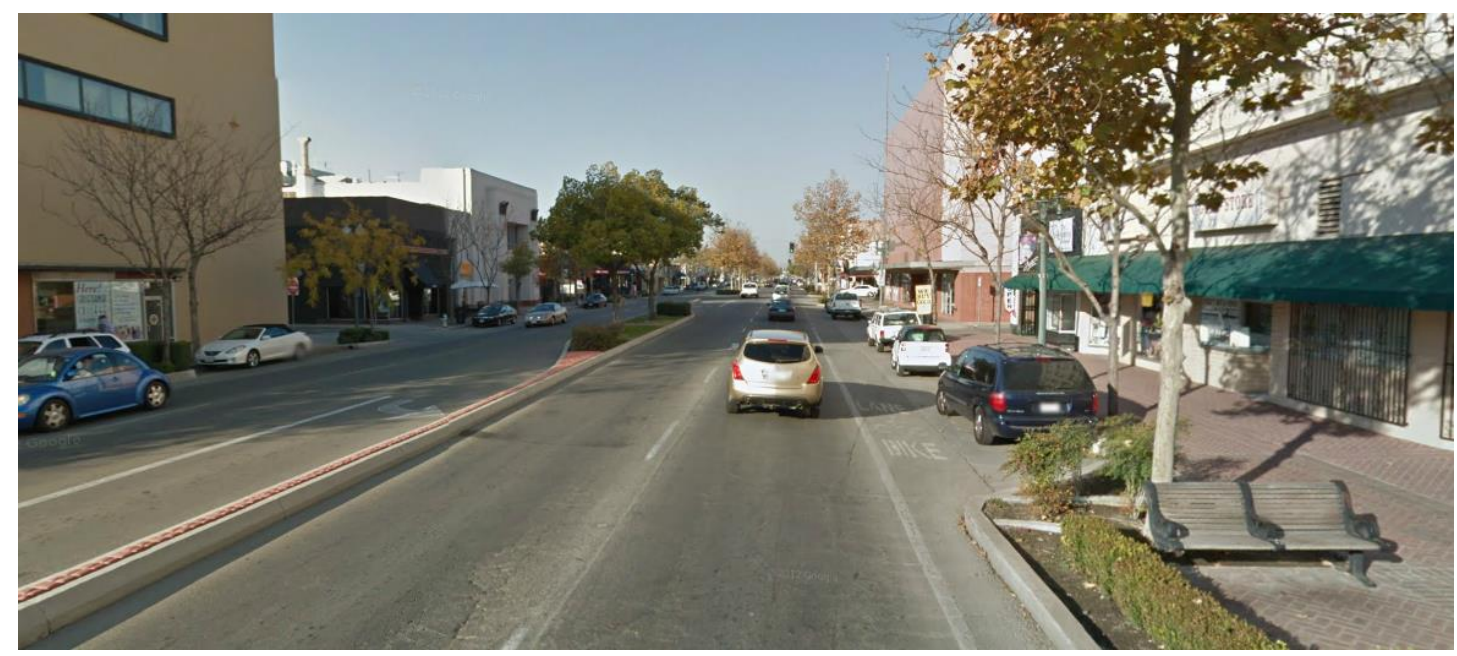

Figure 39. Avenue Character, Chester Avenue, Bakersfield, CA. Source: Google Earth

Street (conventionally local street) - connect adjoining neighborhoods to each other. Streets join directly neighborhoods with adjacent land uses like commercial and other districts. They also link to the overall street network. Typically, streets have low traffic volumes with low designated speed. Lane widths are based on land use, density, and lot size. Streets serve a local function for vehicles and transit. They are designed to be walkable and have strong focus pedestrian and bicycle movement. On street parking occurs at different levels. 


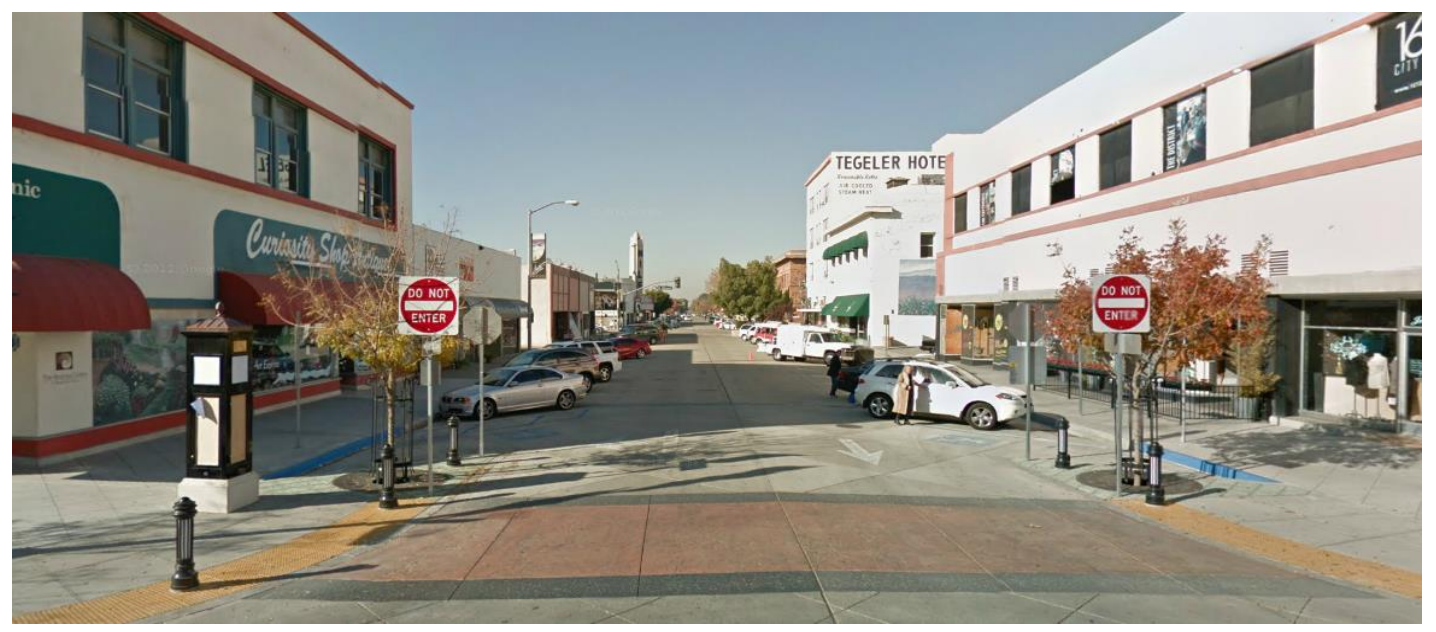

Figure 40. Street Character, $19^{\text {th }}$ Street, Bakersfield, CA. Source: Google Earth

Alley/Lane - the link between streets; a created vehicular driveway. Provides access to parking, service areas, and rear uses such as secondary units. They may also serve as an easement for utilities. Alleys are narrow and without sidewalks with very low speeds.

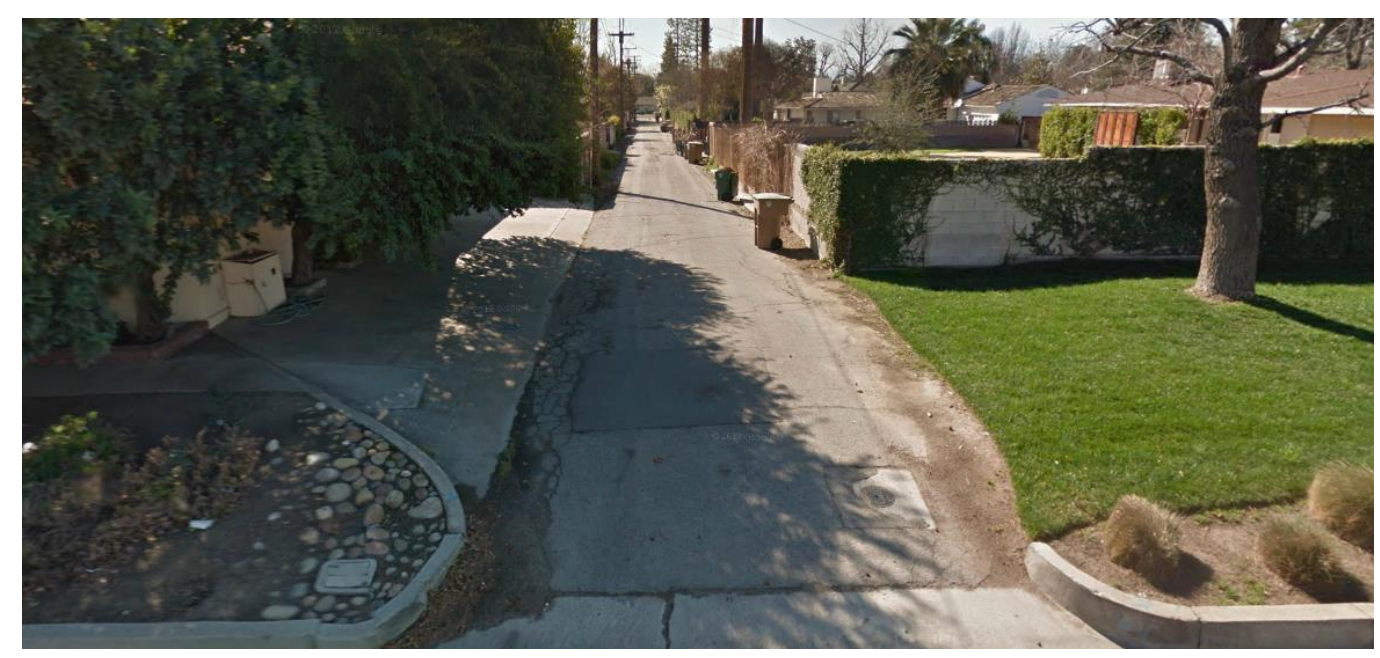

Figure 41. Alley Character, Lawn Street, Bakersfield, CA. Source: Google Earth

In addition to the commonly listed street typologies above, there may be segments of streets with specialized functions and features. For example, a Main Street 
or Festival Street typology may be exclusively or mostly pedestrian-oriented and serves as a low-speed destination for thoroughfare traffic circulation. A parkway is the most auto/truck oriented, but may provide design to improve safety for bicyclists, pedestrians with adjacent multi-use paths.

Developing new street types combines an existing functional classification to adopt context design that account for different needs. With this approach, plans, site design review, and environmental documentation in the city planning process accounts for how both private development and municipal infrastructure improvement projects will support or detract from the broader context of the street (San Diego Section of The American Planning Association \& WALK San Diego, 2012). Other quantitative factors affecting street design, including Level of Service or Average Daily Traffic standards, are converted to a more qualitative approach of considering context of a street with the community, a priority to the success of a Complete Street. Understanding context areas and creating new street typologies will plan for a better Complete Streets network.

\section{Conceptual Design Guidelines}

The following conceptual guideline diagrams in this report provide examples of Complete Street design through the characteristics of each functional classification street type using sample curb-to-curb cross sections. The focus of the cross section is to consider design treatments that provide access for all modes of travel, including pedestrian, bicyclists, and transit users. For each street type design guideline, a brief summary is included to list key design elements and any significant changes from the existing right-of-way [See Appendix B for Bakersfield R.O.W. Description]. The created 
conceptual design guidelines are best used in the decision making process, rather than to be used in isolation. It should be noted that the street cross sections are illustrative and the actual roadway configurations are subject to comprehensive engineering and design.

The design guidelines were created through a number of resources. Concepts were influenced from the report's selected Case Studies. The Sacramento Best Practices for Complete Street (2005) and the Sacramento Resolution to Approve Pedestrian-Friendly Street Standards (2004) were reviewed. Larger plans such as the Fresno Mobility Update Draft (2012) and the Lancaster Downtown Specific Plan (2008) were analyzed for related application. The Model Design Manual for Living Streets: Los Angeles County (2011) and The Complete Streets Complete Networks Manual (ATA, 2012) are recommended resources for additional street standard guidance.

\section{Proposed Roadway Cross section, Arterial}

Existing Arterials have 110 feet of right-of-way with 96 foot traveled way (90 feet when there is no bike lane). Generally located at one-mile intervals.

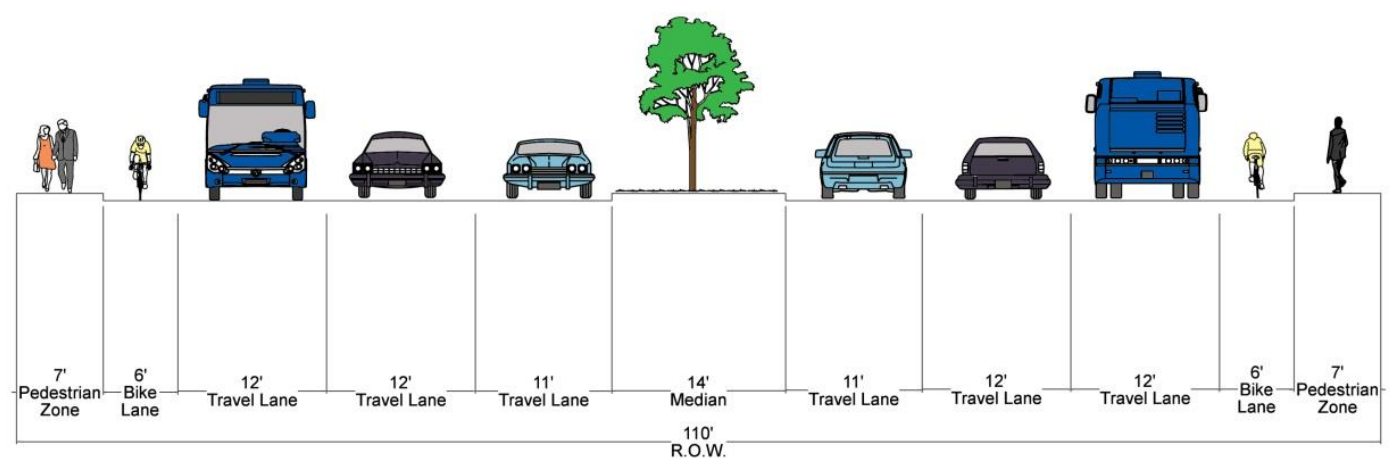

6-Lane Arterial, With Turning Lane and Bike Lane (110' R.O.W.) 
- Narrow vehicle lane width

- Widen bike lane

- Flexibility for dedicated bus lane or heavy truck areas

- No change in pavement width or R.O.W.

- Large median could serve as a turning lane or pedestrian refuge for two-stage crossing at intersection.

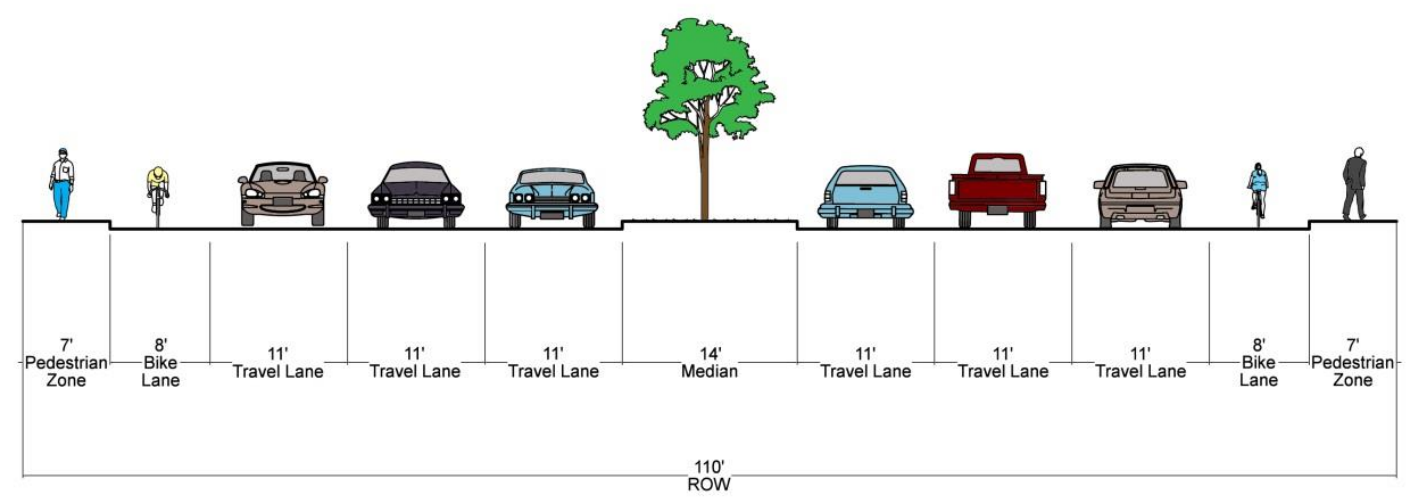

6-Lane Arterial, With Turning Lane and Buffered Bike Lane (110' R.O.W.)

- Narrow vehicle lane width

- Widen bike lane (optional buffer or cycle track - ideal w/ high speed roadways)

- Large median could serve as a turning lane or pedestrian refuge at intersection

- No change in pavement width or R.O.W.

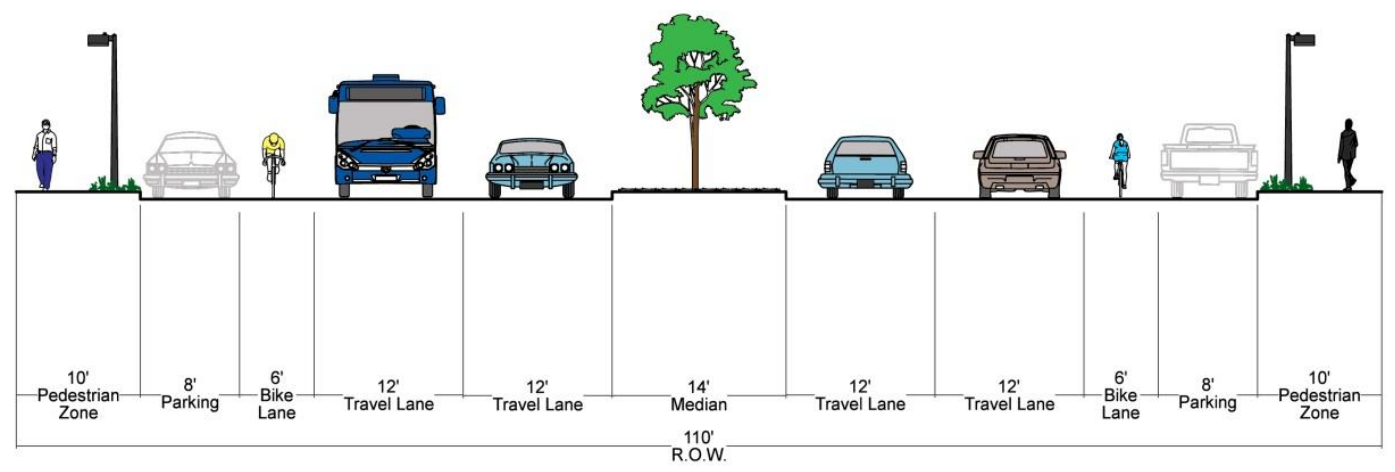

\section{4-Lane Arterial, With Bike Lane and Parking (110' R.O.W.)}

- Original arterial w/o bike lanes

- Reconfigured for parking and bike lanes

- Wide sidewalks for pedestrian walkability

- Large median could serve as a turning lane or pedestrian refuge at intersection

- No change in pavement width or R.O.W. 
Table 5. Additional Arterial Case-by-Case Street Improvements for Complete Street Design

\begin{tabular}{|c|c|c|c|c|c|c|c|c|c|c|c|c|c|c|c|}
\hline $\begin{array}{l}\text { Pedestrian } \\
\text { Features }\end{array}$ & $\begin{array}{l}\frac{n}{=} \\
\frac{\pi}{3} \\
\frac{0}{0} \\
\text { in }\end{array}$ & 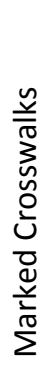 & 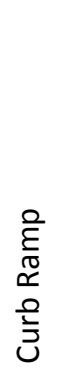 & 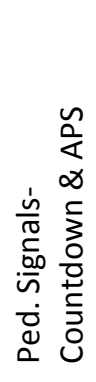 & 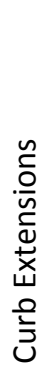 & 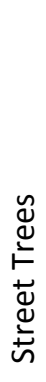 & 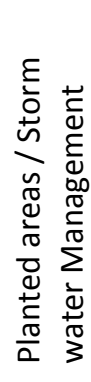 & 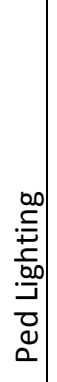 & 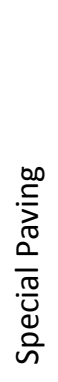 & 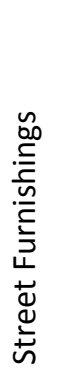 & 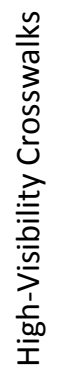 & 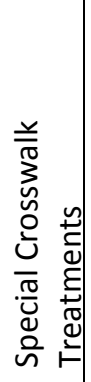 & 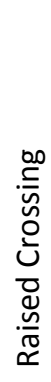 & 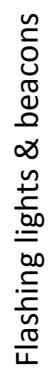 & 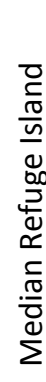 \\
\hline & & & & & & & & & & & & & & & \\
\hline
\end{tabular}

\begin{tabular}{|c|c|c|c|c|c|c|c|c|c|c|c|c|c|c|c|c|}
\hline $\begin{array}{l}\text { Bicycle } \\
\text { Features }\end{array}$ & 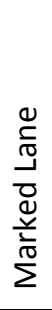 & 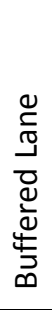 & $\begin{array}{l}\frac{v}{u} \\
\frac{v}{v} \\
\frac{0}{v} \\
\underset{U}{U}\end{array}$ & 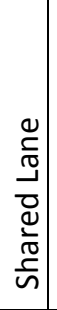 & 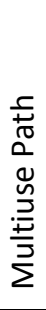 & 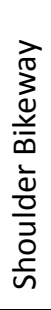 & 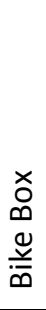 & 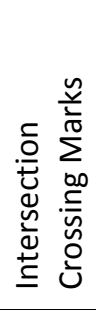 & 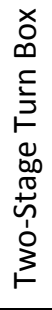 & 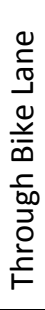 & 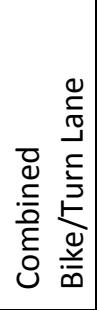 & 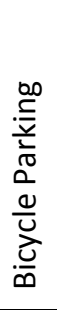 & 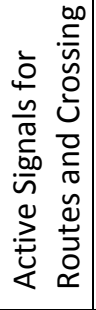 & 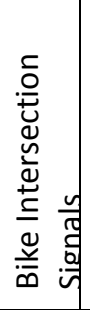 & 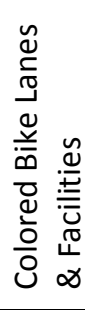 & 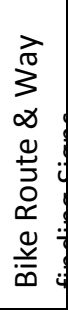 \\
\hline & & & & & & & & & & & & & & & & \\
\hline
\end{tabular}

\begin{tabular}{|c|c|c|c|c|c|c|c|c|c|c|c|c|c|c|c|c|}
\hline Transit features & 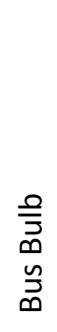 & 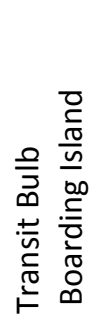 & 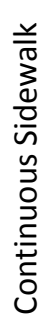 & 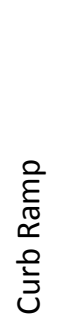 & 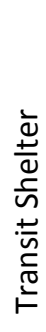 & $\begin{array}{l}n \\
\frac{n}{00} \\
i n \\
00 \\
\frac{\pi}{4}\end{array}$ & 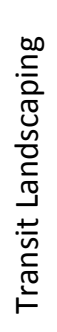 & 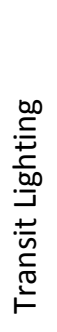 & 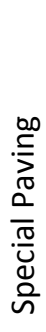 & 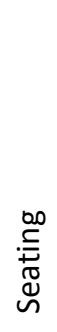 & 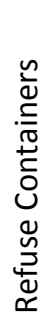 & 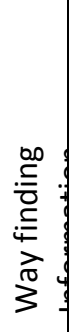 & 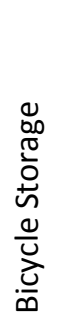 & 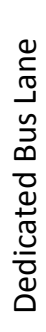 & 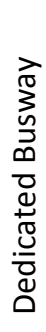 & 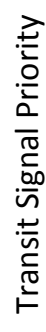 \\
\hline & & & & & & & & & & & & & & & & \\
\hline
\end{tabular}

\begin{tabular}{|c|c|c|c|c|c|c|c|c|c|c|c|c|c|c|c|c|}
\hline Roadway Features & 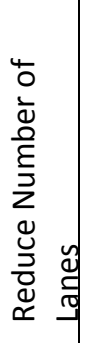 & $\begin{array}{l}\frac{1}{1} \\
.0 \\
3 \\
0 \\
\frac{1}{0} \\
\frac{\pi}{3} \\
3 \\
0 \\
\frac{1}{10} \\
2\end{array}$ & 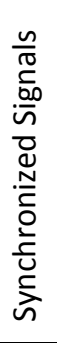 & 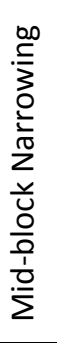 & $\begin{array}{l}\stackrel{0}{\frac{1}{U}} \\
\stackrel{U}{\frac{U}{U}}\end{array}$ & 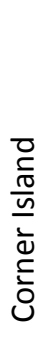 & 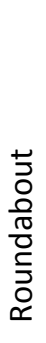 & 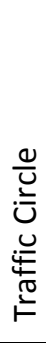 & 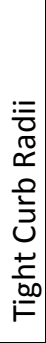 & 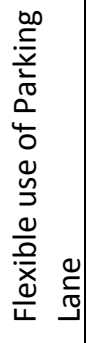 & 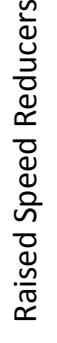 & 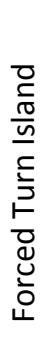 & 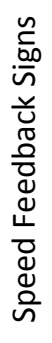 & 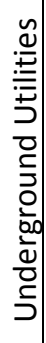 & 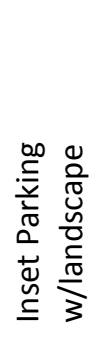 & 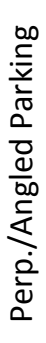 \\
\hline & & & & & & & & & & & & & & & & \\
\hline
\end{tabular}

\begin{tabular}{|l|l|l|l|}
\hline \multirow{2}{*}{ KEY } & & & \\
\cline { 2 - 4 } & $\begin{array}{l}\text { Applicable/ } \\
\text { Encouraged }\end{array}$ & $\begin{array}{l}\text { Consider } \\
\text { w/ } \\
\text { Context }\end{array}$ & $\begin{array}{l}\text { Not } \\
\text { Applicable }\end{array}$ \\
\hline
\end{tabular}

Page 100 


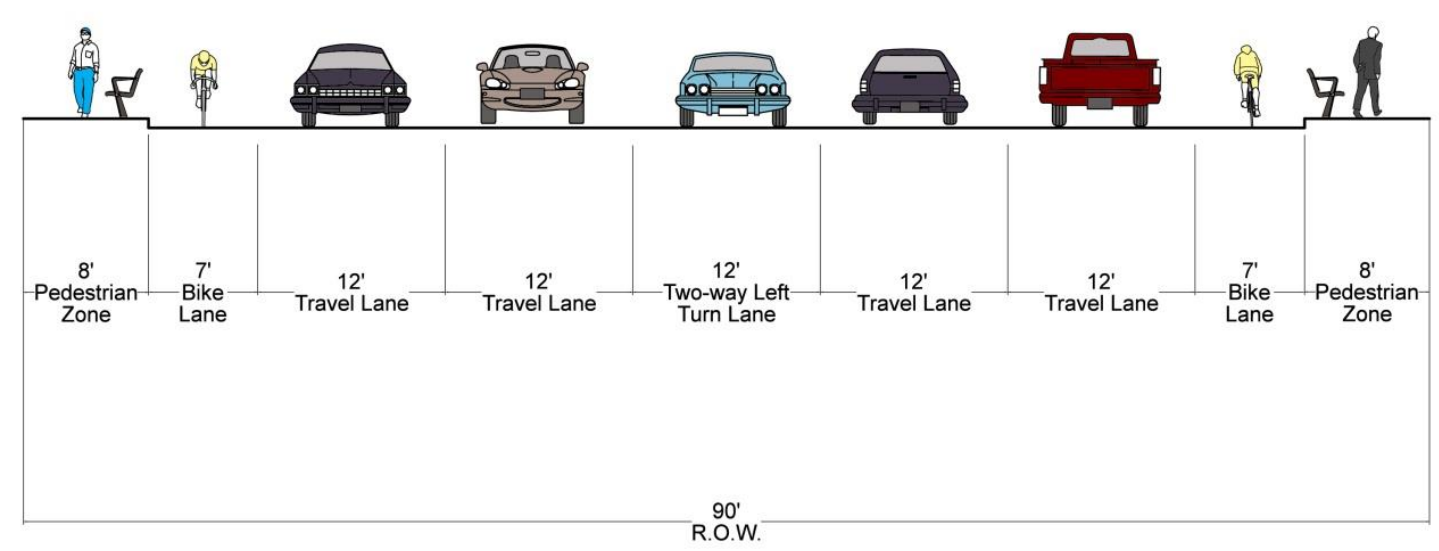

4-Lane Collector, With Bike Lane and Two-way Left Turn Lane (90' R.O.W.)

- Narrow vehicle lane width

- Widen bike lane for buffer from travel lane

- No change in pavement width or existing R.O.W.

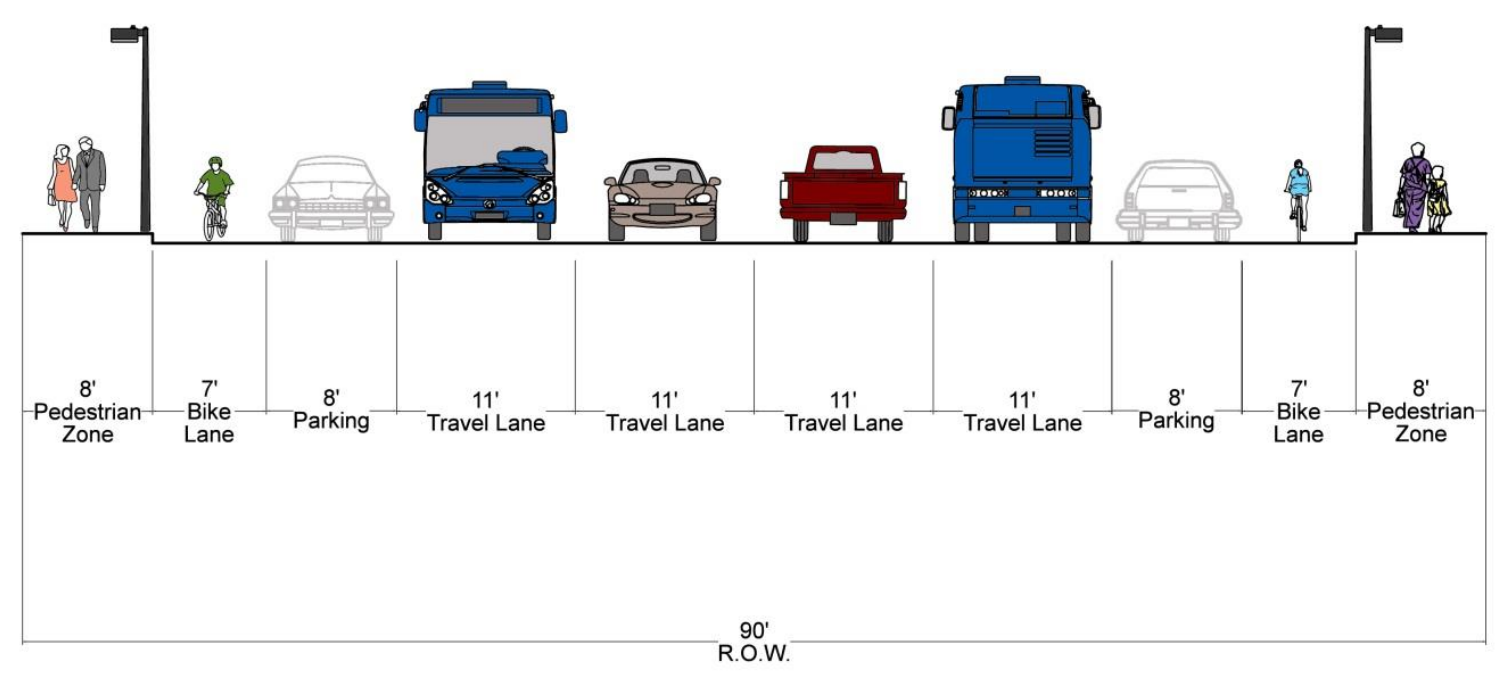

4-Lane Collector, With Bike Lane and Parking (90' R.O.W.)

- Narrow vehicle lane width

- Optional bike lane protected by parking

- Optional interspersed landscaped curb extensions to in parking lane when adjacent to curb 
- No change in pavement width or R.O.W.

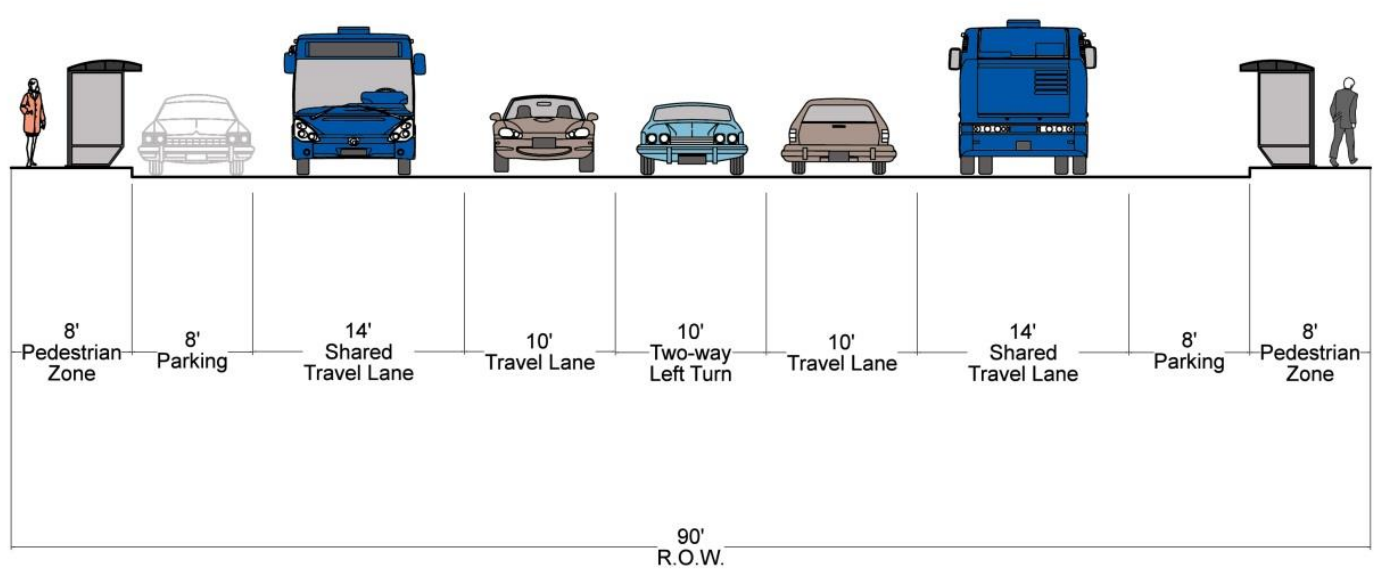

4-Lane Collector, With Two-way Left Turn Lane and Parking (90' R.O.W.)

- Introduces bike lanes through shared travel lane on original 68' pavement width

- Narrow vehicle lane width, preferable for low volume segments near intersections with lower speed facilities.

- Optional interspersed landscaped or transit curb extensions in parking lane

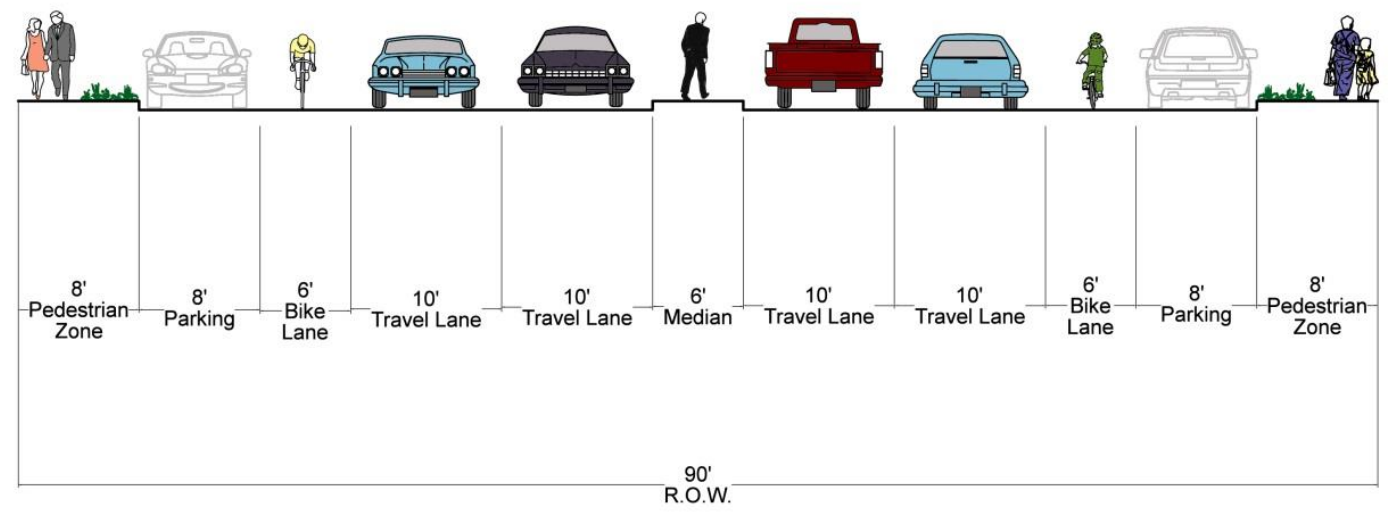

4-Lane Collector, With Pedestrian Refuge Median, Bike Lane, and Parking (90' R.O.W.)

- Narrow vehicle lane width, preferable for low volume segments near intersections with lower speed facilities.

- Widen bike lane width

- Optional interspersed landscaped or transit curb extensions in parking lane

- Six-foot median for pedestrian refuge 


\begin{tabular}{|c|c|c|c|c|c|c|c|c|c|c|c|c|c|c|c|}
\hline $\begin{array}{l}\text { Pedestrian } \\
\text { Features }\end{array}$ & 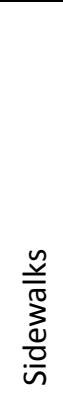 & 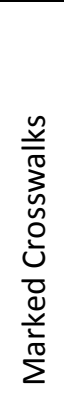 & 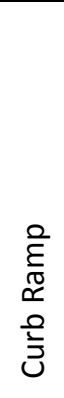 & 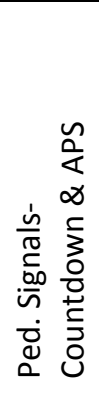 & 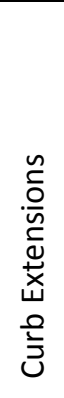 & 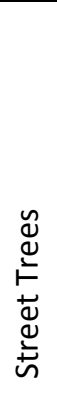 & 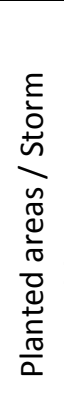 & 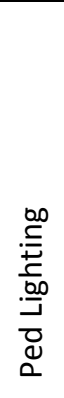 & 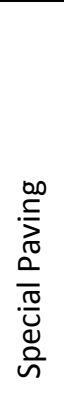 & 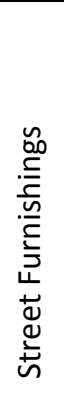 & 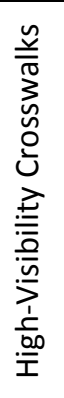 & 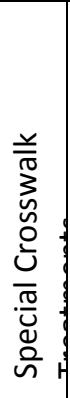 & 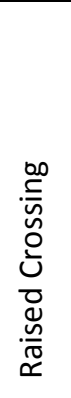 & 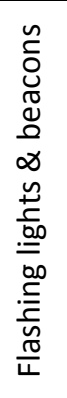 & 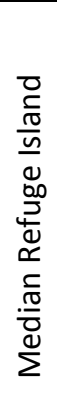 \\
\hline & & & & & & & & & & & & & & & \\
\hline
\end{tabular}

\begin{tabular}{|c|c|c|c|c|c|c|c|c|c|c|c|c|c|c|c|c|}
\hline Bicycle Features & 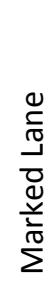 & 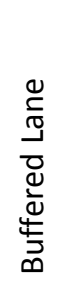 & 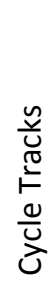 & 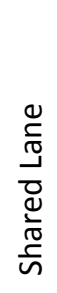 & 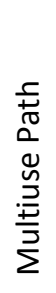 & 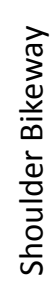 & 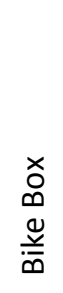 & 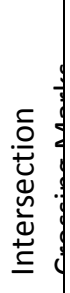 & 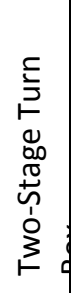 & 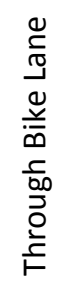 & 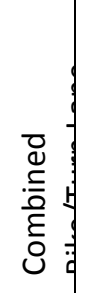 & 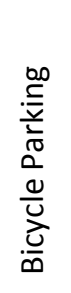 & 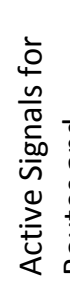 & 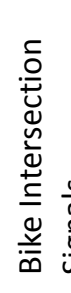 & 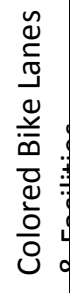 & 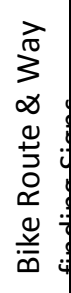 \\
\hline & & & & & & & & & & & & & & & & \\
\hline
\end{tabular}

\begin{tabular}{|c|c|c|c|c|c|c|c|c|c|c|c|c|c|c|c|c|}
\hline $\begin{array}{l}\text { Transit } \\
\text { features }\end{array}$ & $\begin{array}{l}\stackrel{0}{\overline{7}} \\
\infty \\
气 \\
\infty\end{array}$ & 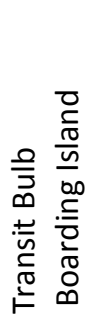 & 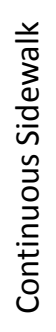 & $\begin{array}{l}\stackrel{0}{E} \\
\frac{1}{\pi} \\
\stackrel{2}{0} \\
\stackrel{0}{J} \\
J\end{array}$ & 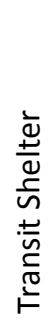 & $\begin{array}{l}\tilde{n} \\
\frac{n}{00} \\
\bar{n} \\
0 \\
\frac{\pi}{4}\end{array}$ & 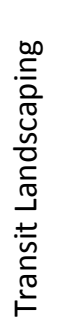 & 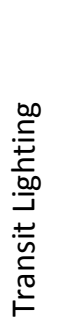 & 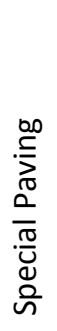 & 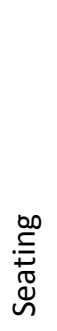 & 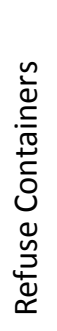 & 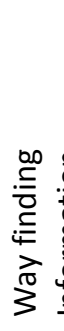 & 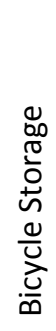 & 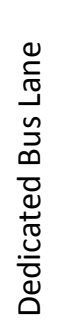 & 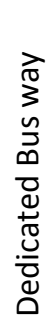 & 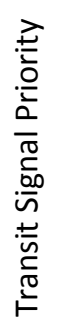 \\
\hline & & & & & & & & & & & & & & & & \\
\hline
\end{tabular}

\begin{tabular}{|c|c|c|c|c|c|c|c|c|c|c|c|c|c|c|c|c|}
\hline $\begin{array}{l}\text { Roadway } \\
\text { Features }\end{array}$ & 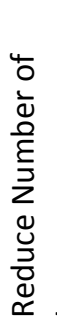 & $\begin{array}{l}\frac{1}{1} \\
\frac{1}{3} \\
3 \\
0 \\
\frac{1}{0} \\
\frac{\pi}{3} \\
0 \\
\frac{1}{10} \\
2\end{array}$ & 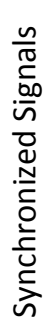 & 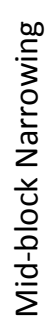 & 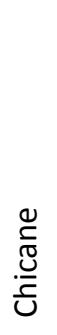 & 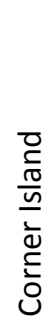 & 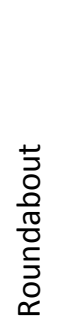 & 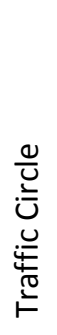 & 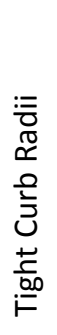 & 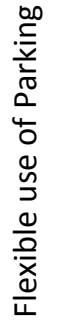 & 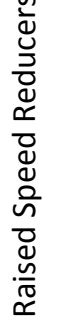 & 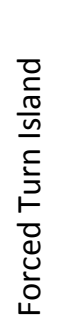 & 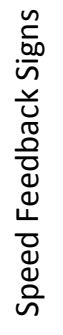 & 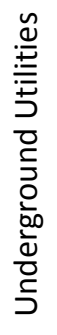 & 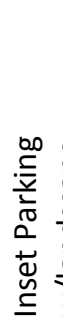 & 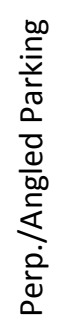 \\
\hline & & & & & & & & & & & & & & & & \\
\hline
\end{tabular}

\begin{tabular}{|l|l|l|l|}
\hline \multirow{2}{*}{ KEY } & & & \\
\cline { 2 - 4 } & $\begin{array}{l}\text { Applicable/ } \\
\text { Encouraged }\end{array}$ & $\begin{array}{l}\text { Consider } \\
\text { w/ } \\
\text { Context }\end{array}$ & Not \\
& & Applicable \\
\hline
\end{tabular}

Page 103 
Proposed Roadway Cross section, Local

Existing Local streets have 60 foot right-of-way with a 36 to 44 foot traveled way.

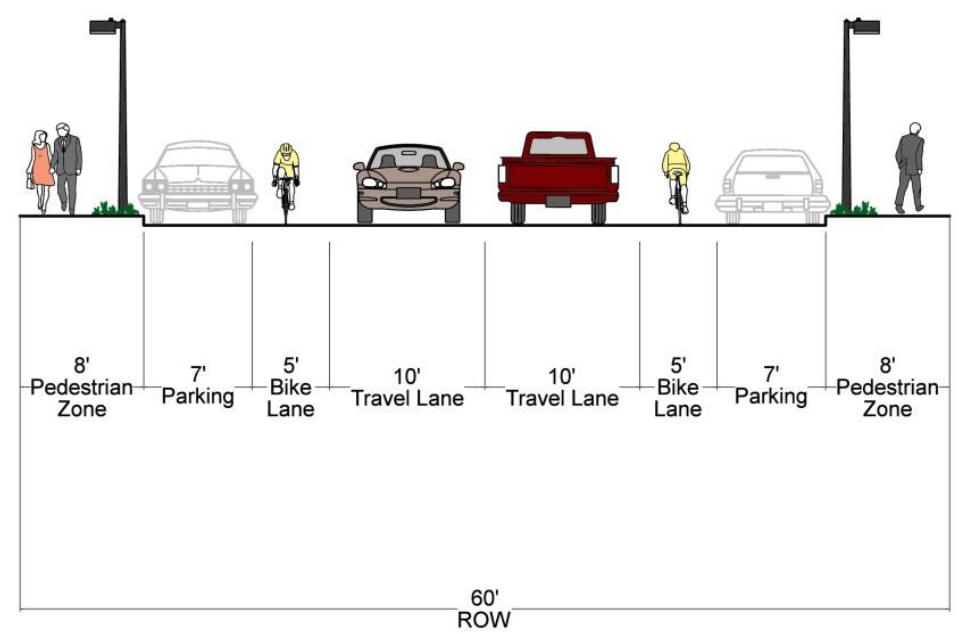

2-Lane Local, With Bike Lane and Parking (60' R.O.W.)

- Narrow vehicle lane width

- Separate bike lane from vehicle travel lane

- Optional interspersed landscaped curb extensions in parking lane

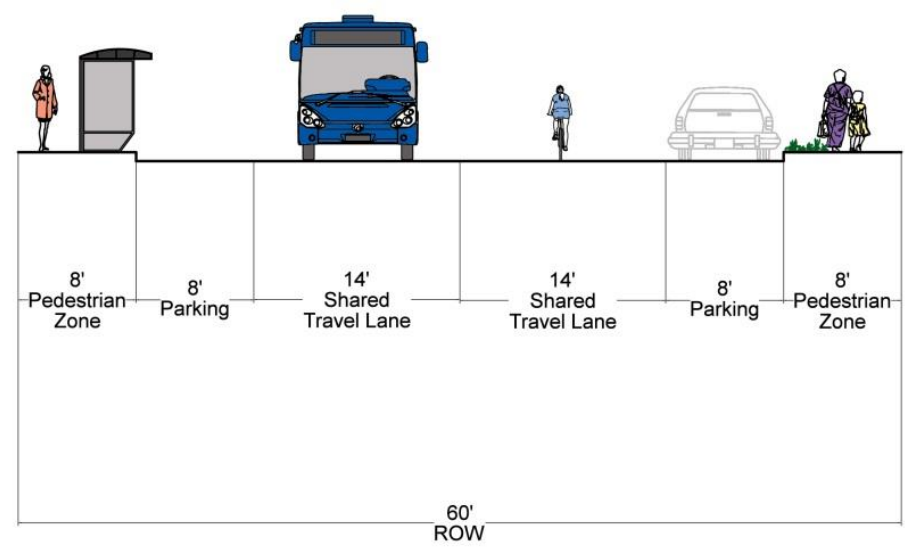

2-Lane Local, With Parking (60' R.O.W.)

- Narrow vehicle travel lane

- Option to create shared travel lane

- Optional interspersed landscaped or transit curb extensions in parking lane

- No change in pavement width or R.O.W 


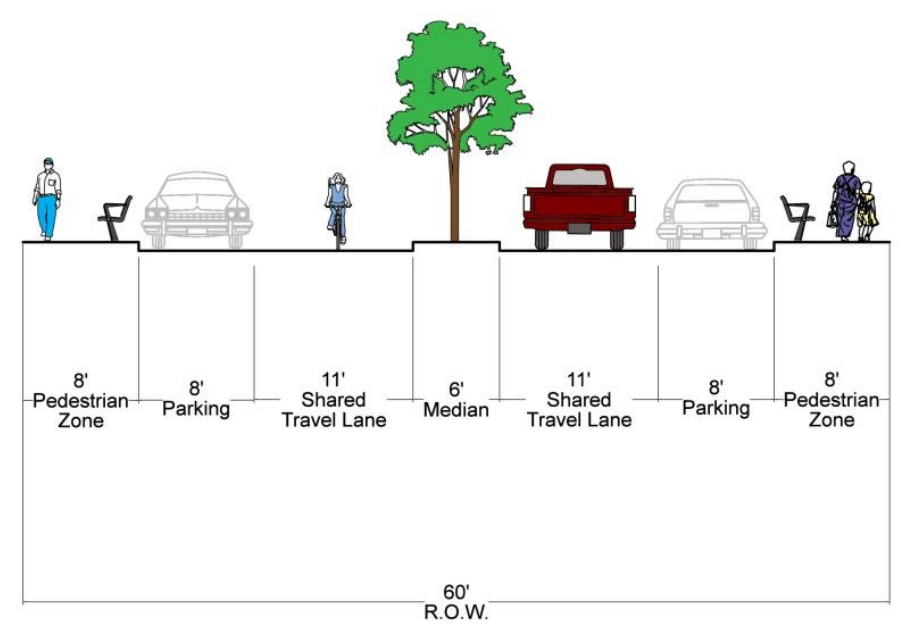

2-Lane Local, With Parking (60' R.O.W.)

- Narrow vehicle travel lane

- Option to create shared travel lane

- Optional interspersed landscaped curb extensions in parking lane

- Six-foot median for pedestrian refuge or additional greenway zone

- No change in R.O.W.

Table 7. Additional Local Street Case-by-Case Street Improvements for Complete Street Design

\begin{tabular}{|c|c|c|c|c|c|c|c|c|c|c|c|c|c|c|c|}
\hline Pedestrian Features & $\begin{array}{l}\frac{n}{\bar{\pi}} \\
\sum_{0}^{0} \\
\frac{0}{0}\end{array}$ & 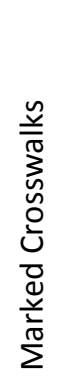 & 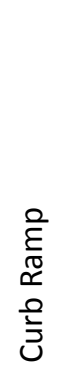 & 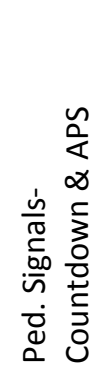 & 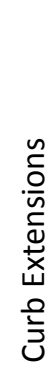 & 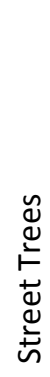 & 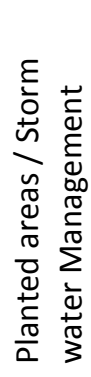 & 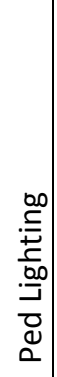 & 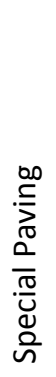 & 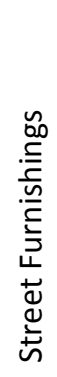 & 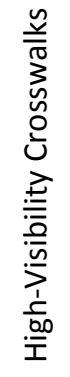 & 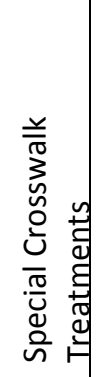 & 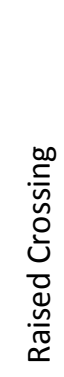 & 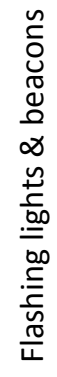 & 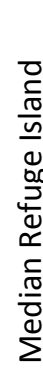 \\
\hline & & & & & & & & & & & & & & & \\
\hline
\end{tabular}

\begin{tabular}{|c|c|c|c|c|c|c|c|c|c|c|c|c|c|c|c|c|}
\hline Bicycle Features & 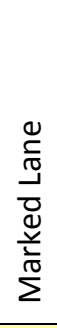 & 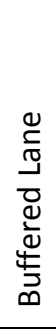 & 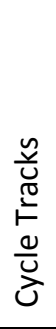 & 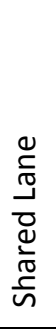 & 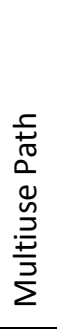 & 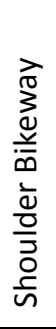 & 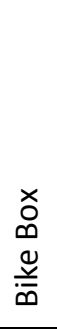 & 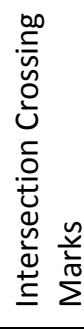 & 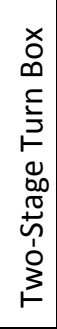 & 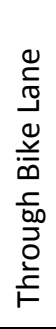 & 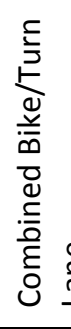 & 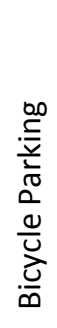 & 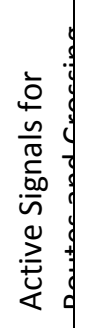 & 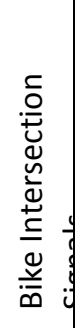 & 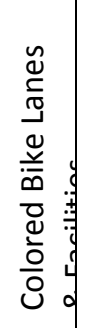 & 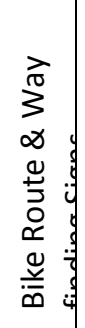 \\
\hline & & & & & & & & & & & & & & & & \\
\hline
\end{tabular}

Page 105 


\begin{tabular}{|c|c|c|c|c|c|c|c|c|c|c|c|c|c|c|c|c|}
\hline Transit features & $\begin{array}{l}\frac{0}{5} \\
0 \\
n \\
\tilde{0}\end{array}$ & 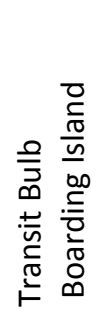 & 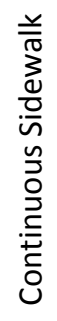 & 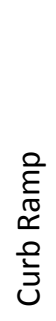 & 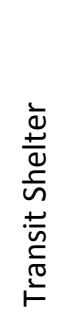 & 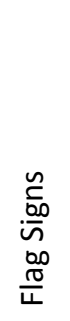 & 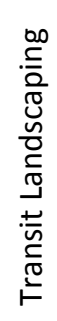 & 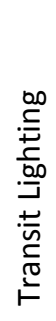 & 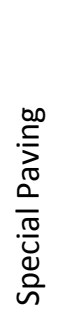 & 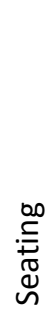 & 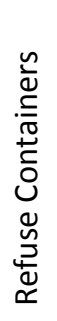 & 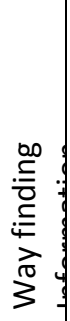 & 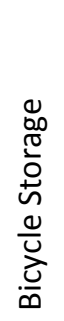 & 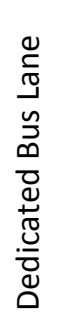 & 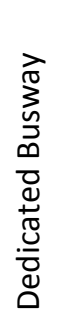 & 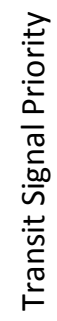 \\
\hline & & & & & & & & & & & & & & & & \\
\hline
\end{tabular}

\begin{tabular}{|c|c|c|c|c|c|c|c|c|c|c|c|c|c|c|c|c|}
\hline Roadway Features & 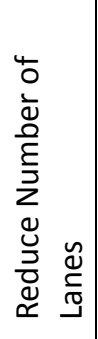 & $\begin{array}{l}\frac{5}{5} \\
.0 \\
3 \\
0 \\
0 \\
\frac{1}{0} \\
3 \\
0 \\
0 \\
\frac{1}{0} \\
2\end{array}$ & 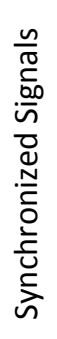 & 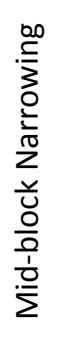 & 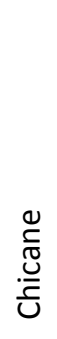 & 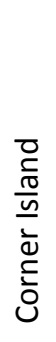 & 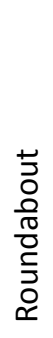 & 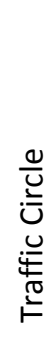 & 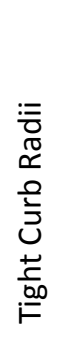 & 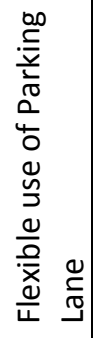 & 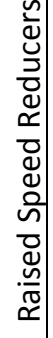 & 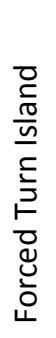 & 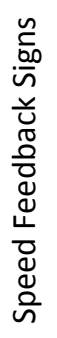 & 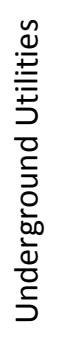 & 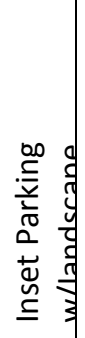 & 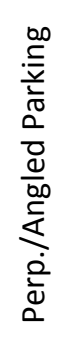 \\
\hline & & & & & & & & & & & & & & & & \\
\hline
\end{tabular}

KEY

\begin{tabular}{|l|l|l|} 
& & \\
\hline $\begin{array}{l}\text { Applicable/ } \\
\text { Encouraged }\end{array}$ & $\begin{array}{l}\text { Consider } \\
\text { w/ } \\
\text { Context }\end{array}$ & Not \\
& Applicable \\
\hline
\end{tabular}

Page 106 


\section{CHAPTER 4: POLICY ANALYSIS}

A recently adopted Complete Streets resolution has added Bakersfield to a growing number of communities joining the Complete Street Movement encouraging safe travel for everyone and redefining streets as a way to move pedestrians, cyclists, and vehicles. The Policy Analysis chapter reviews the new adopted Bakersfield Complete Street Policy and its related existing documents that direct Complete Street implementation with established "best practices" that should help the City secure a more effective Complete Street process as they progress in the future.

\section{The City of Bakersfield Complete Street Policy}

On April 17, 2013, the Bakersfield City Council approved A Resolution of the Council of the City of Bakersfield Adopting a Policy Regarding Complete Streets. The Complete Street Policy is the first step to provide political support for Complete Street implementation in the community. The new Policy identifies specific actions to implement Complete Streets citywide through:

- Defining Complete Streets as transportation facilities that are planned, designed, operated, and maintained to provide safe mobility for all users, including bicyclists, pedestrians, transit riders, and motorists appropriate to the function and context of the facility

- Aiming to create a safe and efficient transportation system that promotes the health and mobility of all citizens and visitors by incorporating the recommendations guidelines of the "Complete Street" concept 
- Defining the objectives of the Complete Street policy and acknowledging the City's desire to develop City transportation facilities to meet the goals of Complete Streets.

- Incorporating existing codes, policies, and standards currently in use, which support Complete Streets to provide guidance for staff and developers

- Establishing the City's desire to be in conformance with Caltrans Deputy Directive DD-64-R1.

- Applying the Resolution to all transportation related projects including those involving new construction, reconstruction, retrofits, repaving, rehabilitation, or changes in the allocation of the pavement space on an existing roadway, including roadway involved in new privately built roads and easement intended for public use. (City of Bakersfield, Administrative Report, Item 8.e, April 17, 2013)

The functional purpose of The Bakersfield Complete Streets Policy is to identify and direct the City, developers, and public to codes, policies, and plans supporting Complete Streets. The City has identified the following existing City documents:

- The Circulation Element of the Metropolitan Bakersfield General Plan Includes street, bikeways, and transit goals that aim to provide safe traffic movement for all transportation modes.

- The Administrative Policy of the Multi-Purpose Trails 
Policy to establish design standards for multi-purpose trails connecting major recreational amenities within Metropolitan Bakersfield. For new development projects when deemed appropriate. Includes standard park \& trail cross section.

- The Adopted Metropolitan Bakersfield Trails Map Included map, which identifies the existing General Plan roadway network, bike pedestrian trails, equestrian trails, and multi-use trails within the city's boundaries and Metropolitan area.

- The Caltrans Deputy Directive DD-64-R1

The California Department of Transportation's Complete Street Policy titled, Complete Streets - Integrating the Transportation System. Includes policy on viewing all improvements as opportunity to improve safety access and mobility for all travelers in California in the transportation system. Provides definitions, responsibilities, and applicability of the Directive to Caltrans staff.

[See Appendix C for Bakersfield Complete Street Policy]

Background of Policy. Newly elected City Councilmember Bob Smith, representing Ward 4, requested Council Referral \#349 to the Planning and Development Committee Staff, a subcommittee of the City Council. The staff was directed to create a Complete Street policy to apply citywide in the design of all projects. The Councilmember asked the Committee and Staff to review various Complete Street guidelines and policies including: Smart Growth America's Complete Streets Local Policy Workbook, the City of Baldwin's Park adopted Complete Street Policy, 
Administrative Policy \#027, and Caltrans Deputy Directive-64-R1, for referral (City of Bakersfield, 2013a).

On April 2, 2013, the Resolution of the Council of the City of Bakersfield Adopting A Policy Regarding Complete Streets was presented to the Planning and Development Committee. After review, the policy was recommended for approval by the City Council within the following two weeks. The Resolution was passed unanimously. During the City Council Meeting, Councilmember Bob Smith spoke in support of the Resolution, the importance of Complete Streets, and the Public Works maintenance actions previously implemented to improve the roadway for all users within the City. Councilmember Smith expressed interest in reviewing or creating new standards to better comply with Complete Streets discussed earlier in Chapter 3: Design Guidelines).

Significance of Policy. A resolution is issued by the city council. It is a nonbinding, official statement of support for approaching community transportation projects through a Complete Street lens, as a way to improve safety, access, public health and quality of life (NCSC, 2012). However, resolutions do not require action. This Resolution formalizes what existing Bakersfield plans and policies to follow the Complete Street concept, rather than introducing new guidelines or standards that require an update. To avoid neglecting a resolution, strong elected leader support must continue and implementation steps are recommended (NCSC, 2012).

\section{Analysis of Bakersfield Complete Street Policy}

The National Complete Street Coalition (NCSC) has released the Best Complete Street Policies of 2012 Report. While every city is different, ten ideal "best practice" 
policy elements have been identified by the National Complete Street Coalition in consultation with the NCSC Steering Committee, the NCSC Workshop Instructor corps, with consultation of the Complete Streets: Best Policy and Implementation Practices Report (McCann and Rynne, 2010).

The National Complete Streets Coalition's comprehensive policy model includes the following:

1. Vision and intent.

2. All users and modes.

3. All projects and phrases.

4. Clear, accountable exceptions.

5. Network.

6. Jurisdiction.

7. Design.

8. Context sensitivity.

9. Performance measures.

10. Implementation next steps.

This analysis will compare policy language adopted by the Bakersfield City Council to the National Complete Street Coalition's ten elements of an ideal policy.

\section{Measuring Complete Streets Implementation}

Based on the ten ideal policy elements listed above, a scoring system was created by the National Complete Street Coalition [Table 8]. Each element is assigned a total possible five points. Five points represents complete fulfillment of that ideal 
element and makes it simple to establish a benchmark in each category without drawing unnecessary comparisons (NCSC, 2013).

Some elements of a Complete Street policy are believed more valuable to immediate establishment of a policy than others. A weighting system is used so points earned per element are placed in context of the overall policy. The weight is based on National Complete Street Coalition research, case studies, and experience in policy development (NCSC, 2013). Weighting is added to make a total possible score of 100 and does not require complex mathematical formula.

To calculate the final score, the determined weight of each element is multiplied by the points awarded based on fulfillment of the element, then divided by 5 (which is the highest possible number of points). Adding scores for each element together creates a score between 0 and 100, the final score. A higher number indicates a policy closer to "ideal."

\section{Policy Element Scoring System.}

Table 8. Standard Policy Element Scoring System

\begin{tabular}{|l|l|}
\hline Policy element & Points \\
\hline 1. Vision and intent & Weight: 6 \\
\hline Indirect: Indirect statement ("shall implement Complete Streets principles" etc.) & 1 \\
\hline Average: Direct statement with equivocating or weaker language ("consider", "may") & 3 \\
\hline Direct: Direct statement of accommodation ("must," "shall," "will”) & 5 \\
\hline 2. All users and modes & Weight: 20 \\
\hline "Bicyclists and pedestrians" (required for consideration & Req. \\
\hline "Bicyclists, pedestrians and transit" & 1 \\
\hline
\end{tabular}




\begin{tabular}{|c|c|}
\hline "Bicyclists, pedestrians and transit," plus one more mode & 2 \\
\hline "Bicyclists, pedestrians and transit," plus two more modes & 3 \\
\hline Additional point for including reference to "users of all ages" & 1 \\
\hline Additional point for including reference to "users of all abilities" & 1 \\
\hline 3. All projects and phases & Weight: 12 \\
\hline Applies to new construction only & 0 \\
\hline Applies to new and retrofit/reconstruction projects & 3 \\
\hline $\begin{array}{l}\text { Additional points if the policy clearly applies to all projects, or specifically includes repair/3R } \\
\text { projects, maintenance and/or operations }\end{array}$ & 2 \\
\hline 4. Exceptions & Weight: 16 \\
\hline No mention & 0 \\
\hline Lists exceptions, but at least one lacks clarity or allows loose interpretation & 1 \\
\hline Lists exceptions, none are inappropriate & 2 \\
\hline Additional points for specifying an approval process & 3 \\
\hline 5. Network & Weight: 2 \\
\hline No mention & 0 \\
\hline Acknowledge & 5 \\
\hline 6. Jurisdiction & Weight: 8 \\
\hline Agency-owned (assumed) & -- \\
\hline States and regions: agency-funded, but not agency-owned & 3 \\
\hline Counties and cities: privately-built roads & 3 \\
\hline $\begin{array}{l}\text { Additional points for recognizing the need to work with other agencies, departments or } \\
\text { jurisdictions }\end{array}$ & 2 \\
\hline 7. Design & Weight: 4 \\
\hline No mention & 0 \\
\hline Reference specific design criteria or direction use of the best and latest & 3 \\
\hline References design flexibility in the balance of user needs & 2 \\
\hline 8. Context sensitivity & Weight: 8 \\
\hline No mention & 0 \\
\hline
\end{tabular}

Page 113 


\begin{tabular}{|l|l|}
\hline Acknowledge & 5 \\
\hline 9. Performance standards & Weight: 4 \\
\hline Not mentioned and not one of next steps & 0 \\
\hline Establishes new measures (does not count in next steps points) & 5 \\
\hline 10. Implementation next steps & Weight: 20 \\
\hline No implementation plan specified & 0 \\
\hline Addresses implementation in general & 1 \\
\hline Address two to four implementation steps & 3 \\
\hline $\begin{array}{l}\text { Additional point for assigning oversight of implementation to a person or advisory board or } \\
\text { for establishing a reporting requirement }\end{array}$ & 1 \\
\hline Additional point for directing changes to project selection criteria & 1 \\
\hline
\end{tabular}

Table 9. Policy Element Scoring System reviewed with Bakersfield "Complete Streets" Policy Resolution

\begin{tabular}{|l|l|}
\hline Policy element & Points \\
\hline 1. Vision and intent & Weight: 6 \\
\hline Indirect: Indirect statement ("shall implement Complete Streets principles" etc.) & 1 \\
\hline Average: Direct statement with equivocating or weaker language ("consider", "may") & 3 \\
\hline Direct: Direct statement of accommodation ("must," "shall," "will") & 5 \\
\hline 2. All users and modes & Weight: 20 \\
\hline "Bicyclists and pedestrians" (required for consideration) & Req. \\
\hline "Bicyclists, pedestrians and transit" & 1 \\
\hline "Bicyclists, pedestrians and transit," plus one more mode & 2 \\
\hline "Bicyclists, pedestrians and transit," plus two more modes & 3 \\
\hline Additional point for including reference to "users of all ages" & 1 \\
\hline Additional point for including reference to "users of all abilities" & 1 \\
\hline 3. All projects and phases & Weight: 12 \\
\hline Applies to new construction only & 0 \\
\hline Applies to new and retrofit/reconstruction projects & 3 \\
\hline
\end{tabular}

Page 114 


\begin{tabular}{|c|c|}
\hline $\begin{array}{l}\text { Additional points if the policy clearly applies to all projects, or specifically includes } \\
\text { repair/3R projects, maintenance and/or operations }\end{array}$ & 2 \\
\hline 4. Exceptions & Weight: 16 \\
\hline No mention & 0 \\
\hline Lists exceptions, but at least one lacks clarity or allows loose interpretation & 1 \\
\hline Lists exceptions, none are inappropriate & 2 \\
\hline Additional points for specifying an approval process & 3 \\
\hline 5. Network & Weight: 2 \\
\hline No mention & 0 \\
\hline Acknowledge & 5 \\
\hline 6. Jurisdiction & Weight: 8 \\
\hline Agency-owned (assumed) & -- \\
\hline States and regions: agency-funded, but not agency-owned & 3 \\
\hline Counties and cities: privately-built roads & 3 \\
\hline $\begin{array}{l}\text { Additional points for recognizing the need to work with other agencies, departments or } \\
\text { jurisdictions }\end{array}$ & 2 \\
\hline 7. Design & Weight: 4 \\
\hline No mention & 0 \\
\hline Reference specific design criteria or direction use of the best and latest & 3 \\
\hline References design flexibility in the balance of user needs & 2 \\
\hline 8. Context sensitivity & Weight: 8 \\
\hline No mention & 0 \\
\hline Acknowledge & 5 \\
\hline 9. Performance standards & Weight: 4 \\
\hline Not mentioned and not one of next steps & 0 \\
\hline Establishes new measures (does not count in next steps points) & 5 \\
\hline 10. Implementation next steps & Weight: 20 \\
\hline No implementation plan specified & 0 \\
\hline Addresses implementation in general & 1 \\
\hline
\end{tabular}




\begin{tabular}{|l|l|}
\hline Address two to four implementation steps & 3 \\
\hline $\begin{array}{l}\text { Additional point for assigning oversight of implementation to a person or advisory board } \\
\text { or for establishing a reporting requirement }\end{array}$ & 1 \\
\hline Additional point for directing changes to project selection criteria & 1 \\
\hline
\end{tabular}

In Table 9, the allocated points, represented by yellow highlight, are determined from the Evaluation Criteria and Recommendation section discussed below. The total score of the Bakersfield Complete Street Policy Resolution is 44 of 100 points. This score is below the National Complete Street Coalition's Top 10 Complete Street Policies of 2012 average score of 81.6 total points. However, the National Complete Street Coalition's total average score of all Complete Street Policies indexed was approximately 43.7 total points (NSCS, 2013).

The City of Bakersfield had no score in the following categories:

- Exceptions

- Design

- Context Sensitivity

- Performance Standards

- Implementation

Within these categories, exceptions and implementation are the most heavily weighted categories of the entire scoring matrix. Fulfilling these categories would have provided the Bakersfield Complete Street Policy with a possibility of over 20 additional points. Deign, context sensitivity, and performance standards all relate to the more specific actions needed for the implementation and support of building a Complete Streets network. Discussed previously, The Bakersfield Complete Street Policy is an 
adopted city resolution. As a first statement publicly supporting a stronger multi-modal network, this policy formalizes Bakersfield's existing actions toward Complete Streets, rather than requiring additional resources to achieve new actions required from introducing the policy. Additionally, the City of Bakersfield has adopted standards or design guidelines, such as Bicycle Parking Design Requirements, which relate to these unfulfilled categories but are not mentioned in the new policy (City of Bakersfield, 2013d).

\section{Evaluation Criteria and Recommendations}

The following section provides greater detail of the National Complete Street Coalition's criteria used in the evaluation of Complete Street policies. Bakersfield should use the criteria to encourage new pieces of effective implementation or policy language for future transportation decision-making. Recommendations are provided based on the weighted score measurement: identifying what works effectively and opportunities for stronger policy language.

Vision and Intent. "A strong vision can inspire a community to follow through on its Complete Street policy (NCSC, 2013)." Having strong writing creates clearly understood goals and determines changes necessary to fulfill the Complete Street policy's intent. The City of Bakersfield has made the policy intent clear by defining Complete Streets and using direct language. Even though traditional words "shall" or "must" are not been used, the intent of the policy is clear with phrases "will apply" and "desires" in the recitals of the Resolution promoting a safe and efficient transportation system for the mobility of all citizens and transportation facilities. 


\section{Recommendation:}

- State the vision of a Complete Street network in the Metropolitan Bakersfield Circulation Element Update, providing compliance with California Complete Streets Act Update in 2011.

- Departments responsible for the planning and development of transportation facilities in the future should include a statement of compliance with The Bakersfield Complete Street Policy.

All Users and Modes. "No policy is a Complete Street policy without the clear statement affirming that people who travel by foot or on bicycle are legitimate users of the transportation system and equally deserving of safe facilities to accommodate their travel (NCSC, 2013)." A clear strength of the existing Bakersfield Complete Street Policy is the commitment to recognize all users and multiple modes of transportation. The Resolution identifies special populations including children, seniors, persons with disabilities, and visitors as equal users of the roadways.

\section{Recommendation:}

- Beyond the listed modes of transportation (motorists, bicyclists, pedestrians, and transit users), the City should recognize its users of specialized transportation modes. Other specialized modes include emergency response vehicles and freight traffic.

All Projects and Phases. "The ideal results of a Complete Street policy are that all transportation improvements are viewed as opportunities to create safer, more 
accessible streets for all users (NCSC, 2013)." The Bakersfield Complete Streets Policy successfully writes ideal opportunities to create Complete Streets by applying the policy to all roadway projects, including new construction, reconstruction, retrofits, repaving, rehabilitation, or change in allocation of pavement space. Beyond expectations, the policy also applies to new privately built roads and easements indented for public use.

\section{Recommendation:}

- Expectations currently met for All Projects and Phases evaluation criteria section.

Exceptions. "Making a policy work in practice requires a process for exceptions to providing for all modes in each project (NCSC, 2013)." Defining key exceptions may help facilitate the policy in the real world, but excessively listing exceptions will weaken the policy and create loopholes to the Complete Street intent. Exceptions should have a clear process for granting them.

\section{Recommendation:}

- Exceptions should be updated within the Bakersfield Complete Street Policy or a future Public Works Street Standard revision, which addresses new Complete Street design guidelines.

- The Federal Highway Administration has listed three or more considerations that must be met as exceptions to establishing bicycle and pedestrian travel on new and retrofitted roadways (FHWA, 2013):

- Bicyclists and pedestrians are prohibited by law from using the roadway. In this instance, a greater effort may be necessary to accommodate 
bicyclists and pedestrians elsewhere within the right of way or within the same transportation corridor.

- The cost of establishing bikeways or walkways would be excessively disproportionate to the need or probable use. Excessively disproportionate is defined as exceeding twenty percent of the cost of the larger transportation project.

- Where sparsity of population or other factors indicate an absence of need.

- Note how exceptions are granted through the Director of Public Works, the Director of Community Development or the City Council.

Network. "An ideal Complete Streets policy recognizes the need for a connected, integrated network that provides transportation options to a resident's many potential destinations (NCSC, 2013)." Creating a Complete Street Network allows flexibility when balancing the needs of all users. Instead of a street accommodating for all users, a Complete Street network emphasizes different modes on an interwoven array of streets (NCSC, 2010g). For example, an established bicycle route or transit route located on a specific street may prioritize its access to facilities. The City of Bakersfield acknowledges building a Complete Street network by requiring large, new development to provide interconnected street networks in conformance with its Complete Streets policy. The existing policy lists the responsible local agencies, including collaboration with TRIPP and Caltrans, who will be responsible for following Complete Street design. 


\section{Recommendation:}

- Discuss small block size, intersection density, and land use context, which generates multiple routes and convenience for a more direct connection within a new development requirement in the existing Bakersfield Complete Street Policy.

- Review the Bicycle Transportation Plan to identify gaps in the existing bicycle network

- Seek Safe Routes to School funding to improve connectivity and safety for pedestrians of special populations (children) within neighborhoods.

Jurisdiction. "Creating Complete Street networks requires collaboration among many different agencies (NCSC, 2013)." Roads are built and maintained by state, county and local agencies, and private developers. Without collaboration, multimodal facilities and infrastructure improvements between one jurisdiction's roadway and other may not coincide, creating gaps in the Complete Street network.

\section{Recommendation:}

- Update The Bakersfield Complete Street Policy to address work with other agencies and jurisdictions.

- Use the joint Metropolitan Bakersfield General Plan to establish policy for important jurisdiction agreement on a Complete Street network.

- Potential discrepancies between permitted design features, such as the removal of curb parking on arterials should be resolved in a manner most effective for Complete Street vision. 
- Include elements of the Complete Street Policy within an appropriate subdivision regulation, which addresses how private developers build new streets.

- Recognizing Safe Routes to School programs with Unified School Districts to improve network and jurisdiction collaboration.

Design. "Communities adopting Complete Streets policies should use the best and latest design standards available to them (NSCS, 2013)." Stating current design standards or reference to the best available design guidelines ensure the ability for Bakersfield to accommodate all modes of travel. Providing flexibility in design guidelines will allow a Complete Street project to be implemented and recognize balance of user needs, even under unique circumstance (NCSC, 2010g). Design guidance is seldom the first Complete Street policy adopted in a community (NCSC, 2013). Instead, the existing Bakersfield Complete Street Policy compiles existing codes, policies and standards related with the design of Complete Streets currently in use through the Metropolitan Bakersfield Circulation Element and Design Standards for Multi-Purpose Trails.

\section{Recommendation:}

- If no design guidelines created, refer to existing design guidelines such as those issued by AASHTO, Caltrans, NATCO Bikeway Guidance, and the Americans with Disabilities Act Accessibility Guidelines, as reference to the latest design standards available for implementing Complete Streets in Bakersfield (NCSC, 2010g). 
- Revise a new Public Works Street Standard to display street improvements including facilities and amenities that contribute to Complete Streets.

- Collaborate with important agencies or stakeholder groups that contribute to development of new street standards, like the emergency response providers with uniform fire codes, American with Disabilities (ADA) requirements, bicycle advocacy groups, developers, and residential stakeholders.

- Integrate Complete Street design guidelines or street standards into specific plans, such as the Bicycle Transportation Plan or the Specific Trails Plans to promote flexibility of design.

Context Sensitivity. "An effective Complete Streets policy must be sensitive to the community context (NSCS, 2013)." People utilize a street and the buildings adjacent for activities beyond transportation. For example, recreation, education, and vending are other activities that create trip destinations and define a street's context (FHWA, 2005b). Discussion of adapting roads to fit the character of surrounding neighborhoods and development is encouraged in an ideal Complete Street policy (NCSC, 2012). The only context sensitive category in the policy element scoring system is divided between no mention and acknowledgement. A policy that mentions the need to be land use contextsensitive receives full five points. Context helps align transportation and land use planning goals, introduces appropriate design facilities and promotes sensitivity to the community. As discussed in the Chapter 3 Design Guidelines, adapting roads to fit the character of the surrounding neighborhood and development is highly encouraged to 
create an effective Complete Street. The following recommendations respond accordingly.

Recommendation:

- Include Complete Street typologies to expand upon the functional classification appropriate to street context and land uses in The Circulation Element Update of the Metropolitan Bakersfield General Plan.

- Expand the Bakersfield Complete Street Policy to include context sensitivity conditions (Huntington Park, Ca Resolution NO. 2012-18):

- Plan its streets in harmony with the adjacent land uses and neighborhoods.

- Solicit input from local stakeholders during the planning process

- Integrate natural features, such as waterways, and other topography into design of streets

- Coordinate street improvements with merchants along retail and commercial corridors to develop vibrant and livable districts

Performance Standards. "Communities with Complete Street policies can measure success a number of different ways, from miles of bike lanes to percentage of the sidewalk network completed to the number of people who choose to ride public transit (NCSC, 2013)." Alternative performance measures to Level of Service track the progress of implementing Complete Streets and other long term goals. This is very important for the transparency of funding and policy intent linking the public and the City. Chosen measurements should reflect the General Plan and related policy 
documents. Performance may be placed within the existing Bakersfield Complete Street Policy or a new Public Works Street Standard. Project level performance measures should also be established at a community level, having stakeholders involved in the process, creating accountability and meaning (NCSC, 2010g).

\section{Recommendation:}

- Establish an agreement of benchmark performance measures for the implementation of future Complete Street related projects and seek appropriate baseline data

- Consider the following performance measures to track multimodal facility implementation (NCSC, 2010h):

- Counting facilities or miles of facilities such as sidewalks, bike lanes, and street trees

- Counting intersections improved by signal timing, medians, count down timers, curb extensions, and other improvements

- Tracking dollar amounts or percentage of funds used for each mode

- On-road transit performance such as the performance of busses running on time

- Air Quality Improvement measured by Greenhouse gasses

- Health Indicators like physical activity

- Economic impact such as increases in revenue or number of jobs within proximity of Complete Streets or near multimodal facilities.

- Crashes by mode 
- Mode shift (changes in number of people using alternative transportation) or Vehicles Miles Travel trip reduction

- Collaboration with others including health and safety departments and public organizations or advocacy groups should contribute to collecting and analyzing data.

- Results of tracking performance measures should be released in an accessible document, annually, or quarterly to the public.

Implementation. "Taking a Complete Streets policy from paper to practice is not easy, but providing some momentum with specific implementation steps can help (NCSC, 2010g)." The City has recognized its preliminary direction for Complete Streets by providing the existing codes, policies, and standards currently in use within the Circulation Element of the Metropolitan Bakersfield General Plan and design standards from the Bakersfield Multipurpose Trails Master Plan. By providing next steps for implementation, Bakersfield can progress its formal commitment to Complete Streets.

\section{Recommendation:}

- The National Complete Street Coalition identifies four key steps for successful implementation for of a Complete Street policy, which the City should integrate with the existing Bakersfield Complete Street Policy (NCSC, 2012):

- Restructure or revise related procedures, plans, regulations, and other processes to accommodate all users on every project. 
- Develop new design policies and guide or revise existing to reflect the current state of best practices in transportation design. Communities may also elect to adopt national or state level recognized design guidance.

- Offer workshops and other training opportunities to transportation staff, community leaders, and the general public to help understand the importance of Complete Streets vision and intent.

- Develop and institute better ways to measure performance and collect data on how well the streets are serving all users.

- Create a Complete Streets advisory board to drive implementation. This group should be inter-departmental and seek representatives from bicycling, disabilities, youth and senior communities with other advocacy organizations relevant to transportation planning. Should be responsible for annual reporting to city council on Complete Street network progress.

\section{Strategic Approach with Final Recommendations}

The following "next steps" should be used as a strategic approach for implementing Complete Streets in the City of Bakersfield:

1. BUILD Institutional Capacity and Community Partnerships

- Create an "internal" committee with representatives from multiple departments to ensure staff has a thorough understanding of what is required and a commitment to Complete Streets. This committee may require training to fulfill an educational need. 
- Create an "external" committee with representation from city agencies, bicycle advocates, pedestrian advocates, and special populations including older populations, children, or people with disabilities. This committee may come in the form of a Complete Streets Advisory Board or a Bicycle and Pedestrian Advisory Committee.

- Partnerships with business associations, private developers, civic groups, and transportation providers will be critical to providing access when building a Complete Street network and should continue to be included in the design and implementation process.

- UPDATE Related Plans and Procedures to Incorporate Complete Street Principles

- The Metropolitan Bakersfield General Plan Circulation Element

- Future Bicycle and Pedestrian Transportation Plans

- Prioritize multimodal projects in the Capital Improvement Program

- Review of development proposals and site plans to ensure Complete Street policy requirements are met

- CREATE Complete Street Design Guidance

- Adopt or direct new standards to include the latest versions of:

- AASHTO: A Policy on Geometric Design of Highways and Streets (“Green Book")

- AASHTO: Guide for Planning, Designing, and Operating Pedestrian Facilities, 
- AASHTO: Guide for the Development of Bicycle Facilities,

- ITE: Designing Walkable Urban Thoroughfares: A Context Sensitive Approach,

- NACTO: Urban Bikeway Design Guide,

- US Access Board: Public Right-of-Way Accessibility Guidelines, and/or

- 2010 Highway Capacity Manual

- Update or Create a Public Works Street Standard that incorporates Complete Street design guidelines under engineering review through collaboration across departments and advisory committees.

- Provide relevant updates to Land Use Standards, Zoning and Subdivision Codes, and Parking Policies

- INITIATE Pilot Projects to Demonstrate value of Complete Streets

- Adopt transportation and community performance measures

- Introduce new streetscape improvements (Permanent or Temporary)

- Create new Bicycle Routes (network of Sharrows identified with Bicycle Transportation Plan)

- Filling gap in sidewalk network (as needed)

- SEEK Appropriate Funding Opportunities

- Federal "Moving Ahead for Progress in the $21^{\text {st }}$ Century Act"

- Transportation Alternatives Program (TAP)

- Surface Transportation Program (STP)

- Federal TIGER Discretionary Grants

- California Cap and Trade Program for Greenhouse Gas Reduction

- SB 1532

- SB 535 
- Caltrans Bicycle Transportation Account Funds

- KernCOG Regional Transportation Governments

- Congestion Mitigation and Air Quality Program

- Highway Safety Improvement Program

- Local Conditions in Operation and Maintenance Budgets

- Local Special Maintenance Districts

- Developer Impact Fees/Exactions

- Private Partnerships 


\section{References}

23ABCNews. (2009). Safe Routes To School Grant Approved: Oildale To Get New Sidewalks. 23 ABC News Kero Bakersfield. Retrieved from http://www.turnto23.com/news/your-neighborhood/north-river-county/safe-routesto-school-grant-approved

Active Transportation Alliance (ATA). (2012). Complete Streets Complete Networks: A Manual for the Design of Active Transportation. Retrieved from http://activetransportationpolicy.org/Design

Alliance for Biking \& Walking. (2012). Bicycling and Walking in the United States: 2012 Benchmark Report. Washington, DC: Author

American Lung Association. (2013a). Bakersfield-Delano, CA. State of the Air 2013.

Retrieved from http://www.stateoftheair.org/2013/msas/bakersfield-delanoca.html\#pmann

American Lung Association. (2013b). Particle Pollution. State of the Air 2013. Retrieved from http://www.stateoftheair.org/2013/health-risks/health-risksparticle.html\#whatis

American Planning Association [APA]. (n.d.). Great Places in America: Streets. American Planning Association. Retrieved from http://www.planning.org/greatplaces/streets/2010/ 
American Planning Association [APA]. (2013). Characteristics and Guidelines of Great Streets. American Planning Association. Retrieved from http://www.planning.org/greatplaces/streets/characteristics.htm

Baerg, R. (2013, August 30). Lancaster: Creating Complete Streets for Prosperity [Web log message]. Retrieved from http://saferoutescalifornia.wordpress.com/2012/08/30/lancaster/

Berg, N. (2011, September 28). Why Does California's Central Valley Have Such Bad Air Pollution? The Atlantic Cities. Retrieved from http://www.theatlanticcities.com/neighborhoods/2011/09/behind-pollutioncalifornias-central-valley/207/

Bicycle Friendly America. (2011). Bicycle friendly community: Fresno, ca / bronze level. Retrieved from http://www.bikeleague.org/programs/bicyclefriendlyamerica/communities/bfc fresno.php

BikeBakersfield. (n.d.). Safe Routes to School. Bike Bakersfield. Retrieved from http://www.bikebakersfield.org/programs/srts.html

Bain, L., Gray, B., \& Rodgers, D. (2012). Living Streets: strategies for crafting public space. Hoboken, NJ: John Wiley \& Sons, Inc.

California Department of Transportation [Caltrans]. (2010a). Complete Streets Implementation Action Plan. Retrieved from http://www.dot.ca.gov/hq/tpp/offices/ocp/complete streets files/CompleteStreets IP03-10-10.pdf 
California Department of Transportation [Caltrans]. (2010b). Smart Mobility 2010: A Call to Action for the New Decade. Sacramento, CA: Author. Retrieved from http://www.dot.ca.gov/hq/tpp/offices/ocp/smf files/SMF handbook 062210.pdf

California Department of Transportation (Caltrans), Division of Design. (2012, November). Caltrans Highway Design Manual. Retrieved from http://www.dot.ca.gov/hq/oppd/hdm/HDM Complete 02Nov2012.pdf

California Department of Transportation [Caltrans]. (2013). Safe Routes To School. Caltrans Division of Local Assistance. Retrieved from http://www.dot.ca.gov/hq/LocalPrograms/saferoutes/saferoutes.htm

California Resources Agency. (2005, May 25). Chapter 1 Policy. The California Environmental Quality Act. Retrieved from http://ceres.ca.gov/cega/stat/chap1.html

Campbell, B., Zegeer, C., Huang, H., \& Cynecki, M., (2004, January). A Review of Pedestrian Safety Research in the United States and Abroad (FHWA-RD-03042). McLean, VA: Federal Highway Administration, Office of Safety Research and Development.

City of Bakersfield. (n.d.) Planning Division - Bicycle Transportation Planning Efforts. Official Municipal Website, City of Bakersfield, California. Retrieved from http://www.bakersfieldcity.us/cityservices/community development/planning/bicy cle transportation planning.html 
City of Bakersfield. (2013a). Special Meeting of the Planning and Development Committee of the City Council - City of Bakersfield, Agenda Packet. Bakersfield, CA: Retrieved from http://www.bakersfieldcity.us/weblink7/0/doc/990888/Electronic.aspx

City of Bakersfield. (2013b). Bakersfield City Council Agenda Administrative Report, Agenda Section, Consent Calendar Item 8.e. Bakersfield, CA: Retrieved from http://www.bakersfieldcity.us/weblink7/0/doc/991761/Page1.aspx

City of Bakersfield. (Producer). (2013c). City of Bakersfield City Council Meeting [Online Broadcast]. Bakersfield, CA: Local Public Broadcasting. Retrieved from http://www.bakersfieldcity.us/administration/mayor council/VideoCouncil/index.htm

City of Bakersfield. (2013d). Regular Meeting of the Community Services Committee of the City Council - City of Bakersfield, Agenda Packet. Bakersfield, CA: Retrieved from http://www.bakersfieldcity.us/weblink7/0/doc/988820/Electronic.aspx

City of Fresno (2010). City of Fresno Bicycle, Pedestrian, and Trails Master Plan.

Retrieved from http://www.fresno.gov/NR/rdonlyres/5DBFAA2D-5352-47D2-84BA3A9BEDC99351/0/FresnoBMP.pdf

City of Fresno (2010a). City Breaks Ground on The BLVD Transformation Project. Retrieved from: http://www.cityoflancasterca.org/index.aspx?recordid=1566andpage $=20$

City of Fresno (2012a). May 3, 2012 City Council Agenda, Agenda Item No. F. Retrieved from 
http://www.fresno.gov/Government/CityClerk/CityCouncilAgendasMinutes/2012.h tm

City of Fresno, Development and Resource Management Department (2012b). Fresno General Plan Update: Mobility and Transportation Preliminary Workshop Discussion Draft. Retrieved from: http://www.fresno.gov/planningdocs/Dec122012/A.pdf

City of Fresno (2012c). TIGER 2012: High-Speed Train Station Area Complete Street Connectivity Project. Retrieved from: http://www.fresno.gov/NR/rdonlyres/4DD731657CEB-43F3-989B-3A280B463B48/24340/TIGERapplicationnarrative.pdf

City of Fresno, Traffic Engineering. (n.d.a). Intelligent Transportation Systems. Retrieved from: http://www.fresno.gov/Government/DepartmentDirectory/PublicWorks/TrafficEngineering/ITS/defa ult.htm

City of Fresno, Traffic Engineering. (n.d.b). Road Diets. Retrieved from: http://www.fresno.gov/Government/DepartmentDirectory/PublicWorks/TrafficEngineering/RoadDi ets.htm

City of Lancaster, Planning Department. (2008a). Downtown Lancaster Specific Plan (State Clearinghouse Number - 200707114). Retrieved from: http://www.cityoflancasterca.org/index.aspx?page=484

City of Lancaster, Public Works Department, Traffic Engineering Division. (2008b). Citywide Traffic Calming Policy. Retrieved from: http://www.cityoflancasterca.org/index.aspx?page $=407$ 
City of Lancaster. (2009a). City of Lancaster: North downtown transit village project (ndtv). Retrieved from http://www.cityoflancasterca.org/index.aspx?page=174 (City of Lancaster, 2009)

City of Lancaster. (2009b). General Plan 2030. Retrieved from http://www.cityoflancasterca.org/index.aspx?page $=427$

City of Lancaster (2012). City of Lancaster Master Plan of Trails and Bikeways.

Retrieved from http://www.cityoflancasterca.org/index.aspx?page=920

City of Lancaster. (Producer) (2013). Brian Ludicke Outlook [Web]. Retrieved from https://vimeo.com/61631408

City of New Haven. (2010, March). New Haven Complete Streets Design Manual.

Retrieved from http://www.cityofnewhaven.com/TrafficParking/pdfs/CS-Manual-0405-10.pdf

City of Portland. (n.d.). Green Streets Tour Map. Tours / The City of Portland Oregon. Retrieved from http://www.portlandoregon.gov/bes/34604?

City of Sacramento. (2004). Resolution No. 2004-118, Resolution to Approve Pedestrian Friendly Streets Standards.

City of San Francisco. (2010, December 7). San Francisco Better Streets Plan: Policies and Guidelines For The Pedestrian Realm. San Francisco, CA: Author.

Congress for New Urbanism [CNU]. (n.d.). Learn About New Urbanism. Retrieved from http://www.cnu.org/Intro to new urbanism 
Council of Fresno County Governments (2008, June). Bus Rapid Transit Master Plan. Retrieved from http://www.fresno.gov/DiscoverFresno/PublicTransportation/Plans/BRT.htm

Cox, E. (n.d.) Completing Streets: Lessons Learned [PowerPoint Slides]. Retrieved from: http://www.sacog.org/completestreets/toolkit/files/docs/Cox Completing\%20Streets\%20Lessons\%20Learned.pdf

Cox, J. (2012, October 22). New bicycle master plan makes Kern eligible for state grants - BakersfieldCalifornian.com. The Bakersfield Californian. Retrieved from http://www.bakersfieldcalifornian.com/local/x1526556788/New-bicycle-masterplan-makes-Kern-eligible-for-state-grants

Dock, F., Greenberg, E., \& Yamarone, M. (2012). Multimodal and Complete Streets Performance Measures in Pasadena, California. Institute of Transportation Engineers, 82(1), 33

Geraghty, A. et al., all (2009). Partnership Moves Community Toward Complete Streets. American Journal of Preventative Medicine, 37 (6S2), S420-S427.

Gordon-Koven, L. (2012, December 12). Complete Street winners, big and small [Web log message]. Retrieved from http://www.smartgrowthamerica.org/2012/12/12/completestreets-winners-big-and-small/

Green LA Coalition. (2012). The Living Streets Initiative: Los Angeles. Los Angeles, CA. Author Retrieved from http://www.livingstreetsla.org/about-lsla/ 
Gunnarsson, S.O. (2004). The pedestrian and the city: A historical review, from the Hippodamian city, to the modernist city and to the sustainable and walkingfriendly city. Copenhagen: Walk 21-V Conference on Cities for People. Retrieved from

http://www.walk21.com/papers/Copenhagen\%2004\%20Gunnarsson\%20The\%20 pedestrian\%20and\%20the\%20city.pdf

Governor's Office of Planning and Research [OPR]. (December 15, 2010). Update to the General Plan Guidelines: Complete Streets and the Circulation Element. Sacramento, CA: Author.

Hand, C. (2010) Woonerf: A Dutch Residential Streetscape. University of Massachusetts: Landscape Architecture Study Tour. http://people.umass.edu/latour/Netherlands/hand/

Highway Safety Information System. (2010, June). Evaluation of Lane Reduction "Road Diet" Measures on Crashes (FHWA-HRT-10-053). McLean, VA: U.S. Department of Transportation, Federal Highway Administration. Retrieved from http://www.fhwa.dot.gov/publications/research/safety/10053/

Hill, S., and Disher, S. (2009). Transportation Reframed: Creating the case for Complete Streets Policies. Plan Canada, 29(4), 30 - 33.

Hillard, L. \& Milam, R. (2009, June). Vehicle Level of Service Policies and Complete Streets: How Roadway Planning Influences Walkable and Bikeable Communities [Handout]. Fehr \& Peers Transportation Consultants. Retrieved from 
http://www.sacog.org/complete-

streets/toolkit/files/docs/Fehr\%20\&\%20Peers Vehicle\%20Level\%20of\%20Service\% 20Policies\%20and\%20C5\%20How\%20Roadway\%20Planning\%20Influences.pdf

Institute of Transportation Engineers (ITE). (2010). An ITE Recommended Practice:

Designing Walkable Urban Thoroughfares: A Context Sensitive Approach.

Publication No. RP-036A. Washington, DC: Author.

Jackson, R. (2011). Designing Healthy Communities. New York City, NY: Wiley.

Kern County Council of Governments [KernCOG]. (2012, September). Kern County Bicycle Master Plan and Complete Streets Recommendations. Kern County, CA: Author.

King, M., Carnegie, J. \& Ewing, R. (2003). Pedestrian Safety Through a Raised Median and Redesigned Intersections. Transportation Research Board, 1828 (2003), 5666.

KFSN-TV Fresno, CA. (Producer). (2012, May 22). Proposed Northeast Fresno bike lanes creating controversy [Web Video]. Retrieved from http://abclocal.go.com/kfsn/story?section=news/localandid=8672751

Konar, G. (2012, May 19). Lancaster Showcases "Living Street". San Diego Planning Journal, Retrieved from http://sdapa.org/go/lancaster-showcases-model-living-street/ 
Lancaster Redevelopment Agency (LRA), (2012). The Blvd transformation project.

Retrieved from website:

http://www.insitedevelopment.com/pdfs/BLVD transformation project.pdf

LaPlante, J., \& McCann, B. (2008). Complete Streets: We Can Get There From Here. Institute of Transportation Engineers Journal, 78(5), 24-28.

League of American Bicyclists \& American Bikes. (2010, January 8). 2009 National Household Travel Survey [Fact sheet]. Federal Highway Administration, Office of Policy. Retrieved from http://www.bikeleague.org/resources/reports/pdfs/nhts09.pdf

Litman, T. (2003). Measuring Transportation: Traffic, Mobility and Accessibility. Institute of Transportation Engineers, 73(10), 28.

Living Streets LA. (n.d.) Sunset Triangle Plaza. Living Streets $L A$. Retrieved from http://www.livingstreetsla.org/streets-for-people/sunset-triangle/

Los Angeles County of Department of Public Health \& UCLA Luskin School of Public Affairs. (2011). The Model Design Manual for Living Streets. Los Angeles, CA: Author. Retrieved from http://www.modelstreetdesignmanual.com/

Ludicke, B. personal communication, April 19, 2013.

McCann, B. A., \& Rynne, S. (2010). Complete streets: best policy and implementation practices. Chicago: American Planning Association 
MacDonald, J., Stokes, R., Cohen, D., Kofner, A., \& Ridgeway, G. (2010). The Effect of Light Rail Transit on Body Mass Index and Physical Activity. American Journal of Preventative Medicine. 39 (2) 105-112.

McCann, B. A., \& Rynne, S. (2010). Complete Streets: best policy and implementation practices. Chicago: American Planning Association.

Millard, B. (2011). Complete Streets: if only Mumford had lived to see this. Oculus, 73(4) 30-33.

Moule and Polyzoides. (2013). Lancaster boulevard transformation. Retrieved from http://www.mparchitects.com/site/projects/lancaster-boulevard-transformation (Moule and Polyzoides, 2013)

National Complete Streets Coalition. (2010a). Fundamentals. Smart Growth America. Retrieved from http://www.smartgrowthamerica.org/complete-streets/completestreets-fundamentals

National Complete Streets Coalition. (2010b). Who We Are. Smart Growth America. Retrieved from http://www.smartgrowthamerica.org/complete-streets/who-we-are

National Complete Streets Coalition. (2010c). Green Streets. Smart Growth America. Retrieved from http://www.smartgrowthamerica.org/completestreets/implementation/factsheets/green-streets/ 
National Complete Streets Coalition. (2010d). Networks of Complete Streets. Smart Growth America. Retrieved from http://www.smartgrowthamerica.org/completestreets/implementation/factsheets/networks/

National Complete Streets Coalition. (2010e). Climate Change. Smart Growth America. Retrieved from http://www.smartgrowthamerica.org/complete-streets/completestreets-fundamentals/factsheets/climate-change

National Complete Streets Coalition. (2010f). Economic Development. Smart Growth America. Retrieved from http://www.smartgrowthamerica.org/completestreets/complete-streets-fundamentals/factsheets/economic-revitalization

National Complete Streets Coalition (NCSC). (2010g). Policy Elements. Smart Growth America. Retrieved from http://www.smartgrowthamerica.org/complete$\underline{\text { streets/changing-policy/policy-elements }}$

National Complete Streets Coalition (NCSC). (2010h). Measuring Performance. Smart Growth America. Retrieved from http://www.smartgrowthamerica.org/complete$\underline{\text { streets/implementation/measuring-performance }}$

National Complete Streets Coalition. (2012). Complete Streets: local policy workbook. Washington, DC. Author.

National Complete Streets Coalition (NSCS). (2013, April). The Best Complete Streets Policies of 2012. Retrieved from http://www.smartgrowthamerica.org/documents/cs2012-policy-analysis.pdf 
National Complete Streets Coalition (NCSC), Local Government Commission (2012). Complete Streets in California. Retrieved from http://www.smartgrowthamerica.org/documents/cs/resources/cs-in-california.pdf

North Carolina Department of Transportation (NCDOT). (2012, July). Complete Streets Planning and Design Guidelines. Retrieved from http://www.completestreetsnc.org/wpcontent/themes/CompleteStreets Custom/pdfs/NCDOT-Complete-Streets-PlanningDesign-Guidelines.pdf

Owens, G. (1999). Developing Street Standards That Allow Flexibility. Transportation Research Circular, (E-C019: Urban Street Symposium). Retrieved from http://onlinepubs.trb.org/onlinepubs/circulars/ec019/Ec019 j3.pdf

Poeschel, D. (2009). Overcoming resistance to narrower streets. Practicing Planner, 7(2), Retrieved from http://www.planning.org/practicingplanner/2009/fall/feature.htm

Potts, I., Harwood, D., \& Richard, K. (2007). Relationship of Lane Width to Safety for Urban and Suburban Arterials. Paper presented at Transportation Research Board: $86^{\text {th }}$ Annual Meeting, Washington, D.C.

Preston, Terry. Personal communication, April 5, 2013.

Project for Public Spaces [PPS]. (n.d.). Allen Jacobs. Retrieved from http://www.pps.org/reference/ajacobs/ 
Pucher, J., Dill, J., \& Handy, S. (2010). Infrastructure, programs, and policies to increase bicycling: An international review. Journal of Preventive Medicine, 50(S1), S106-S125.

Sacramento Area Bicycle Advocates (SABA). (2008). The Squeaky Wheel (63). 1,4. Retrieved from: http://sacbike.org/newsletter/2008 06.pdf

Sacramento Transportation \& Air Quality Collaborative. (2005, October). Best Practices for Complete Streets. Retrieved from

http://www.cityofsacramento.org/transportation/dot media/engineer media/pdf/bpCompleteStreets.pdf

Sadler, W. (2010, May). Complete streets make healthier people: Reforming street design policies to combat obesity. Paper presented at Congress of New Urbanism: Annual Congress, Atlanta, GA.

Saelens, B. E., Sallis, J. F., \& Frank, L. D. (2003). Environmental correlates of walking and cycling: findings from the transportation, urban design, and planning literatures. Annals of Behavioral Medicine, 25, 80-91.

San Diego Section of The American Planning Association \& WALK San Diego, Complete Streets Task Force. (2012, June). From Policy To Pavement. Retrieved from http://www.calapa.org/attachments/files/1851/APA Report Final compressed.pdf 
San Joaquin Valley Air Pollution Control District. (2012). 2012 PM2.5 Plan. Fresno, CA: Author. Retrieved from http://www.valleyair.org/Air Quality Plans/PM25Plans2012.htm

Smart Growth America. (n.d.). Transportation / Smart Growth America. Retrieved April 21, 2013, from http://www.smartgrowthamerica.org/issues/transportation/

Smith, R., Reed, S., \& Baker, S. (2011, April 7). Street Design: Part 1—Complete Streets - Vol. 74 - No. 1 - Public Roads. Federal Highway Administration. Retrieved from http://www.fhwa.dot.gov/publications/publicroads/10julaug/03.cfm

Southworth, M., Ben-Joseph, E. (1997). Streets and the Shaping of Towns and Cities. New York: McGraw-Hill.

Transportation for America. (2011). Dangerous by Design 2011 State Info. Transportation For America. Retrieved from http://t4america.org/resources/dangerousbydesign2011/states/?state=ca

U.S. Department of Transportation, Federal Highway Administration (FHWA). (2005a). CSS \& "Macro" Land Use: Urban, Suburban, Rural| Context Sensitive Soutions.org - A CSS support center for the transportation community. Retrieved from http://contextsensitivesolutions.org/content/topics/context/physical-setting-m/urbanrural-suburban/

U.S. Department of Transportation, Federal Highway Administration (FHWA). (2005b). Context Sensitive Solutions.org - Complete Streets. Retrieved from 
http://contextsensitivesolutions.org/content/topics/what_is_css/changing-societycommunities/complete-streets/

United States Department of Transportation, Federal Highway Administration. (2010, February). Access Management in the Vicinity of Intersections [Technical Summary]. (FHWA-SA-10-002). Retrieved from http://safety.fhwa.dot.gov/intersection/resources/fhwasa10002/fhwasa10002.pdf

U.S. Department of Transportation, Federal Highway Administration. (2012a, September 19). Chapter 3: Functional Classification - Flexibility - Publications Environment - FHWA. Retrieved from http://www.fhwa.dot.gov/environment/publications/flexibility/ch03.cfm

U.S. Department of Transportation, Federal Highway Administration. (2012b, September 19). Chapter 4: Design Controls. Environment. Retrieved from http://www.fhwa.dot.gov/environment/publications/flexibility/ch04.cfm

U.S. Department of Transportation, Federal Highway Administration. (2013a). Section II - Concepts, Definitions, and System Characteristics - Functional Classification Related - Statewide Transportation Planning - Processes - Planning. Retrieved from http://www.fhwa.dot.gov/planning/processes/statewide/related/functional classificati on/fc02.cfm

U.S. Department of Transportation, Federal Highway Administration (FHWA). (2013b). Accommodating Bicycle and Pedestrian Travel: A Recommended Approach. Bicycle 
\& Pedestrian. Retrieved from

http://www.fhwa.dot.gov/environment/bicycle_pedestrian/guidance/design_guidance/ design.cfm\#d4

United States Department of Transportation, National Highway Traffic Safety Administration. (2012, August). Traffic Safety Facts 2010 Data: Pedestrians Fact Sheet. Washington, DC: NHTSA's National Center for Statistics and Analysis. Retrieved from http://www-nrd.nhtsa.dot.gov/Pubs/811625.pdf

United States Department of Transportation, National Highway Traffic Safety Administration. (2013, April). Traffic Safety Facts 2011 Data: Bicyclists and Other Cyclists Fact Sheet. Washington, DC: NHTSA's National Center for Statistics and Analysis. Retrieved from http://www-nrd.nhtsa.dot.gov/Pubs/811743.pdf

United States Environmental Protection Agency [EPA]. (2012a, October 30). About Smart Growth. US Environmental Protection Agency. Retrieved April 18, 2013, from http://www.epa.gov/dced/about sg.htm

United States Environmental Protection Agency [EPA]. (2012b, December 14). 2012 National Award for Smart Growth Achievement. US Environmental Protection Agency. Retrieved from http://www.epa.gov/smartgrowth/awards/sg awards publication 2012.htm\#over all excellence 
United States Environmental Protection Agency, Office of Sustainable Communities (1807T). (2012c). America's children and the environment (EPA-231-K-12-002). Retrieved from http://www.epa.gov/dced/pdf/sg awards 2012

United States Environmental Protection Agency. (2013, April 22). Climate Change: Transportation Sector Emissions. Retrieved from http://www.epa.gov/climatechange/ghgemissions/sources/transportation.html

Watkins, B. (2012, May). Gettysburg Bike Lanes Passes 6-1 [Web long message]. Retrieved from http://ibikefresno.org/interact/blog/169-gettysburg-bike-lane-passes-6-1 Image References

Figure 1. City of Portland (2008, July). Green Street Storm water Facilities: Sustainable Storm water Management. [Image]. Retrieved from http://www.portlandoregon.gov/bes/article/196225

Figure 2. Daniels, Elizabeth (2012, March 5). Check Out Sunset Triangle Plaza, LA's First Pedestrian Plaza. [Image]. Retrieved from http://la.curbed.com/archives/2012/03/check out sunset triangle plaza las first pedestrian plaza 1.php

Figure 3. American Planning Association. (2010). Image 01, $5^{\text {th }}$ Avenue San Diego, California. [Image]. Retrieved from http://www.planning.org/greatplaces/streets/2010/gallery02/image01.jpg 
Figure 4. City of San Francisco Municipal Transportation Authority. (2012). Bulb-out. [Image]. SF Better Streets. Retrieved from http://sfbetterstreets2.sfplanning.org/wp-content/uploads/2012/04/bulb-out.jpg

Figure 5. New York City Department of Transportation. (2010). Median safety island with landscaping and tree: Empire Boulevard, Brooklyn [Image]. Street Design Manual. New York City, NY: Author.

Figure 6. City of San Francisco Municipal Transportation Authority. (2012). Paving. [Image]. SF Better Streets. Retrieved from http://www.sfbetterstreets.org/findproject-types/streetscape-elements/sidewalk_paving/

Figure 7. New York City Department of Transportation. (2010). Street trees planted in individual tree pits, Avenue S, Brooklyn [Image]. Street Design Manual. New York City, NY: Author.

Figure 8. Silicon Valley Bicycle Coalition. (n.d.). veterans-blvd-bike-lane-web. [Image]. Retrieved from http://bikesiliconvalley.org/area-report/2011/11/redwood-city-newasphalt-brings-new-bike-infrastructure

Figure 9. National Association of City Transportation Officials (via Caltrans). (2012). Bikebox_San Luis Obispo_Caltrans. [Image]. Bike Boxes. Retrieved from http://nacto.org/wpcontent/gallery/2012 bikebox/bikebox sanluisobispo caltrans.jpg 
Figure 10. National Association of City Transportation Officials. (2012). Loopdetector_pdx. [Image]. Signal Detection and Actuation. Retrieved from http://nacto.org/wp-content/gallery/2012 detectionactuation/loopdetector pdx.jpg

Figure 11. National Association of City Transportation Officials. (2012). Sharrow_-missoula-mt. [Image]. SF Better Streets. Retrieved from http://nacto.org/wpcontent/gallery/2012 sharedlanemarkings/sharrow- -missoula-mt.jpg

Figure 12. City of San Francisco Planning Department. (2011). Bus bulb-out improve transit performance by allowing transit vehicles to load from the travel lane. [Image]. SF Better Streets Plan. San Francisco, CA: Author.

Figure 13. Snyder, R. (2010). Bus stops should be integrated with their surroundings: Glendale, CA. [Image] The Model Design Manual for Living Streets. Los Angeles, CA: Author.

Figure 14. Yim, K. (2010). Bus-only lane: Santa Monica, CA. [Image]. The Model Design Manual for Living Streets. Los Angeles, CA: Author.

Figure 15. Lockwood, I. (2010). One-lane chicane. [Image]. The Model Design Manual for Living Streets. Los Angeles, CA: Author.

Figure 16. City of San Francisco Municipal Transportation Authority. (2012). Traffic Circle. [Image]. Sf Better Streets. Retrieved from http://www.sfbetterstreets.org/find-project-types/pedestrian-safety-and-trafficcalming/traffic-calming-overview/traffic-circles/\#design_guidelines 
Figure 17. New York City Department of Transportation. (2010). Speed hump: Bolton Avenue, The Bronx [Image]. Street Design Manual. New York City, NY: Author.

Figure 18, 19. Duarte and Jacobsen. (Photographer). (2009). [Web Photo]. Retrieved from: http://www.sacog.org/completestreets/toolkit/files/docs/Duarte\%20and\%20Jacobsen What\%20lf\%20All\%20Our \%20Streets\%20Were\%20Complete.pdf

Figure 28. Sargent Town Planning. (Photographer). The BLVD in 2009 [Web Photo]. Retrieved from http://www.sargenttownplanning.com/projects/lancaster$\underline{\text { boulevard-transformation }}$

Figure 29. Lancaster Local Government Commission. (Photographer). (2012, February 22). [Print Photo, It's A Safe Decision].

Figure 30, 33. United States Environmental Protection Agency (EPA). (Producer). (2012b). EPA's 2012 National Award for Smart Growth Achievement: Blvd Transformation Project, Lancaster, CA [Web Video]. Retrieved from http://youtu.be/pojylzK2uSM

Figure 31. Moule and Polyzoides. (Photographer). [Web Photo]. Retrieved from http://www.mparchitects.com/site/projects/lancaster-boulevard-transformation

Figure 32. Essers, C. (Photographer). (2010, June 12). The Blvd 2 [Web Photo]. Retrieved from http://www.flickr.com/photos/avcellshots/4694119647/ (Essers, The Blvd 2) Figure 37. Transect-Ecozones [PNG Electronic Image]. (2007). Retrieved from: http://thinkorwim.com/wp-content/uploads/2007/05/transect-ecozones.png 
Appendix
A. Bakersfield Circulation Map
B. Bakersfield Existing R.O.W. Description
C. Adopted Bakersfield Complete Streets Policy 


\section{APPENDIX A \\ Bakersfield Circulation Map}

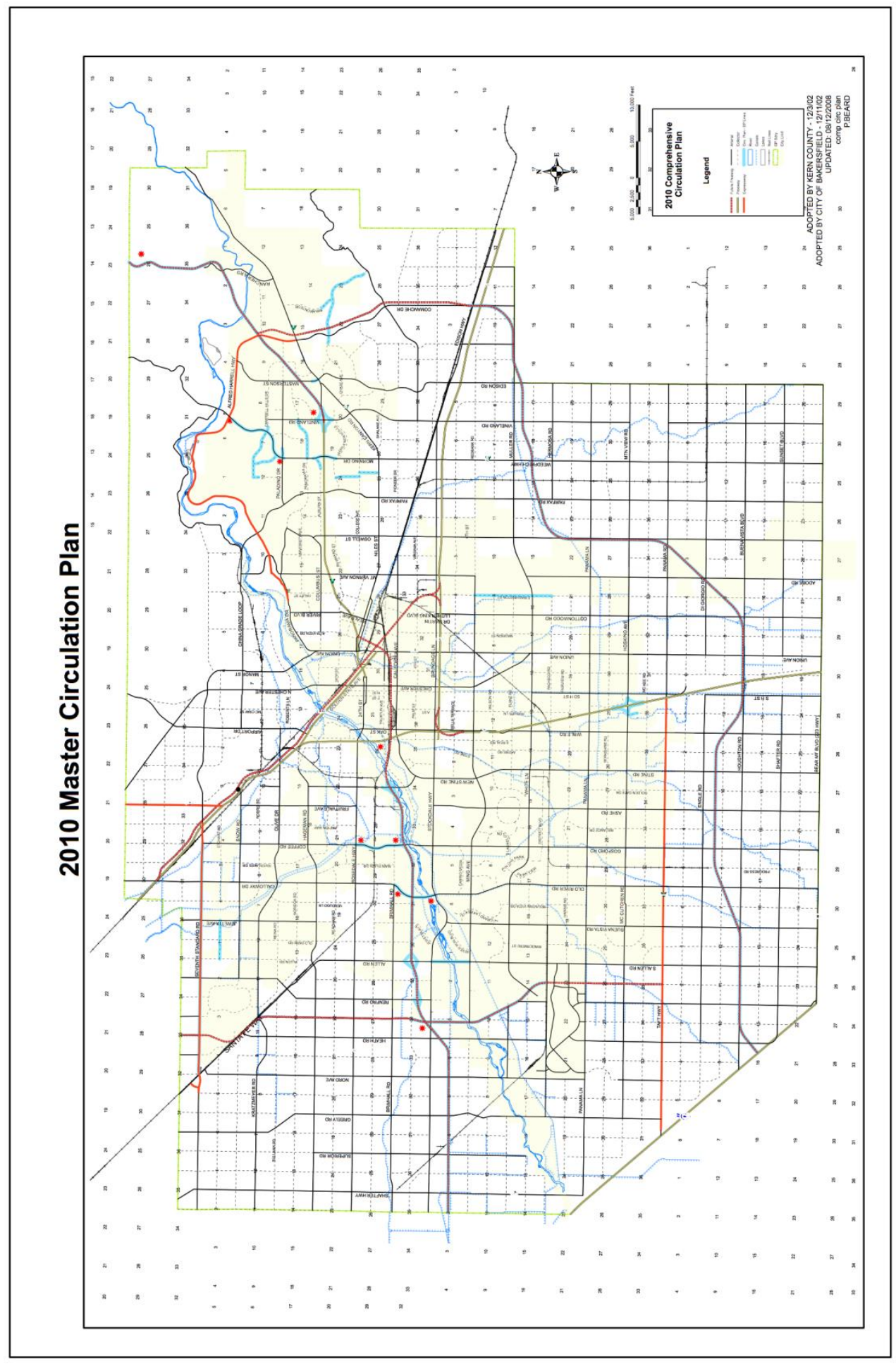

Page 153 


\section{APPENDIX B Bakersfield Right-of-Way Description}

Right-of-way is an area of land over which people, goods and services have the right to pass or travel. Public right-of-way is a form of easement typically dedicated to the City during the subdivision process. Unless fee simple title is specifically granted to the City, a street dedication is an easement and the underlying fee holder is usually the adjacent property owner.

The City of Bakersfield has certain privileges associated with a right-of-way granted to it. The City controls all use of public streets and may use the right-of-way not only for public passage of goods and services via vehicles, bicycles and pedestrians, but also for the collection and transport of storm water and to allow or disallow on-street parking. The City controls access locations from adjacent property onto public streets. The City can use its right-of-way for storm drain lines and sewer lines and can also grant franchises and/or licenses to public utilities and private parties.

Only the City can build or allow others to build in the right-of-way through the use of a Street Construction Permit or an Encroachment Permit. No permanent or unauthorized structures are allowed in the right-of-way, and construction in the right-of-way is limited to pavement, curbs, gutters, sidewalks, drive approaches, and in the area behind the sidewalk and the line of sight - walls and fences.

Street dedication to the City of Bakersfield, with the acceptance of improvements through a Notice of Completion, means that the City of Bakersfield is responsible for the maintenance of the public improvements within the travelled way. The travelled way is that portion of the street right-of-way between the curb faces. This includes street sweeping, patching of potholes, resurfacing of the street and reconstruction when necessary. Maintenance of sidewalk is the responsibility of the property owner.

Any lot being developed - with a subdivision map or even a building permit - will be required to dedicate the full right-of-way. The Metropolitan Bakersfield General Plan and the Municipal Code will not allow the construction of any buildings within an existing or future right-of-way or Specific Plan Line.

The Circulation Element of the Metropolitan Bakersfield General Plan shows the future location of all arterials and collectors within the metropolitan boundary. The Metropolitan Bakersfield General Plan and the Engineering and Design Manual of the City of Bakersfield specify the widths required for the various classifications of streets. Our City's street pattern generally follows a grid pattern, with certain obvious exceptions.

- Arterials have 110 feet of right-of-way with a 96 foot travelled way ( 90 feet when there is no bike lane). These are generally located at one mile intervals.

- Collectors have a 90 foot right-of-way with a 74 foot travelled way ( 68 feet when there is no bike lane). These are generally located at the half-mile between arterials.

- Local streets have a 60 foot right-of-way with a 36 to 44 foot travelled way. 


\title{
APPENDIX C Bakersfield Complete Street Policy
}

POLICY RESOLUTION NO.

\author{
A RESOLUTION OF THE COUNCIL OF THE CITY OF \\ BAKERSFIELD ADOPTING A POUICY REGARDING \\ "COMPLETE STREETS"
}

\section{RECITALS}

Whereas, the City of Bakersfield desires to create a safe and efficient transportation system that promotes the health and mobility of all citizens and visitors by incorporating high quality transportation facilities for motorists. bicyclists, pedestrians, and transit access to all destinations throughout the city; and

Whereas, the City of Bakersfield also understands that children, seniors and persons with disabilities will require special accommodations; and

Whereas, the City of Bakersfield addresses the safety and mobility of all citizens and visitors in all projects, regardless of funding source; and

Whereas, "Complete Streets" is defined as transportation facilities that are planned, designed, operated, and maintained to provide safe mobility for all users, including motorists, bicyclists, pedestrians, and transit riders appropriate to the function and context of the facility: and

Whereas, the City of Bakersfield will apply this "Complete Streets" policy to all roadway projects including those involving new construction, reconstruction, retrofits, repaving, rehabilitation or changes in the allocation of the pavement space on an existing roadway as well as those that involve new privately built roads and easements intended for public use; and

Whereas, the City of Bakersfield will also require large new developments to provide interconnected street networks in conformance with the "Complete Streets" policy: and 
Whereas, the Clity of Bakersfield has compiled and attached documents that support the "Complete Streets" concept as shown in existing codes, policies and standards currently in use within the Circulation Element. Chapter III of the Metropolitan Bakersfield General Plan (Exhibit A), the Administrative Policy Memorandum regarding Design standards for Multi-purpose Tralls (Exhibit B) and Adopted Metropolitan Bakersfield Trials Map (Exhibit C):

Whereas, the City of Bakersfield also desires to be in conformance with the CalTrans Deputy Directive DD-64-R1 (Exhibit D); and

Whereas, every City Department responsible for the planning and development of transportation facilities including, but not limited to, Administration. Public Works, Community Development, Recreation and Parks, and TRIP will follow this policy.

NOW, THEREFORE, BE IT RESOLVED by the Council of the City of Bakersfield as follows:

1. The above recitals are true and correct and are incorporated herein by reference.

2. All departments of the City of Bakersfield are hereby directed give equal consideration to bicyclists, pedestrians, transit riders and motorists for any and all projects within the City's Sphere of Influence.

3. All departments of the City of Bakersfield are also to include the codes, policies and standards compiled and presented in the following Exhibits for any and all projects within the City's Sphere of Influence.

a. Exhibit "A" - the Circulation Element of the Metropolitan Bakersfield General Plan

b. Exhibit " $B$ " - Administrative Policy re: Multi-Purpose Trails

c. Exhibit "C" - Adopted Metropolitan Bakersfield Trails Map

d. Exhibit " $D$ " - Caltrans Deputy Directive DD-64-R1 